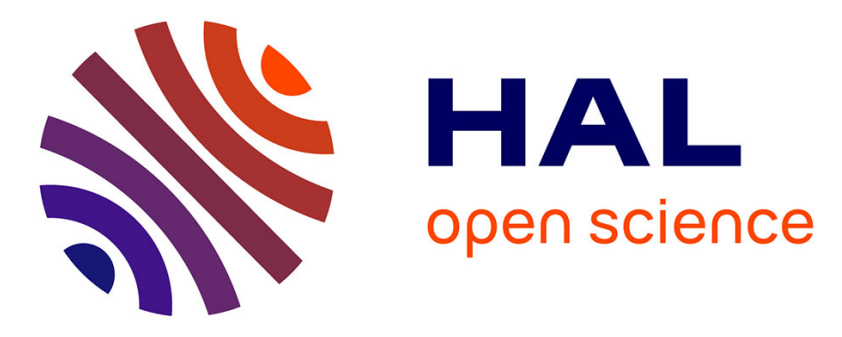

\title{
Un village chasséen dans le Sud de la France: Cazan "le Clos du Moulin ", Vernègues (Bouches-du-Rhône)
}

Clément Moreau, Vanessa Lea, Claire Delhon, Frédéric Magnin, Luke Howarth, Jimmy Linton, Lucas Pacotte, Sylvain Foucras, Cristiano Nicosia, François-Xavier Le Bourdonnec, et al.

\section{To cite this version:}

Clément Moreau, Vanessa Lea, Claire Delhon, Frédéric Magnin, Luke Howarth, et al.. Un village chasséen dans le Sud de la France: Cazan " le Clos du Moulin ", Vernègues (Bouches-du-Rhône). Bulletin de la Société préhistorique française, 2017, 114 (1), pp.53-91. 10.3406/bspf.2017.14751 . hal-01874619

\section{HAL Id: hal-01874619 \\ https://hal.science/hal-01874619}

Submitted on 13 Dec 2021

HAL is a multi-disciplinary open access archive for the deposit and dissemination of scientific research documents, whether they are published or not. The documents may come from teaching and research institutions in France or abroad, or from public or private research centers.
L'archive ouverte pluridisciplinaire HAL, est destinée au dépôt et à la diffusion de documents scientifiques de niveau recherche, publiés ou non, émanant des établissements d'enseignement et de recherche français ou étrangers, des laboratoires publics ou privés. 


\title{
Un village chasséen dans le Sud de la France
}

\section{Cazan « le Clos du Moulin », Vernègues (Bouches-du-Rhône)}

\author{
Clément Moreau, Vanessa Léa, Claire Delhon, Frédéric Magnin, Luke Howarth, \\ Jimmy Linton, Lucas Pacotte, Sylvain Foucras, Cristiano Nicosia, \\ François-Xavier Le Bourdonnec, Julie Gerez et Ingrid SÉnÉPART
}

Résumé: Une fouille réalisée en 2013 à Cazan « le Clos du Moulin » Vernègues (Bouches-du Rhône) a permis de mettre en évidence une importante occupation du Chasséen récent en fond de vallon. Aucun niveau de sol n'a été retrouvé, mais plus de 600 structures en creux permettent de documenter un des premiers sites d'habitat structuré de cette période dans le Sud de la France. Les attributions chronologiques reposent sur huit datations au ${ }^{14} \mathrm{C}$ comprises en 4100 et 3800 avant notre ère et sur un abondant mobilier archéologique qui concorde avec l'attribution à une étape récente du Chasséen. Le gisement livre plusieurs fosses, des puits et une concentration de structures à pierres chauffées, mais aussi et surtout de nombreux trous de poteau et fosses d'implantation qui permettent de restituer les plans d'environ quinze bâtiments. Ces derniers correspondent notamment à dix édifices standards; trois ensembles architecturaux plus imposants s'insèrent au sein de cette organisation et traduisent sans doute la présence d'édifices socialement plus valorisés.

L'analyse du mobilier archéologique ne permet pas de déterminer assurément de chronologies relatives au sein de ces structures et aménagements, mais elle met en évidence plusieurs zones d'activités privilégiées en particulier pour le travail du silex et de l'obsidienne. Ces activités signent une occupation domestique a priori pérenne au sein d'un paysage largement anthropisé et maitrisé d'après les observations anthracologiques et malacologiques.

L'ensemble de ces résultats tend à prouver l'attachement des populations chasséennes à ce territoire où elles se sont installées et ont vécues. Ce site permet donc enfin d'approcher pleinement la notion de village pour le Chasséen récent.

Mots clés : Néolithique moyen, Chasséen, habitat, maison, bâtiment, puits, foyer, céramique, silex, obsidienne, tracéologie, malacologie, anthracologie, matériel de mouture, faune.

\begin{abstract}
In 2013 excavations near Vernègues (Bouches-du Rhône), "Cazan-Le Clos du Moulin", revealed an important occupation site dating from the Middle Neolithic (late Chassey culture). The village of Vernègues is located just south of the Massif du Luberon, approximately $60 \mathrm{~km}$ north-west of Marseille and the Mediterranean. The area excavated, a little over one hectare, is located in the centre of a small valley which joins the valley of the Durance just to the north. This valley is remarkable for the density of Neolithic remains and "Cazan-Le Clos du Moulin" is situated in the centre of a cluster of sites. The different sites form a discontinuous network across the floor of the valley, which is undoubtedly linked to the network of watercourses which drain the valley.

While no occupation ground was uncovered during the excavation, over 600 archaeological features were preserved. These features record one of the first structured dwelling sites for this period in the south of France. The occupation of this site has been dated by eight radiocarbon dates (4100 - 3800 BCE) and a large assemblage of archaeological finds, which confirm the attribution to the late Chassey culture.

The site contained many pits, five wells and a concentration of twenty burnt stone combustion features, which are typical of this period. Through analysis of these structures we observe how two pairs of wells seem to have functioned together, particularly in their secondary use as middens. The burnt stone combustion features are all circular and organised into four sub-parallel lines. These features group two different types of hearths, which may reflect a chronological difference or differences in use.

However, the most notable aspect of this site resides in the discovery of many postholes and foundation pits, which trace the outline of at least fifteen different architectural structures. These are the earliest buildings recorded for the late Chassey in the south of France.

They notably consist of ten houses which were implanted on well-preserved postholes. These structures repeat the same overall plan, based around a dozen posts organised into two aisles, with a probable ridge beam extending beyond the ridge purlin. Two smaller posts in front of the southern gable end probably indicate the location of an entrance. The surface area of these buildings varies between 80 and $180 \mathrm{~m}^{2}$. There are few comparable examples for these structures
\end{abstract}


for this period and they are markedly distinct from other examples in France or in northern Italy, which are generally rectangular in plan and frequently have foundation trenches.

In addition, three other architectural structures have been identified, which are defined by a series of very large foundation pits. The pits are rectangular in plan with asymmetric profiles (at times triangular, occasionally trapezoidal): they can be up to $2 \mathrm{~m}$ deep with an over-cut at the base. We find even fewer archaeological parallels for these buildings. However their construction clearly demanded a significant investment of time and effort, which could indicate the coordination of a group or community of individuals.

All of these buildings follow a plan which was clearly collectively predefined; all the buildings are orientated NW-SE, which coincides with the prevailing wind in the valley. Moreover, the distribution of these postholes and pits indicates that several houses were completely rebuilt in the same place, up to two to three times. Each new phase of construction was preceded by the partial deconstruction of the remains of the previous phase. We note that some of the posts had clearly begun to decompose in situ, prior to being burnt and/or removed. Finally, some of the pits/postholes from the previous phases were backfilled with stones and broken fragments of querns.

Analysis of the archaeological finds has not allowed us to establish a relative chronology between these different buildings or the diverse features. However, it has enabled us to define several zones of activity, specifically related to the working of flint and obsidian. The obsidian comes from Sardinia and we have observed elements associated with shaping and working nuclei as well as debitage from a knapping area which were found in a well.

Obsidian is not the only example of imported material found; it is accompanied by several ceramic and earthenware objects (including a loom weight) and a copper awl, all of which probably originate from northern Italy. Furthermore, analysis of the querns recovered from the postholes and analysis of the marks on the worked flints indicate agricultural activities related to grain farming. The faunal remains were almost exclusively recovered from the deposits infilling the wells. These remains record the importance of caprines in the livestock, indicating pastoral activities were also important at Cazan, as at many other sites of the same period.

These different activities imply a domestic occupation, seemingly permanent, in a predominantly anthropogenically modified landscape (based on malacological analysis). The preliminary analysis of the snail assemblage indicates an open environment during the late Chassey culture, and this observation seems to be confirmed by the charcoal analysis. Furthermore, the study of the charcoal from the postholes and hearths allows us to distinguish the selection of different species of wood: oak is used for the posts while strawberry tree (arbutus unedo) is used as fuel.

These results suggest the attachment of the Chassey population to this place and the surrounding landscape, which they occupied and reoccupied several times over 300 years. While an important part of their activity was based around a mobile lifestyle and pastoral management, this site allows us to consider the concept of a Neolithic village. These first results presented here renew the debate and research concerning the character of the occupation of this landscape during this period.

Keywords: Middle Neolithic, Chassey culture, dwelling site, house, building, well, hearth, ceramic, flint industry, obsidian, use-wear analysis, malacology, charcoal analysis, stone grinding tools, archaeozoology.

$\mathrm{J}$ USQU'À PRÉSENT, le Chasséen récent était surtout caractérisé, dans le Sud-Est de la France, par des sites en grottes ou par d'importantes occupations de plaine comme dans la moyenne vallée du Rhône (Montélimar, Saint-Paul-Trois-Châteaux, etc.) ou le pourtour méditerranéen, de Carcassonne, Aude, à Trets, Bouches-du-Rhône (Beeching et al., 2000; Beeching et Léa, 2015). Ces occupations ont donné nombre de fosses, structures à pierres chauffées ou puits, mais leur interprétation se heurte toutefois à l'absence d'habitat avéré associé. Or, en 2013, sur la commune de Vernègues (Bouches-du-Rhône), au sein du vallon de Cazan, qui est interprété comme le siège d'un site chasséen d'importance (Thirault et al., 2016), une fouille a été réalisée au lieu-dit « le Clos du Moulin » et a permis la découverte de 642 structures archéologiques sur une surface de $11000 \mathrm{~m}^{2}$.

Plusieurs fosses-silos, une sépulture double en fond de silo et une inhumation simple sous meule ont été attribuées à une phase ancienne d'occupation, comprise entre la fin du Néolithique ancien et le Chasséen ancien. Un petit édifice antique de la fin du $\mathrm{I}^{\mathrm{er}}$ siècle avant notre ère, associé à des structures funéraires, a aussi été découvert au nord de l'emprise de fouille.

Toutefois, pour l'essentiel (près de 600 structures en creux), l'occupation reconnue au Clos du Moulin se rattache à plusieurs phases d'occupation pendant le Chasséen récent qui s'échelonnent entre 4100 et 3800 av. notre ère. Ces vestiges dessinent l'un des premiers habitats structurés connus pour la période dans le Sud de la France. Il rassemble cinq puits, vingt structures à pierres chauffées, de nombreux trous de poteau circulaires et des fosses d'implantations plus importantes qui tracent les plans d'environ quinze bâtiments.

Pour le Chasséen méridional, les traces d'habitat structuré étaient jusqu'alors encore isolées (Saintot, 2002). Le site du Clos du Moulin offre la possibilité d'analyser un habitat d'ampleur au même titre que celui, plus septentrional, de Beaumont (Saintot et Le Barrier, 2009). Nous présenterons donc ses aménagements, ainsi que les structures associées (structures à pierres chauffées, puits, fosses dépotoirs). Les premiers résultats issus de l'étude des mobiliers archéologiques, bioarchéologiques et des données paléoenvironnementales seront également 
présentés. Ils permettent d'appréhender au mieux le site dans son environnement, ses fonctions et, par conséquent, son statut au sein de la sphère chasséenne. L'organisation ainsi déduite pourra alors être comparée aux aménagements villageois connus pour le Néolithique moyen, au sein d'autres contextes culturels.

\section{PRÉSENTATION DU SITE}

\section{Contexte géographique}

Le site est localisé entre le Petit Luberon et l'étang de Berre, à environ $10 \mathrm{~km}$ au nord-est de Salon-de-Provence.
Il est implanté au milieu d'une vallée de $1 \mathrm{~km}$ de large pour $5 \mathrm{~km}$ de long, orientée nord-est - sud-ouest, qui s'ouvre au nord-est sur la rive gauche du lit majeur de la Durance (fig. 1). La chaîne des Côtes et le massif de Vernègues encadrent ce vallon avec des coteaux qui montent vers $300 \mathrm{~m}$ NGF; le fond se situe autour de $170 \mathrm{~m}$ NGF.

Ce vallon est entaillé dans des faciès burdigalien, barrémien et hauterivien qui sont partiellement recouverts, dans le vallon et en pied de versant, par des dépôts de pente et des formations fluviatiles pléistocènes et holocènes (fig. 1). Les alluvions et colluvions postglaciaires remanient largement les dépôts burdigaliens et pléistocènes locaux. Plusieurs opérations de fouille (Moreau et al., 2015; Thirault et al., 2016) ont mis en évidence une séquence sédimentaire complexe, présentant

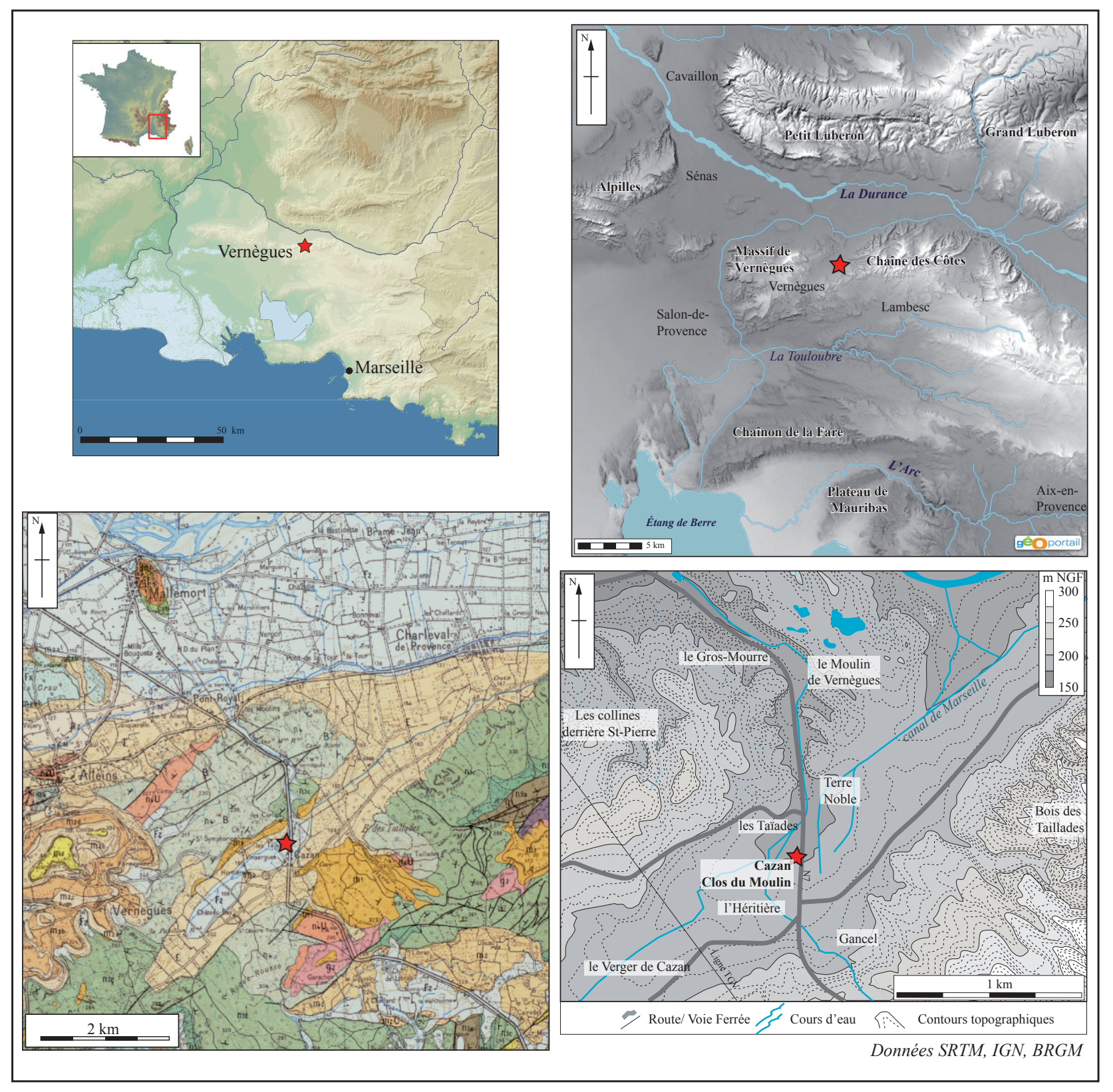

Fig. 1 - Localisation du site dans son contexte topographique et géologique (DAO L. Howarth, C. Moreau).

Fig. 1 - Site location, regional topography and geological setting (CAD L. Howarth, C. Moreau). 
de nombreuses variations de faciès dues à des processus inégaux d'accumulation et d'érosion des sédiments en relation avec la morphologie du substratum et les fluctuations hydrologiques du bassin au cours du Quaternaire.

Le bassin versant, peu étendu, comporte plusieurs ruisseaux qui confluent près de Cazan avant de s'écouler vers le nord jusqu'à la Durance, le long d'un petit vallon assez étroit (fig. 1). Au moins jusqu'à l'époque moderne, le débit devait être suffisant pour faire fonctionner les deux moulins présents dans ce vallon. La zone de fouille est située directement au sud de cette confluence qui coïncide avec une légère dépression topographique à la jonction de la vallée de Cazan et du vallon du Gros-Mourre. Une telle localisation d'un habitat néolithique suggère une interrelation entre le contexte hydrologique de la vallée et l'évolution de son occupation.

\section{Contexte archéologique}

Le site du Clos du Moulin s'inscrit dans une zone de forte densité de sites archéologiques, documentée par des opérations de fouilles anciennes, des prospections, mais aussi et surtout des opérations préventives conduites sur la commune préalablement à l'implantation de la ligne TGV Méditerranée et au cours de l'urbanisation progressive du vallon.

L'ensemble du vallon a livré de multiples traces d'occupations du Néolithique moyen (Thirault et al., 2016). La plupart des occupations du Chasséen récent proviennent toutefois de plusieurs opérations au lieu-dit " l'Héritière » : une portion de fossé, un puits et deux foyers (Chapon et al., 2002); un foyer lenticulaire isolé (Schmit, 2000); un puits riche en mobilier (Gaday et Sargiano, 2008) et enfin deux puits, des fosses et foyers à pierres chauffées (Thirault et al., 2016).

L'ensemble de ces découvertes délimite au Chasséen récent une zone de fréquentation s'étirant sur $3 \mathrm{~km}$ de long (fig. 1). Néanmoins, il existe aussi des secteurs où les opérations de diagnostic se sont avérées négatives pour le Néolithique, traduisant une occupation discontinue, avec des zones de vide et sans doute deux pôles qui se dessinent autour du Clos du Moulin et de l'Héritière. Cette discontinuité est à mettre en rapport avec le contexte hydrographique évoqué plus haut, qui a dû conditionner la localisation des implantations humaines.

\section{LES VESTIGES D'UN HABITAT STRUCTURÉ}

\section{Évolution du site : sédimentation et paléoenvironnements}

Plusieurs logs sédimentaires ont été décrits afin de comprendre la mise en place du site (fig. 2). Au nord-ouest, les analyses sédimentaires et paléoenvironnementales du $\log 4$, qui comprend le lambeau d'un paléosol potentiellement associé à l'occupation néolithique, mènent à la reconstitution de l'histoire géomorphologique (fig. 3). La combinaison des résultats obtenus sur ce log et des données bioarchéologiques et micromorphologiques issues des structures archéologiques permet de tracer les grandes lignes de la formation du site et du cadre environnemental de l'occupation néolithique.

\section{Mise en place du substrat}

Au début de l'Holocène, l'accumulation colluvioalluviale de limons « lœssiques » issus des formations géologiques du bassin a formé le substrat de la séquence pédosédimentaire (fig. 3, US 002). La malacofaune évoque l'association de formations herbacées plus ou moins humides dans un contexte de transition climatique et renvoie à une datation probablement antérieure à $9000 \mathrm{BP}$.

\section{Le paléosol et l'occupation néolithique}

Sur ce substrat limoneux, se développe un sol alluvial (fig. 3, US 1721) marqué par une activité biologique assez importante. Des fragments de cet horizon pédologique sont observés dans les comblements de plusieurs faits archéologiques (ensemble 9 et bâtiment 1), ce qui implique que ce sol était déjà en place avant l'occupation néolithique et encore présent lors du comblement de ces structures. Ce sol a subi des périodes d'humidité relativement importante (argiles d'origine alluviale, nodules manganiques), dont la datation et la durée sont difficiles à préciser. Les assemblages malacologiques caractérisent dans un premier temps un environnement humide, mais non marécageux, connecté à des milieux plus secs, avec un modeste couvert arboré. Ensuite, la malacofaune de la partie supérieure du paléosol suggère des milieux légèrement plus secs et plus fermés (pic d'abondance de Pomatias elegans), quoique les espèces de milieux ouverts restent largement dominantes. Parmi ces dernières, Cernuella virgata compte dans ce niveau ses effectifs les plus élevés; cette espèce volontiers anthropophile abonde par ailleurs sur le site archéologique. La malacofaune extraite des structures révèle en effet, au Chasséen récent, des milieux particulièrement ouverts (fig. 4) : garrigues, pelouses sèches, milieux rudéraux, que confirme l'analyse des charbons de bois (voir infra et fig. 23). En dépit d'un spectre anthracologique très peu diversifié et ne reflétant sans doute qu'une petite part de la diversité ligneuse disponible aux environs, les essences identifiées pour la même période renvoient majoritairement à des formations méditerranéennes dégradées de type garrigue ou maquis, en partie sur sols décarbonatés (abondance de l'arbousier), ou de type pinède sur sols pauvres et secs (pins méditerranéens). Le chêne caducifolié témoigne de formations plus forestières, sur des sols sans doute plus profonds. Les végétations ripicoles sont très peu enregistrées. La présence de mollusques aquatiques, palustres et hygrophiles, jamais abondants (lymnées et espèces hygrophiles, fig. 4), pourrait être liée à des apports accidentels naturels ou anthropiques, ou, localement, à des contextes environnementaux particuliers, intrinsèques à la position en fond de vallon. 


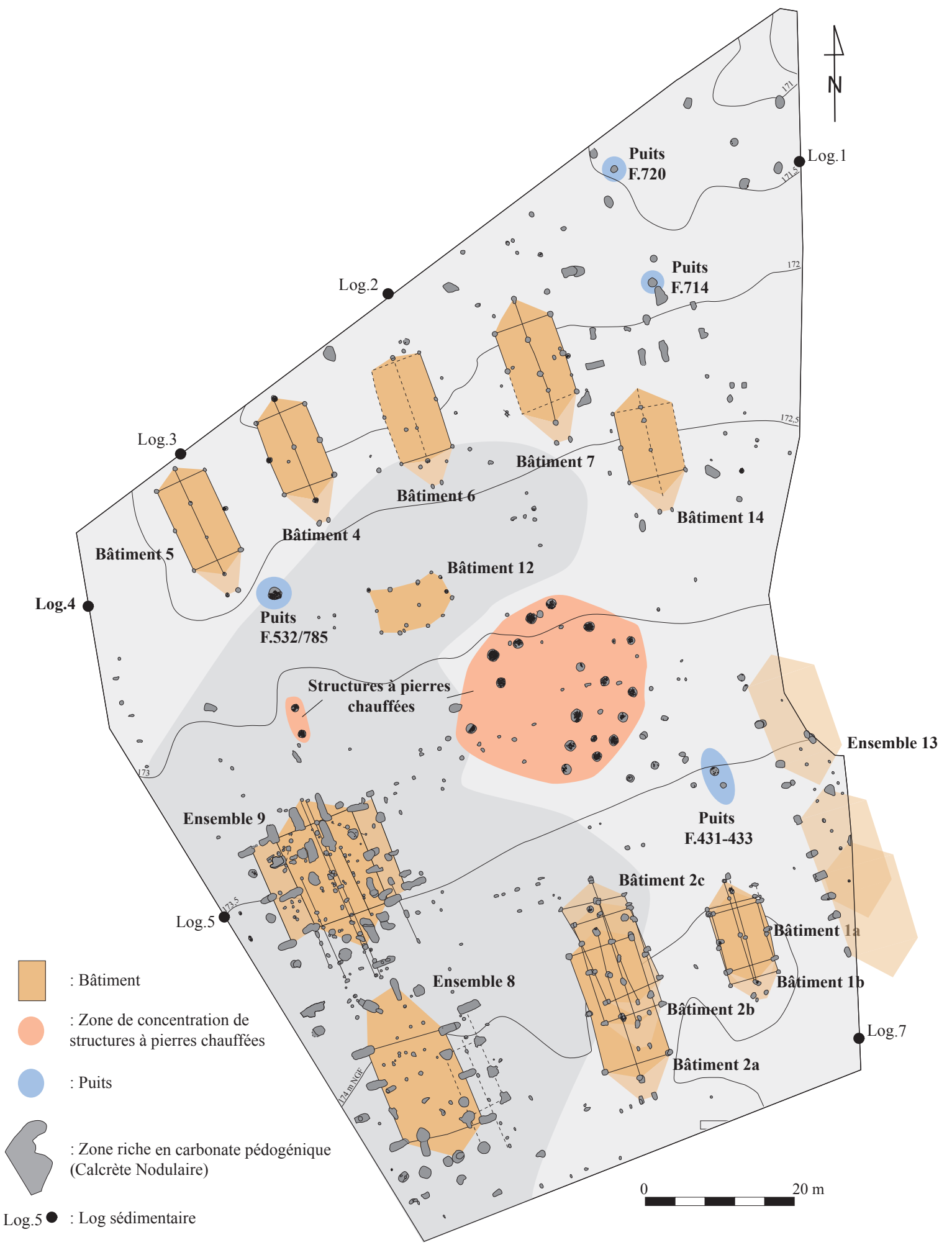

Fig. 2 - Plan des structures raccordées à l'occupation du Chasséen récent (DAO C. Moreau).

Fig. 2 - Plan of the structures dating to the Late Chassey (CAD C. Moreau).

La malacologie a permis d'évaluer le degré d'anthropisation du site, grâce une analyse factorielle des correspondances prenant en compte 46 assemblages issus de vingt-trois structures (choisies à partir d'une analyse préliminaire : Magnin, in Moreau et al., 2015, fig. 4) et quinze espèces terrestres sélectionnées pour leur pertinence à caractériser le gradient entre ouverture et fermeture des formations végétales. L'ordination des espèces, conforme à celle décrite dans les successions post-culturales du Midi de la France (Magnin et Tatoni, 1995), 


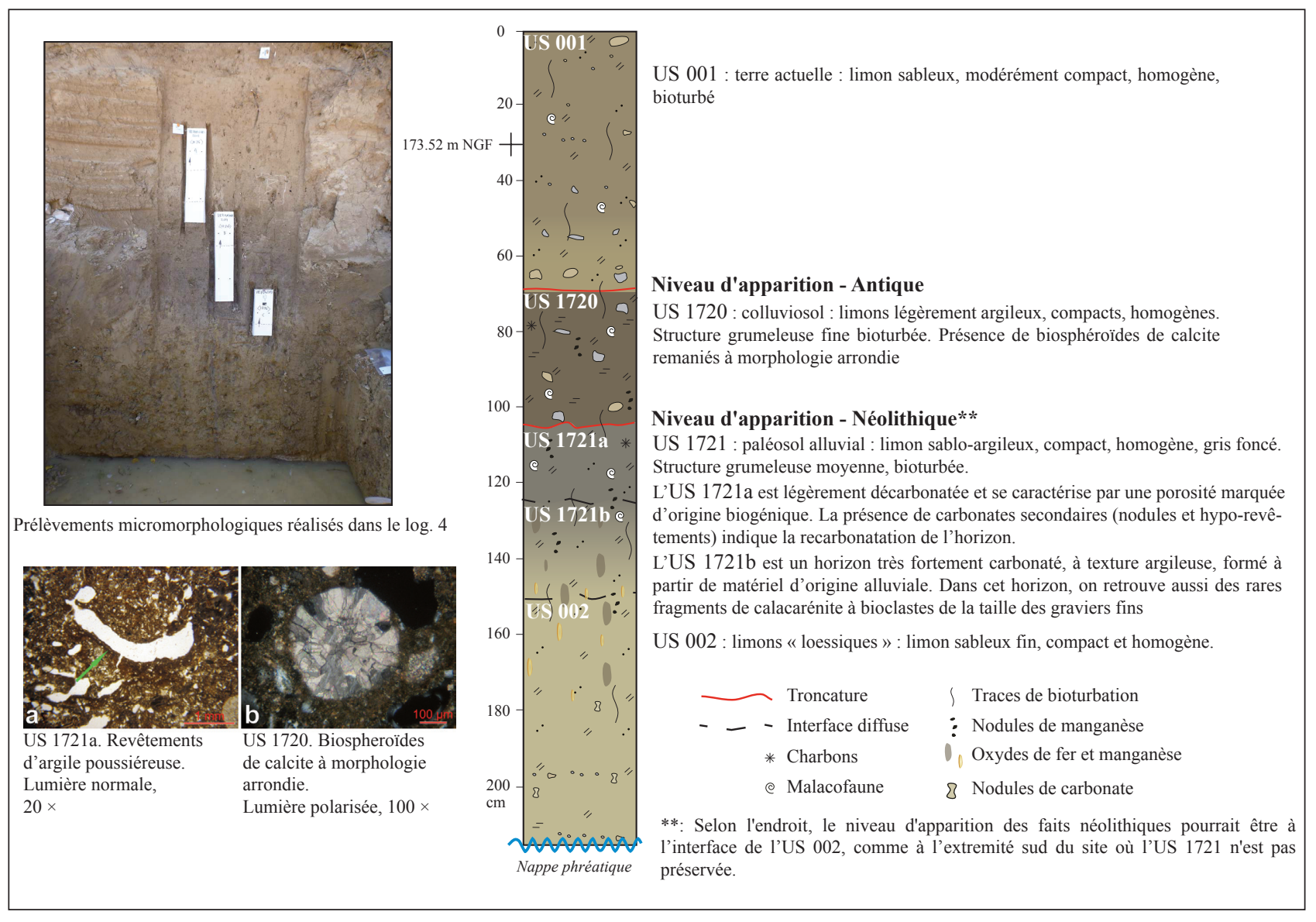

Fig. 3 - Détail de la séquence sédimentaire observée sur le log 4 au nord-ouest du site (DAO et clichés L. Howarth, C. Nicosia).

Fig. 3 - The sedimentary sequence recorded in $\log 4$ in the north-western corner of the site (CAD and photographs L. Howarth, C. Nicosia).

autorise une estimation du degré de « naturalité » ou d'« artificialisation » des environnements décrits par la malacofaune (fig. 5). Les seuls assemblages qui renvoient à des paléoenvironnements à degré de naturalité relativement élevé correspondent aux structures attribuées au Néolithique ancien ou au Chasséen ancien (fig. 4 et 5). Si ces milieux ne peuvent en aucun cas être assimilés à des forêts matures, ils sont tout au moins marqués par la présence d'une litière foliacée abondante et humide. À l'opposé, les paléoenvironnements très artificialisés (milieux rudéraux) se signalent par la bonne représentation de $C$. virgata, espèce méditerranéenne xérophile dont les populations se développent fortement dans la région au Néolithique moyen, en relation avec les activités humaines favorisant à la fois l'ouverture du paysage et la dispersion passive de l'espèce (Magnin et Martin, 2012; Martin et al., 2005). Ces assemblages de milieux très artificialisés caractérisent des puits et des structures à pierres chauffées du Chasséen récent principalement localisés dans la zone centrale de la fouille (en rouge, fig. 4). Entre ces deux extrémités du gradient, associées à des degrés d'artificialisation moins extrêmes (milieux ouverts de type garrigues ou pelouses sèches), se trouvent de nombreuses structures du Chasséen récent (trous de poteau, fosses d'implantation), généralement situées hors de la zone centrale.
$\mathrm{Si}$, par ces résultats malacologiques, les sédiments reflètent une anthropisation marquée du site, étonnamment, à l'échelle microscopique, les comblements des trous de poteau présentent peu de composantes anthropiques. Parmi les dix-neuf lames minces prélevées dans les comblements de quatre bâtiments ( $1 \mathrm{a}, 1 \mathrm{~b}, 2 \mathrm{~b}$ et 9$)$, seules trois montrent des éléments anthropiques (coquille d'œuf brûlée, silex, céramique) et six autres livrent des microcharbons ou cendres, qui pourraient être associés à l'occupation ou l'abandon du site. En revanche, on note très peu d'os brûlé et aucune des lames étudiées n'a livré de coprolithes. Les phénomènes de dissolution ou des phases d'érosion ne suffisent pas à expliquer cette situation. La découverte de restes fauniques et l'abondance de la malacofaune et des biosphéroïdes de vers de terre s'opposent à l'hypothèse d'une dissolution importante des composantes biologiques carbonatées du sédiment. Par ailleurs, le matériel piégé dans le comblement des structures semble à l'abri de remobilisations massives lors d'inondations, que la présence de concentrations importantes de charbons et de malacofaune rend de toute façon improbables.

L'horizon pédologique préservé au niveau du $\log 4$ (fig. 3, US 1721) présente de fréquents revêtements d'ar- 


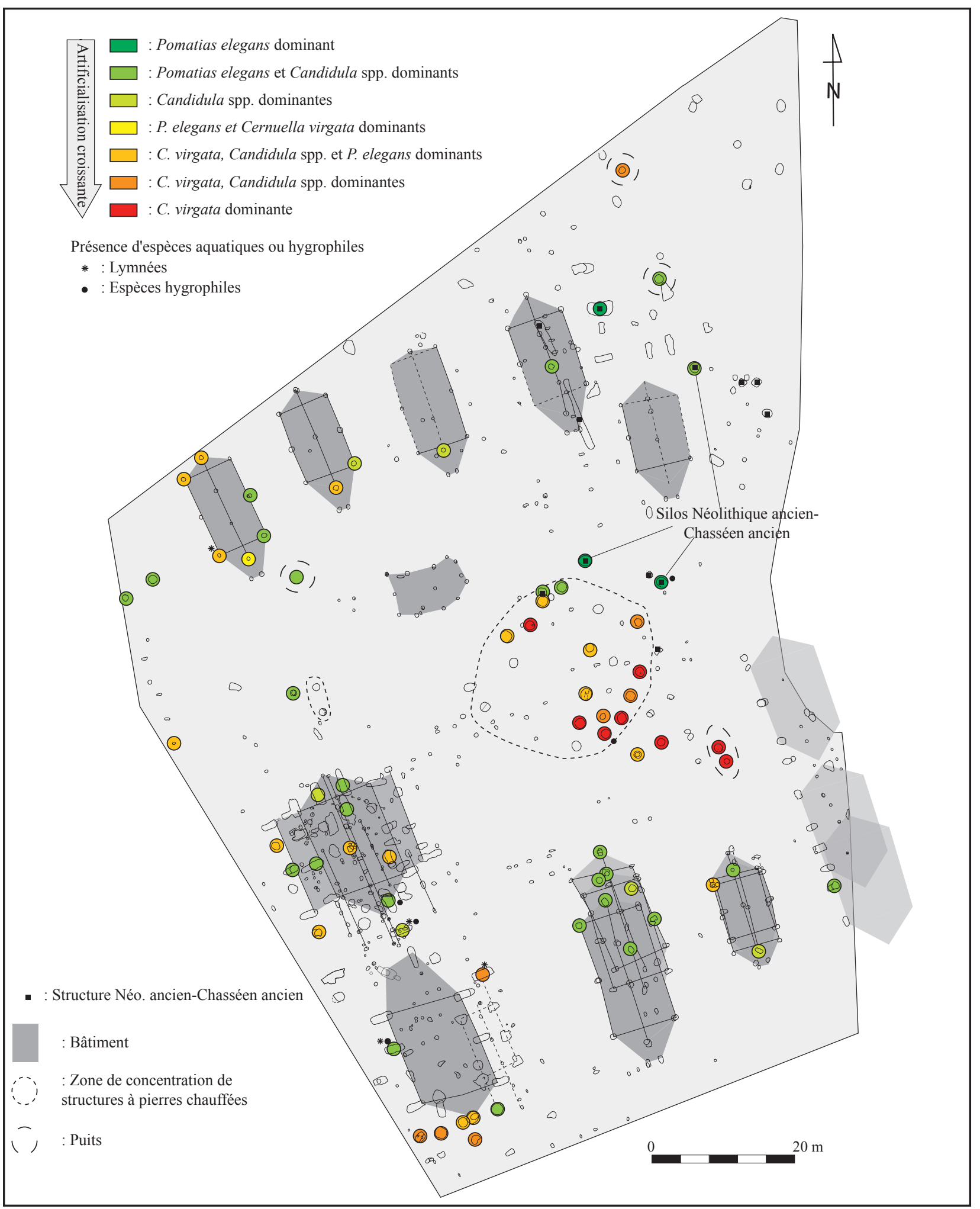

Fig. 4 - Répartition spatiale des assemblages malacologiques des structures Chasséen ancien et Chasséen récent caractérisés par leurs espèces dominantes (DAO F. Magnin, C. Moreau).

Fig. 4 -Distribution and species dominance of the snail assemblages recorded in the Chassey structures (CAD F. Magnin, C. Moreau).

giles poussiéreuses qui témoignent d'une mise à nu de sa surface d'origine, au cours d'une (ou plusieurs) phase(s) d'importante perturbation, dans le cadre possible d'un déboisement lors de l'occupation néolithique (Macphail et al., 1990).

\section{L'enfouissement du site}

Les lambeaux de sol restants, ainsi que le substrat, sont enfin recouverts par un dépôt colluvial (fig. 3, US 1720) composé de sédiments et de fragments de sol rema- 


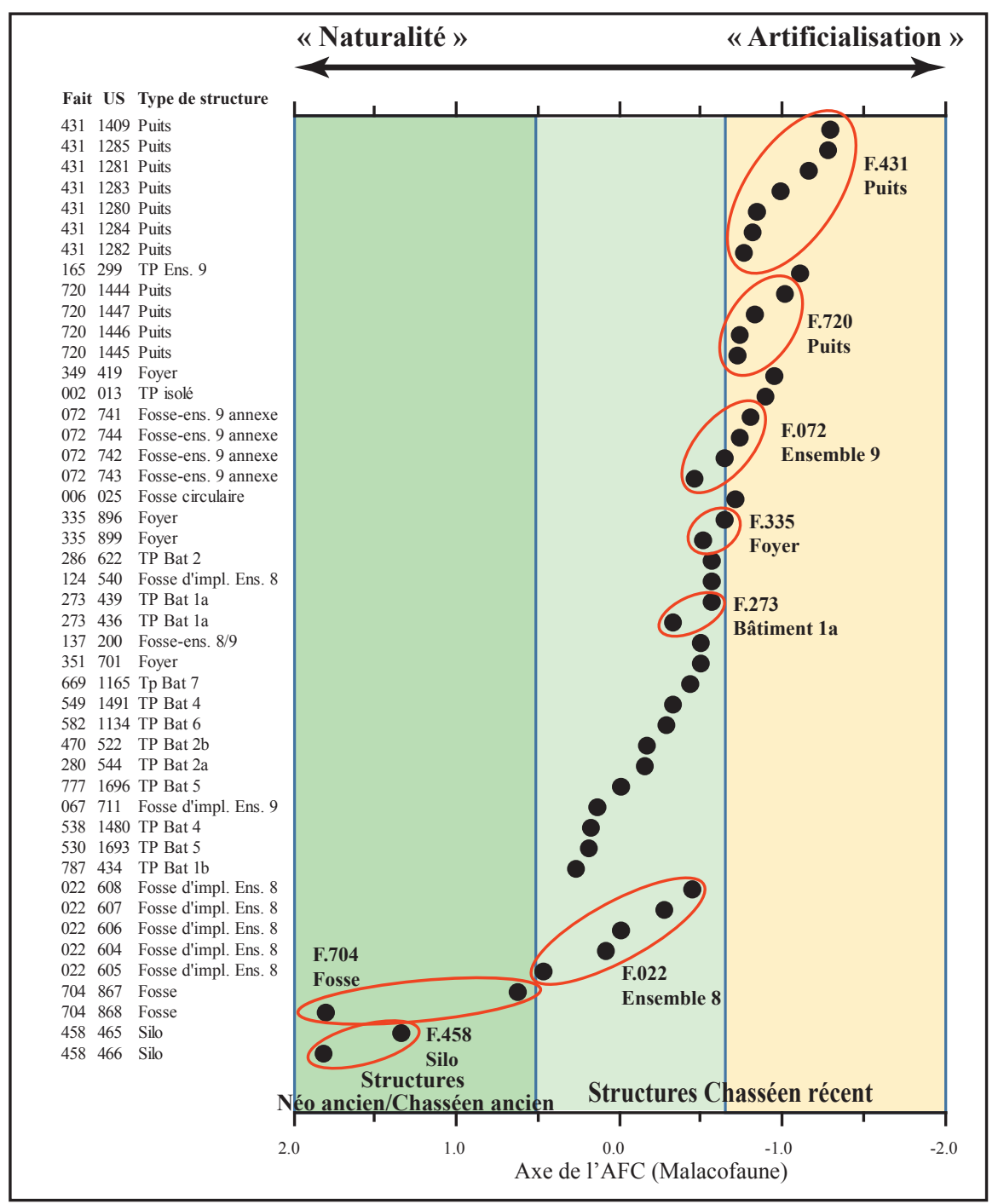

Fig. 5 - Gradient d'artificialisation des milieux, du Néolithique ancien au Chasséen récent, mis en évidence par l'analyse factorielle des correspondances appliquée aux assemblages malacologiques des structures (DAO F. Magnin, C. Moreau).

Fig. 5 - The environment from the Early Neolithic to the Late Chassey, as recorded by the snails assemblages sampled from the fills of the features: artificialization gradient obtained through factorial correspondence analysis (CAD F. Magnin, C. Moreau).

niés, également affecté par un développement pédogénétique. Cette dynamique colluviale, liée à une période de déstabilisation des versants, a eu pour conséquence l'enfouissement et le lissage de la topographie préhistorique. Des vestiges antiques apparaissent à l'interface entre ce colluviosol et la terre actuelle (fig. 3, US 001). La malacofaune du colluviosol et de l'horizon supérieur post-antique (US 1720 et 001 ), riche en espèces xérothermophiles de milieux ouverts, témoigne d'une réduction drastique de la végétation ligneuse au profit des formations herbacées sèches.

\section{Présentation générale des vestiges}

Au Clos du Moulin, si aucun réel niveau de sol ne nous est parvenu, les structures en creux sont en revanche bien conservées et particulièrement visibles dans le substrat. Le riche mobilier archéologique retrouvé lors de leur fouille manuelle ou mécanique ne laisse que peu de doute quant aux attributions chronologiques des structures et des aménagements auxquels elles appartiennent. Ces structures correspondent majoritairement à des vestiges architecturaux avec plus de 500 trous de poteau ou fosses d'implantation, mais aussi une soixantaine de fosses isolées, vingt structures à pierres chauffées et cinq puits.

Toutes les catégories de mobilier renvoient à des occupations très resserrées dans le temps, lors du développement du Chasséen récent, entre 4100 et 3800 avant notre ère. La céramique totalise près de $66 \mathrm{~kg}$ avec 836 individus-vases qui appartiennent à une transition entre la phase ancienne du Chasséen (décors gravés et incisés) et une étape plus récente (coupes à sillon, coupes à carène basse, etc.). Elle se rattache aux étapes $\mathrm{C} 1$ à $\mathrm{D} 1 \mathrm{de}$ C. Lepère (2012), aux styles 3b à 5a de C. Georjon (Georjon et Léa, 2013). Cette céramique est issue de 223 structures réparties sur toute l'emprise, avec des concentrations au niveau des puits et de certains trous de poteau (fig. 6). Les 1330 pièces lithiques taillées proviennent de 226 faits 


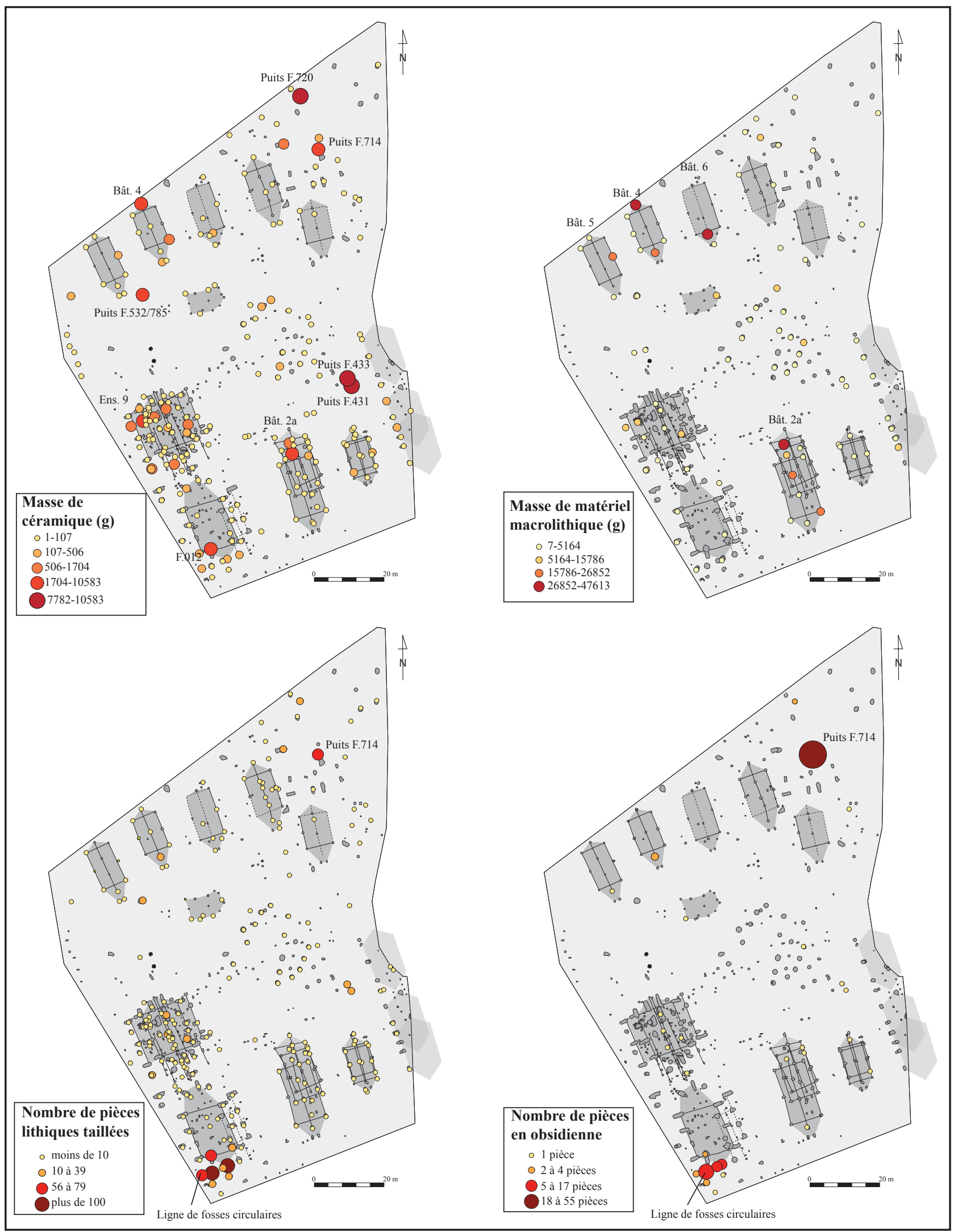

Fig. 6 - Répartition des mobiliers céramiques, macrolithiques et lithiques taillés (DAO C. Moreau).

Fig. 6 - Distribution of the finds: ceramics, worked stone, flint and obsidian (CAD C. Moreau). 
et se caractérisent par une majorité de lamelles en silex et une très bonne représentation des pièces en obsidienne $(\mathrm{n}=123)$. Cette industrie est répartie sur pratiquement tout le site, mais deux concentrations sont tout de même observables au niveau d'une ligne de fosses circulaires au sud-ouest et d'un puits au nord. L'outillage macrolithique est, quant à lui, représenté par 45 meules entières ou fragmentées, vingt-cinq molettes, six broyons, un polissoir, une bille et 213 galets, dont certains ont pu être utilisés comme bouchardes ou percuteurs. Ce corpus est réparti sur l'ensemble du site, avec certaines concentrations au niveau certains bâtiments. Enfin, la faune représente près de $10 \mathrm{~kg}$ avec plus de 1800 restes, presque exclusivement issus des puits.

En complément de ce mobilier archéologique, l'attribution chronologique repose également sur huit datations ${ }^{14} \mathrm{C}$ réalisées sur des graines ou des charbons d'espèces à durée de vie brève sélectionnés après étude anthracologique (tabl. 1). Deux d'entre elles sont principalement comprises entre 4050 et 3950 après calibration à $95,4 \%$; les six autres s'échelonnent entre 3950 et 3800 .

\section{Les bâtiments sur poteaux}

\section{Un modèle de plan répété à dix reprises}

Alors que les maisons chasséennes avérées étaient encore rare dans le Sud de la France (Saintot, 2002 et 2012), le caractère exceptionnel du Clos du Moulin réside dans la mise en évidence de dix plans de bâtiments sur trous de poteau (fig. 2). Au sud-est, deux ensembles de deux et trois constructions superposées ont été perçus (bâtiments 1 et 2); le long de la bordure septentrionale, une ligne de quatre édifices a été découverte (bât. 4, 5, 6 et 7); enfin le bâtiment 14 se situe au sud-est de cette dernière ligne (nous reprendrons ici la numérotation de fouille qui n'est pas continue, car elle inclut des hypothèses architecturales non retenues et les aménagements antiques). Dans leur grande majorité, ces bâtiments ont été vus dès la phase de fouille du fait notamment de la grande similitude de leur organisation architecturale. En effet, même si leurs dimensions peuvent varier, la dispo- sition des poteaux détermine des proportions constantes et il est possible d'établir un modèle d'implantation qui fonctionne avec tous les édifices.

Ce plan standard est composé de deux murs gouttereaux parallèles, comptant chacun trois poteaux régulièrement espacés. L'espace rectangulaire formé par ces deux parois présente toujours les mêmes proportions et la même orientation nord-nord-ouest - sud-sud-est, parallèle à la direction du vent dominant. Une ligne faîtière sépare le plan en deux nefs et vient le compléter en dépassant des deux murs au nord et au sud; elle est constituée de deux petits poteaux au sud, d'un poteau au nord et généralement de deux poteaux centraux, dont la position peut varier. Les deux poteaux au sud pourraient indiquer l'entrée du bâtiment. Le poteau central le plus au nord ne signe a priori pas une abside, mais plutôt une probable faîtière débordante (Moreau et al., à paraître).

Quatorze trous de poteau ont fait l'objet d'une analyse anthracologique (Delhon et al., sous presse; fig. 7). Les charbons se présentent souvent sous la forme de quelques gros fragments en assez mauvais état, présentant des altérations caractéristiques de la combustion de bois en état de décomposition. Les assemblages anthracologiques sont presque toujours mono-spécifiques, et les fragments issus d'un même trou de poteau présentent des similitudes anatomiques qui rendent probable leur appartenance initiale à un même morceau de bois. Il est donc très vraisemblable qu'il s'agisse des poteaux eux-mêmes, carbonisés sur place, et non de charbons produits par ailleurs et piégés dans les trous de poteau. Le chêne semble avoir été préférentiellement utilisé pour la fabrication des poteaux de l'ensemble des bâtiments du site : il est présent dans treize cas sur quatorze, souvent seul (accompagné de frêne dans un seul cas). Un seul trou de poteau n'a fourni que du pin. Les charbons de chêne présentent de nombreux thylles, excroissances cellulaires caractéristiques du bois de cœur ou duramen, qui est la partie la plus âgée du tronc mais aussi la seule durable pour un usage du bois comme matériau.

Sans rentrer dans le descriptif détaillé de chaque structure, nous allons parcourir les caractéristiques principales de ces dix premiers bâtiments sur trous de poteau.

\begin{tabular}{|l|l|l|l|l|l|c|} 
Identifiant & Fait & US & Type de structure & Type/Espèce & Résultat & $\begin{array}{c}\text { Intervalle max. } \\
\text { cal. à 95,4 \% }\end{array}$ \\
\hline Beta-387513 & F.433 & 908 & Puits & Charbon, pin d'Alep & $5240 \pm 30$ BP & $4230-3970$ \\
\hline Beta-387510 & F.252 & 1650 & Trou de poteau, bâtiment 2a & Charbon, frêne & $5200 \pm 30 \mathrm{BP}$ & $4050-3960$ \\
\hline Beta-387508 & F.135 & 594 & Fosse, ensemble 8 & Charbon, arbousier & $5110 \pm 30$ BP & $3975-3800$ \\
\hline Beta-387514 & F.433 & 916 & Puits & Graine & $5100 \pm 30 \mathrm{BP}$ & $3970-3800$ \\
\hline Beta-387509 & F.174 & 1385 & Fosse d'implantation, ensemble 9 & Charbon, arbousier (brindille) & $5060 \pm 30 \mathrm{BP}$ & $3950-3790$ \\
\hline Beta-387511 & F.339 & 767 & Structure à pierres chauffées & Charbon, pin d'Alep & $5050 \pm 30 \mathrm{BP}$ & $3950-3780$ \\
\hline Beta-387515 & F.536 & 1467 & Trou de poteau, bâtiment 4 & Charbon, pin & $5050 \pm 30 \mathrm{BP}$ & $3950-3780$ \\
\hline Beta-387507 & F.070 & 1423 & Fosse d'implantation, ensemble 9 & Charbon, peuplier ou saule & $5010 \pm 30 \mathrm{BP}$ & $3940-3700$ \\
\hline
\end{tabular}

Tabl. 1 - Résultats des huit datations radiocarbones (données Beta Analytic).

Table 1 - The results of 8 radiocarbon dates (Data Beta Analytic). 


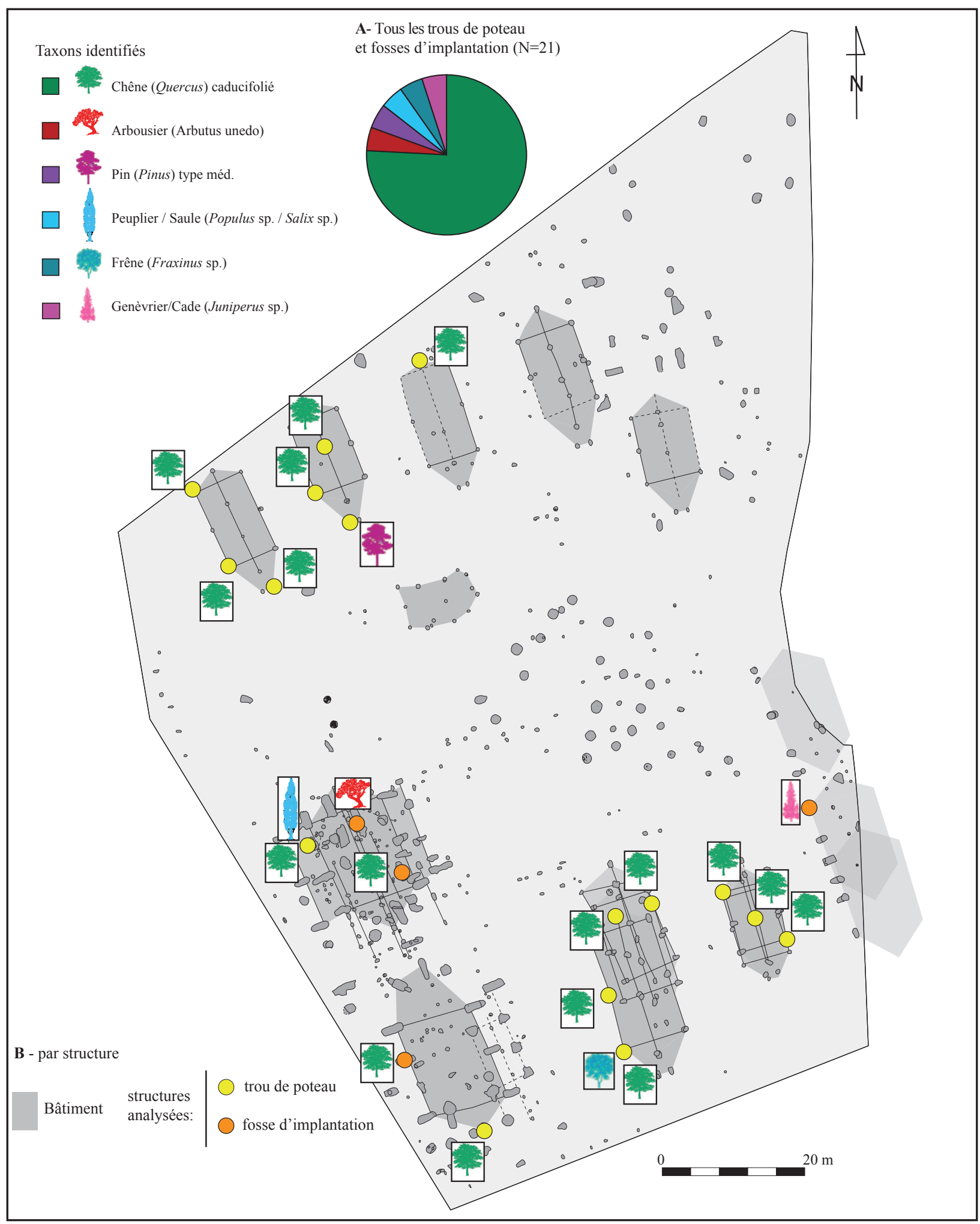

Fig. 7 - Résultats de l'analyse anthracologique globale (A) et par structure (B) des trous de poteau et des fosses d'implantation (DAO C. Delhon, C. Moreau).

Fig. 7 - Charcoal analysis of the potsholes and foundation pits: total site spectrum (A) and results by structure (B) (CAD C. Delhon, C. Moreau).

\section{Les bâtiments $1 \mathrm{a}$ et $1 \mathrm{~b}$}

Ils comptent vingt-huit trous de poteau au sud de l'emprise, qui ont été interprété initialement comme un ensemble composé de double poteaux (Moreau, 2014). Il s'agit en fait de deux bâtiments très similaires, construits pratiquement au même endroit (fig. 8).

Le premier bâtiment 1a repose sur seize trous de poteau qui forment un plan complet de $17 \mathrm{~m}$ de long au 


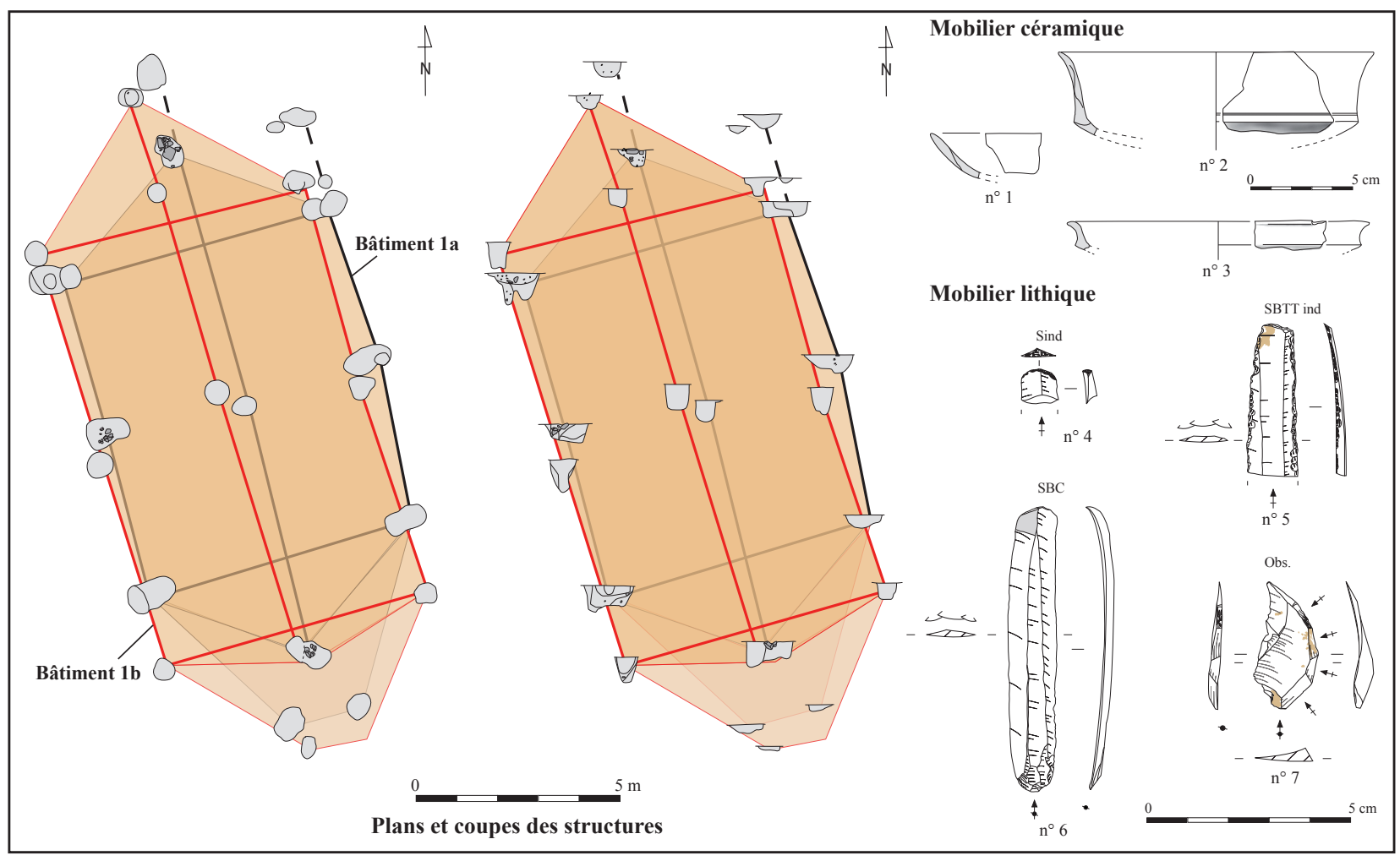

Fig. 8 - Données archéologiques et échantillon de mobilier issu des bâtiments la et $1 \mathrm{~b}$, légende des matières premières lithiques en note 2 (DAO B. Bosc-Zanardo, L. Guichard-Kobal, C. Moreau, V. Léa).

Fig. 8 - Archaeological data and examples of finds from the buildings 1 a and 1 b, key for the lithic material on note 2 (CAD B. BoscZanardo, L. Guichard-Kobal, C. Moreau, V. Léa).

maximum et 7,5 $\mathrm{m}$ de large. Son canevas présente certaines structures qui prolongent les axes faîtiers et orientaux vers le nord. Les trous de poteau sont profonds de 20 à $80 \mathrm{~cm}$ et une de leur particularité réside dans les plans allongés et les profils irréguliers des structures appartenant aux deux murs gouttereaux. Les trous de poteau faîtiers sont plus circulaires et à profil en U; l'un d'eux est recoupé par une structure faitière du bâtiment $1 \mathrm{~b}$. La plupart de leurs remplissages limoneux sont simples, mais certains possèdent néanmoins des stratigraphies complexes et des blocs en surface sur la moitié ouest de la construction.

Le second bâtiment $1 \mathrm{~b}$ est implanté sur au moins douze poteaux, pour la plupart décalés des structures du bâtiment $1 \mathrm{a}$; un seul recoupement a été observé avec l'édifice précédent et un trou de poteau méridional n'est pas conservé (fig. 8). Ils forment un plan cohérent, comparable à celui du bâtiment $1 \mathrm{a}$, mais avec un décalage léger vers le sud-ouest. Si ce bâtiment $1 \mathrm{~b}$ s'individualise bien du bâtiment 1a par l'implantation des poteaux, il s'en distingue aussi par les caractéristiques intrinsèques de ses structures : toutes sont circulaires, à profil en U, avec des remplissages simples.

L'unique recoupement entre structures et les différences de creusement et de comblement entre bâtiments permettent d'établir une chronologie relative entre les deux édifices. Le bâtiment 1a a été implanté dans un premier temps. Après une phase d'abandon probable- ment courte, un second édifice très similaire a été érigé (bâtiment 1b), mais il est possible que certains poteaux antérieurs - ou tout du moins ce qu'il en restait - aient été incendiés et arrachés et les trous comblés avec du sédiment ou des blocs. Les poteaux qui auraient été susceptibles de trop gêner la nouvelle construction décalée vers le sud-ouest sont ceux de la paroi occidentale du bâtiment 1a et les éléments centraux; ceux de la paroi orientale sont en dehors de la seconde emprise, ce qui pourrait expliquer des remplissages plus simples.

\section{Les bâtiments 2a, 2b, 2c}

Plus à l'ouest, un ensemble d'une quarantaine de structures en creux forme trois bâtiments qui se superposent avec, à chaque fois, un décalage vers le nord, sans aucun recoupement entre structures (fig. 2 et 9).

Le bâtiment $2 \mathrm{a}$ est le plus méridional. Il est basé sur douze structures qui dessinent un modèle standard, mais avec des dimensions importantes qui en font le plus grand édifice du site $\left(9,8 \times 24,4 \mathrm{~m}\right.$, soit $\left.182,6 \mathrm{~m}^{2}\right)$. Comme pour le bâtiment $1 \mathrm{a}$, deux structures prolongent les axes centraux et orientaux vers le nord. Les plans de ces structures sont généralement ovoïdes ou irréguliers. Les profils sont bien conservés ( $55 \mathrm{~cm}$ en moyenne), mais très divers, avec certains remplissages complexes indiquant souvent deux phases de creusement et de comblement. Des blocs sont présents en surface de deux trous de poteau. Les remplissages ont livré un mobilier abondant avec en 


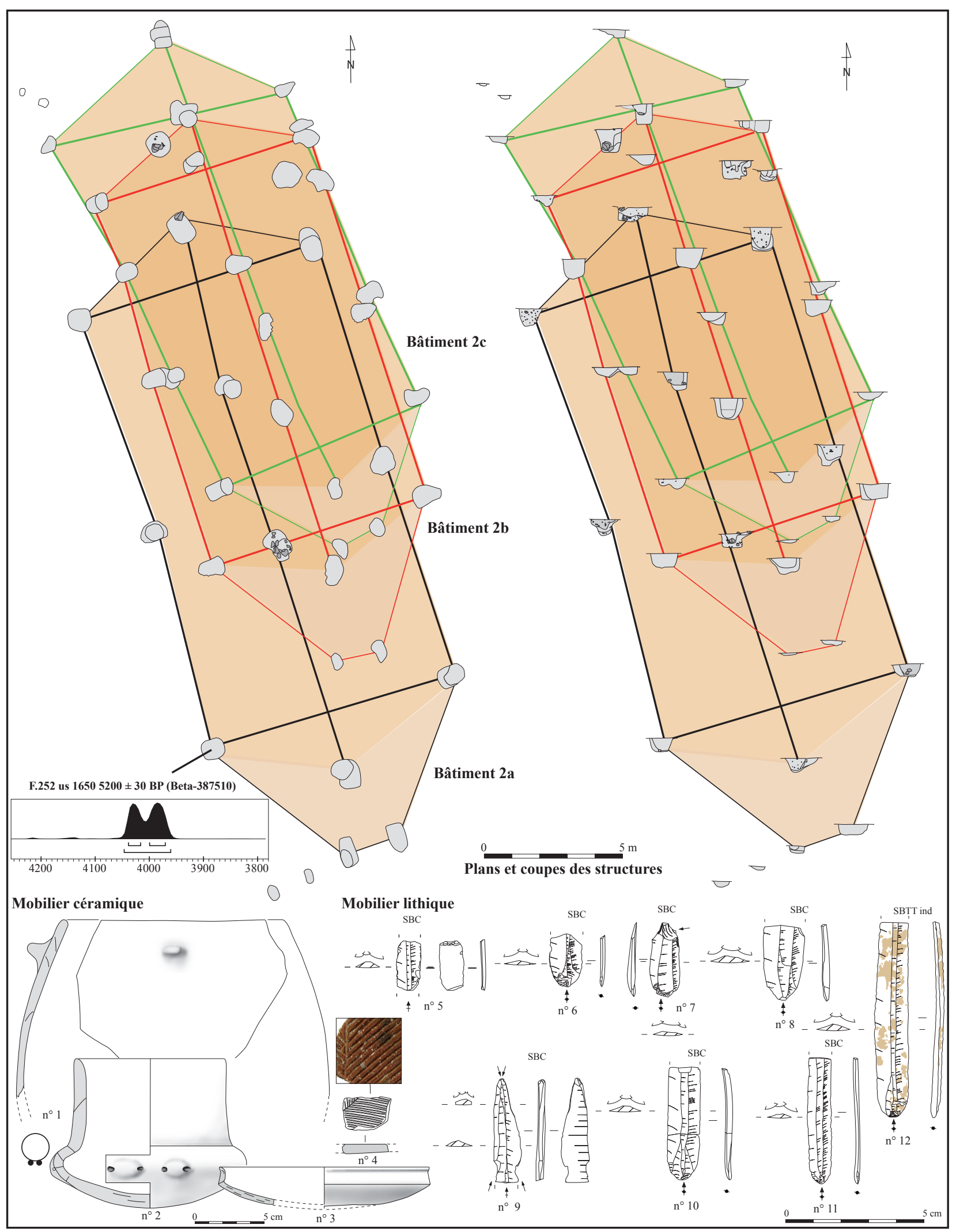

Fig. 9 - Données archéologiques et échantillon du mobilier issu des bâtiments 2a, 2b et 2c (DAO B. Bosc-Zanardo, L. Guichard-Kobal, C. Moreau, V. Léa).

Fig. 9 - Archaeological data and examples of finds from the buildings $2 a, 2 b$ and $2 c$ (CAD B. Bosc-Zanardo, L. Guichard-Kobal, C. Moreau, V. Léa) 
particulier des vases déposés à l'interface entre les deux phases de comblement (fig. $9, \mathrm{n}^{\circ} 2$ par exemple).

Le bâtiment $2 \mathrm{~b}$ se superpose au premier avec un décalage de $5 \mathrm{~m}$ vers le nord. Il possède des dimensions plus réduites, mais son orientation est identique à celle du bâtiment 2a. Trois implantations présentent une réfection ou un doublement des poteaux. Toutes les structures ont des plans ovoïdes avec des profils en U ou en cuvette également bien conservés. Les remplissages sont simples ou composés de deux couches successives, avec assez peu de mobilier.

Le bâtiment $2 \mathrm{c}$ correspond à un édifice qui présente encore un décalage vers le nord. Si la moitié sud de ce bâtiment est cohérente et certaine, sa moitié nord est plus hypothétique. Dans la proposition retenue, aucun recoupement ou même chevauchement de structure n'est visible avec les deux autres édifices. Sa partie sud se situe à environ $3 \mathrm{~m}$ au nord-est de celle du bâtiment $2 \mathrm{~b}$, ce qui permet de dessiner une construction avec un axe central légèrement décalé vers l'ouest par rapport aux édifices précédents. Les trous de poteau sont généralement ovoïdes, mais avec des profils moins bien conservés. Les remplissages sont majoritairement simples et pauvres en mobilier archéologique.

Comme pour l'ensemble 1, cet ensemble de trois bâtiments présente des structures caractéristiques d'une implantation successive des édifices avec des phases d'abandon et l'arrachage de certains poteaux. En outre, une phase de dépôt de céramique a été identifiée dans les structures abandonnées du premier édifice.

Quatre bâtiments alignés au nord du site, les bâtiments 5, 4, 6 et 7

Ces quatre constructions sont alignées sur un axe sudouest - nord-est, régulièrement espacées de 7 à $8 \mathrm{~m}$, soit la largeur moyenne d'un édifice (fig. 2). Le bâtiment 5 est le plus occidental (fig. 10). Douze structures composent un modèle de plan standard avec les deux poteaux faîtiers centraux en position intermédiaire $(9 \times 19 \mathrm{~m})$. Les trous de poteau sont subcirculaires avec des profils en $\mathrm{U}$ ou en cuvette. Leurs remplissages sont généralement uniques et plusieurs structures présentent de gros blocs en surface. Ces dernières rassemblent de nombreux objets de mouture, mais peu de céramique ou d'objets lithiques.

Le bâtiment 4 est très similaire au précédent avec des dimensions approchantes, mais un seul poteau faîtier central (fig. 11). Ses structures sont aussi équivalentes dans leurs plans, leurs profils et leurs dimensions et trois trous de poteau présentent un comblement terminal de blocs en surface, voire sur toute la profondeur conservée. Ces blocs sont trop nombreux pour représenter un vestige de calage et ils signalent plutôt un abandon de l'édifice et un probable rebouchage des trous laissés par les poteaux pourris, incendiés ou arrachés. Comme pour le bâtiment 5 , le

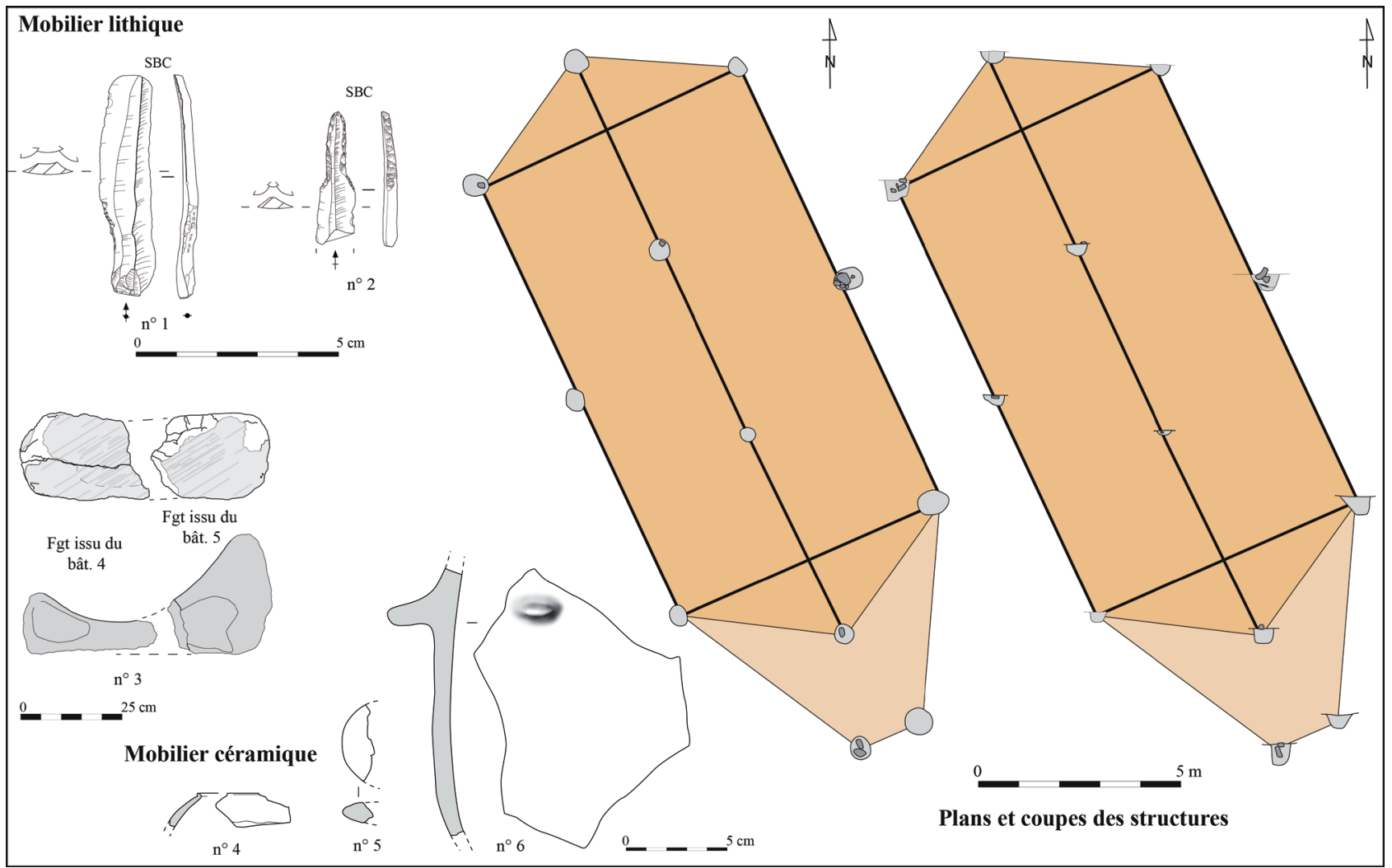

Fig. 10 - Données archéologiques et échantillon du mobilier issu du bâtiment 5 (DAO B. Bosc-Zanardo, L. Guichard-Kobal, C. Moreau, L. Pacotte, V. Léa).

Fig. 10 - Archaeological data and examples of finds from the building 5 (CAD B. Bosc-Zanardo, L. Guichard-Kobal, C. Moreau, L. Pacotte, V. Léa). 


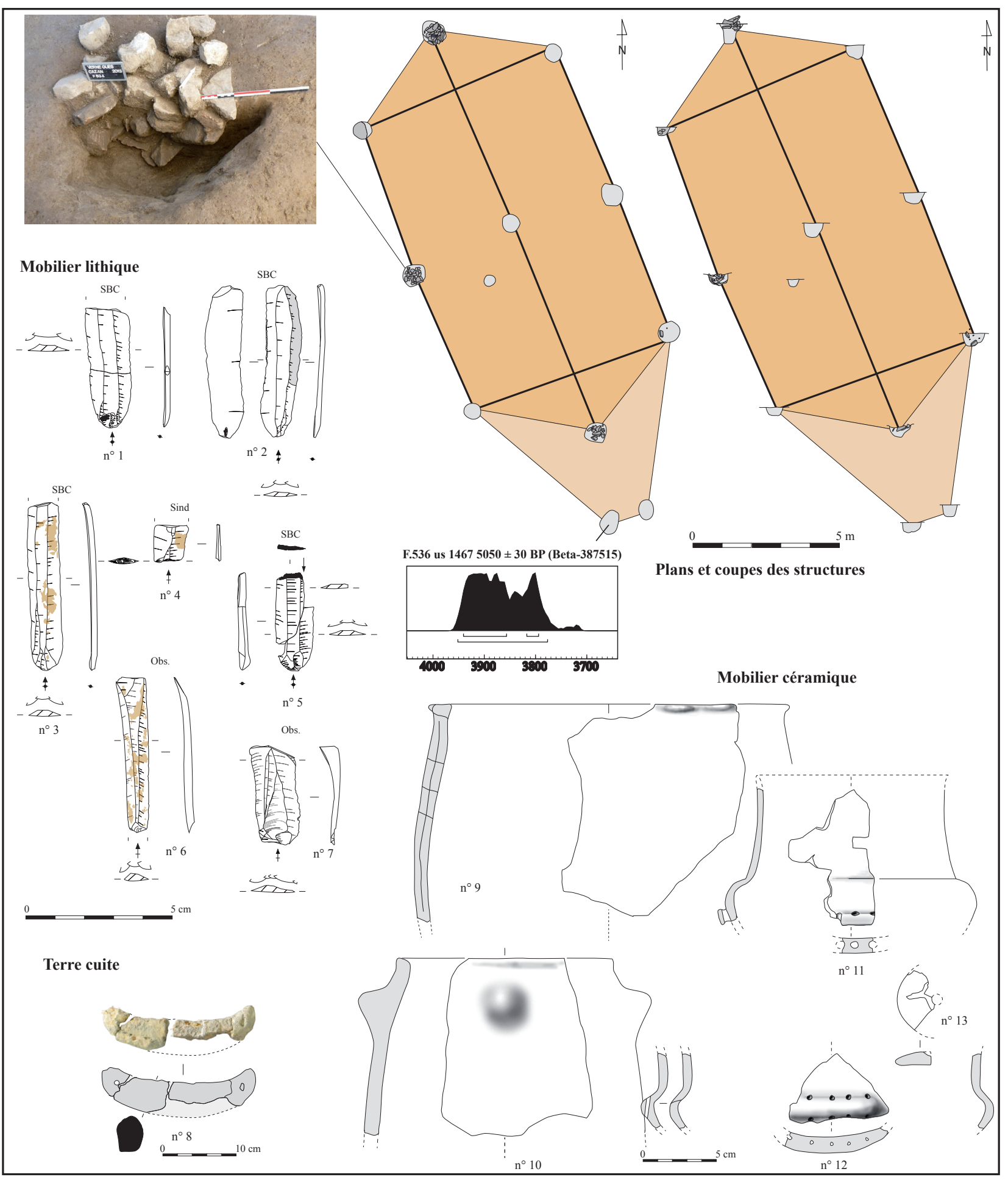

Fig. 11 - Données archéologiques et échantillon du mobilier issu du bâtiment 4 (DAO B. Bosc-Zanardo, L. Guichard-Kobal, C. Moreau, V. Léa).

Fig. 11 - Archaeological data and examples of finds from the building 4 (CAD B. Bosc-Zanardo, L. Guichard-Kobal, C. Moreau, V. Léa).

mobilier de mouture compose une bonne part des blocs; il a été retrouvé avec de nombreux artefacts céramiques et lithiques (respectivement $4,2 \mathrm{~kg}$ et 56 pièces).

Le bâtiment 6 possède des structures circulaires beaucoup plus arasées, d'où une reconnaissance partielle de son plan général (fig. 12). Il faut néanmoins signaler le cas du trou de poteau faitier méridional, bien conservé, qui contient une meule plantée verticalement en son centre (fig. 12, no 1 ).

Le dernier bâtiment 7 de l'alignement septentrional a été retrouvé, quant à lui, au sein d'une multitude de structures qu'il vient apparemment recouper (fig. 12, en blanc sur le plan). Cette situation engendre des doutes sur l'attribution 


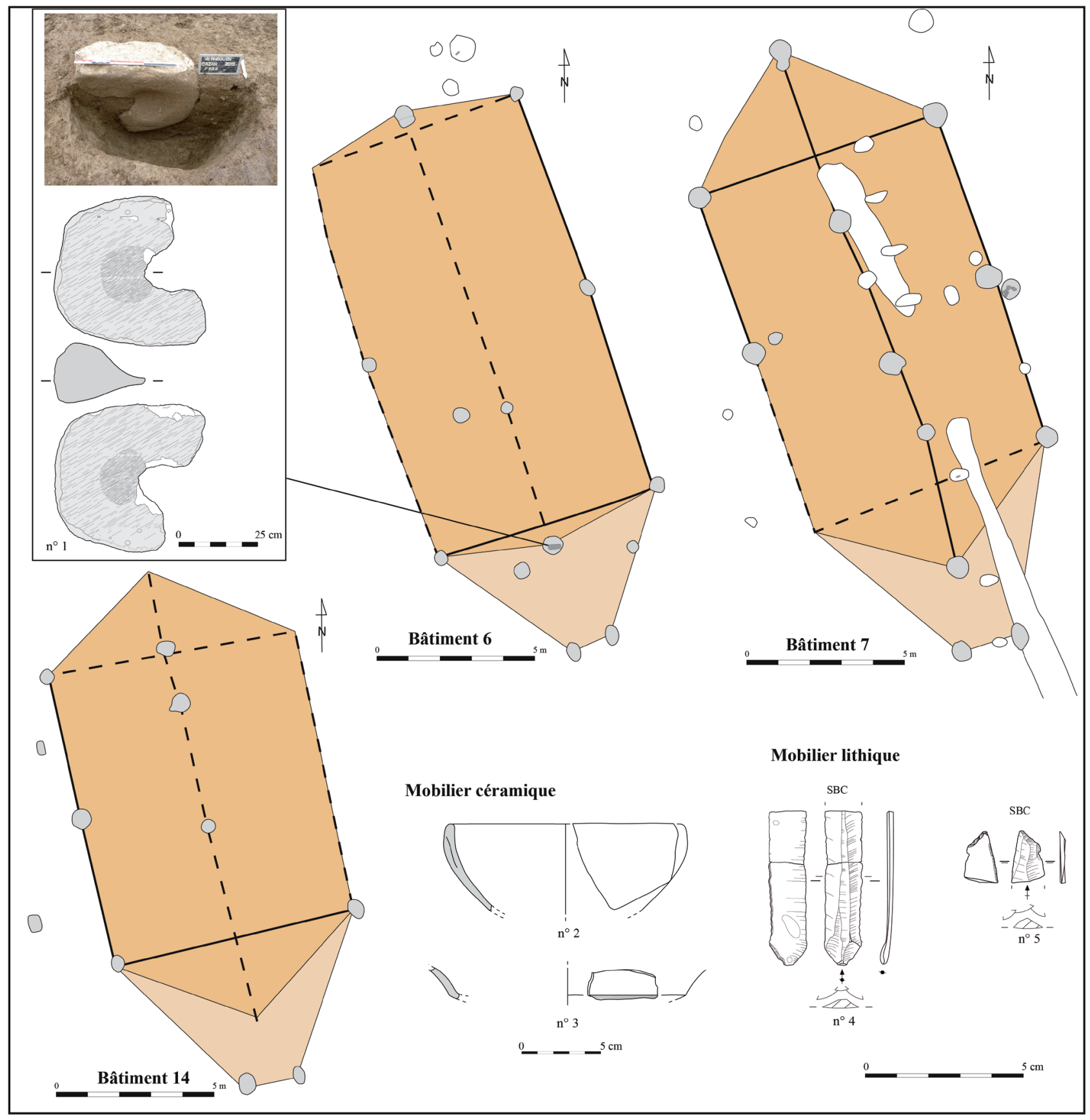

Fig. 12 - Données archéologiques et échantillon du mobilier issu des bâtiments 6, 7 et 14 (DAO B. Bosc-Zanardo, L. Guichard-Kobal, C. Moreau, L. Pacotte, V. Léa).

Fig. 12 - Archaeological data and examples of finds from the buildings 6, 7 and 14 (CAD B. Bosc-Zanardo, L. Guichard-Kobal, C. Moreau, L. Pacotte, V. Léa).

de certaines structures, mais onze à quinze trous de poteau peuvent être associés, dessinant alors un plan conforme au modèle standard dans la version proposée.

Un dernier édifice partiel : le bâtiment 14

$\mathrm{Au}$ sud-est du dernier édifice, huit à neuf trous de poteau peuvent former un dernier plan de bâtiment dont les dimensions conservées atteignent 7,7 par 14,3 m (on estime une longueur totale de $17 \mathrm{~m}$ ). Ses structures sont arasées et n'ont donné que très peu de mobilier et pratiquement aucun charbon de bois.

\section{Organisation et rythmicité des bâtiments}

Les dix bâtiments que nous venons de décrire répètent donc un modèle d'implantation de poteaux, avec certaines variations, notamment de leurs dimensions : les longueurs maximales s'échelonnent entre 16,7 et 24,4 m et les largeurs entre 7 et 9,8 m. Les dimensions moyennes sont de $8,2 \times 19,5 \mathrm{~m}$ et le bâtiment $2 \mathrm{a}$ est le plus original avec des dimensions particulièrement importantes. Les surfaces d'implantation théorique au sol varient aussi en conséquence : elles sont comprises entre 82,8 et $182,6 \mathrm{~m}^{2}$. 
Comme évoqué supra, tous les bâtiments sont orientés suivant les vents dominants avec des entrées méridionales abritées du mistral. Cette même orientation des édifices est à mettre en parallèle avec des emplacements préférentiels. En effet, si, au nord, la plupart des maisons sont régulièrement espacées sur un même axe, au sud, par contre, deux groupes de deux et trois maisons désignent des reconstructions exactement au même emplacement, mais pratiquement sans aucun recoupement de structure.

Ce dernier aspect nous pousse à nous intéresser aux indices de chronologie relative qui permettent d'approcher les différentes phases de construction et d'abandon et les durées de ces phases. Le premier indice se réfère aux caractéristiques de creusement et de comblement des structures. En effet, les premiers édifices (bât. 1 et 2) possèdent des trous de poteau avec des plans allongés, des profils souvent irréguliers et des dynamiques de comblement complexes qui signent des arrachements de poteau. Cet aspect concerne les bâtiments $1 \mathrm{a}, 2 \mathrm{a}$ et $2 \mathrm{~b}$ qui sont donc sans doute les plus anciens. Par ailleurs, les structures du $2 \mathrm{a}$ ont été réutilisées pour des dépôts volontaires (quelques vases y ont été retrouvés entiers) ou en dépotoirs après une première phase d'abandon. Enfin, certains trous des bâtiments $1 \mathrm{a}, 2 \mathrm{a}, 4$ et 5 possèdent des pierres en surface de leur comblement qui traduisent sans nul doute un rebouchage terminal (fig. 8 à 11). Cette action peut avoir une fonction utilitaire si les abords des trous sont toujours occupés par les populations néolithiques, mais d'autres explications sont envisageables au regard de la présence récurrente de mobiliers de mouture. Bien qu'associé à d'autres pierres, le matériel de broyage est très présent dans ces structures et les condamne ostensiblement dans certains cas (cf. bât. 6, fig. 12). Ce mobilier lourd, "symbole de l'établissement d'un foyer ou de la fondation d'une maison » (Hamon, 2006) pourrait alors symboliser une fin d'occupation, de la même façon que les dépôts de meules entières dans les parties supérieures des fosses de Blicquy ou Irchonwelz sont interprétés comme des rites d'abandon des maisons (Hamon, 2008). Les bâtiments 2a, 4, 5 et 6 , ayant livré des dépôts de matériel de broyage, seraient ainsi les témoins d'une première phase d'abandon du site. Cette hypothèse est étayée par la découverte de deux fragments d'un même outil, brisé de manière intentionnelle dans les bâtiments 4 et 5 , sans doute abandonnés et condamnés au même moment (fig. 10, no 3 ).

L'ensemble de ces arguments plaide en faveur d'installations répétées au même endroit, après une phase d'abandon des bâtiments qui devaient toujours être visibles, ce qui a permis d'éviter tout recoupement entre structures (et donc tout problème de stabilité). En raison de la durée de croissance du chêne et de la précision relative des datations ${ }^{14} \mathrm{C}$, il n'a pas été possible d'établir de chronologie relative par la datation des charbons des poteaux. Ces derniers sont toutefois riches d'enseignements, par la présence de nombreux stigmates de pourrissement du bois et d'attaques par des xylophages avant la combustion (trous, effondrements cellulaires, hyphes), montrant ainsi que les poteaux se sont dégradés sur place avant de brûler. On peut alors imaginer, dans un contexte de réoccupations du site, que les anciens bâtiments, ou ce qu'il en restait, étaient détruits par le feu avant reconstruction et réimplantation de nouveaux poteaux. Un poteau en duramen de chêne en contact avec le sol et l'humidité a une durabilité moyenne de 15 à 25 années (Centre technique du bois et de l'ameublement, 1985), ce qui donne une idée du délai entre la mise en place des poteaux et leur destruction par le feu.

L'étude en lame minces des comblements de sept trous de poteau, répartis sur trois bâtiments (1a, $1 \mathrm{~b}$ et $2 b$ ), permet également de percevoir les différentes phases de construction, de réparation et d'abandon. Dans la quasi-totalité des lames minces, les inclusions de fragments végétaux ferruginisés, qui peuvent être interprétées comme des restes de bois dégradé, sont fréquentes, appuyant l'hypothèse de la décomposition des poteaux et témoignant de périodes d'humidité relativement prolongées favorisant cette décomposition. Ce contexte humide explique la nécessité de remplacer et de réparer les poteaux en cours de décomposition. On observe également de fréquents fragments de terre crue, ou terre à bâtir, dans les comblements, qui sont probablement liés aux mêmes phases de réparation ou de destruction. Les structures et l'accumulation de ces comblements semblent attester des épisodes de remblaiements ou d'effondrements associés à la décomposition des poteaux. La seule différence remarquable dans ces comblements concerne les masses basales, largement composées de sol remanié. Dans le bâtiment 1 , ces fragments ou mottes de sol remanié renvoient à des horizons supérieurs semblables à l'US 1721a du $\log 4$ (fig. 3). En revanche, les comblements du bâtiment $2 \mathrm{~b}$ ne contiennent que des fragments de substratum et de substratum partiellement altéré par des processus pédogénétiques. Sachant que le paléosol repéré dans le log 4 semble avoir été largement déblayé lors d'épisodes érosifs au cours du Néolithique (voir infra), cette distinction de comblement entre les deux bâtiments pourrait indiquer qu'ils ont été construits respectivement avant et après ces épisodes. Cela impliquerait par conséquent que la construction des bâtiments $1 \mathrm{a}$ et $1 \mathrm{~b}$ soit antérieure au bâtiment 2 b.

\section{Caractérisation chronologique des bâtiments}

Si certains indices nous poussent à identifier plusieurs phases d'occupation sur le site, il convient maintenant de voir dans quel intervalle chronologique elles se situent. Les charbons issus des bâtiments étant peu propices aux datations ${ }^{14} \mathrm{C}$, seuls les bâtiments $2 \mathrm{a}$ et 4 ont été datés à l'heure actuelle. Les résultats se succèdent sur 250 ans et vont dans le sens d'une ancienneté relative du bâtiment 2a - 4050-3960 av. notre ère - par rapport au bâtiment 4 - 3950-3780 av. notre ère (tabl. 1). Ces datations sont en accord avec une attribution au Chasséen récent, au même titre que les mobiliers céramique et lithique.

De la céramique a été retrouvée dans pratiquement tous les trous de poteau attribués aux bâtiments avec un nombre minimum de quarante-trois individus. Elle est, mal- 
gré tout, beaucoup plus présente dans certaines structures des bâtiments $2 \mathrm{a}, 4$ et 5 , réutilisées après la disparition des poteaux (fig. 9 à 11). Le corpus est dominé par des récipients bas et ouverts comme des coupes évasées simples (fig. $8, \mathrm{n}^{\circ} 1$ ) et des coupes à carène haute prononcée (fig. 8 , $\mathrm{n}^{\circ} 3$; fig. $9, \mathrm{n}^{\circ} 3$ ). Les structures de l'ensemble 2 et surtout les bâtiments 4 et 5 ont toutefois aussi fourni des récipients fermés avec des gobelets à ressaut munis de mamelons de suspension ou barrettes multiforées (fig. 9, $\mathrm{n}^{\circ} 2$; fig. 11, $\mathrm{n}^{\text {os }} 11-12$ ) et des vases de stockage à profil simple (fig. 9 , $\mathrm{n}^{\circ} 1$; fig. $10, \mathrm{n}^{\mathrm{o}} 6$; fig. $\left.11, \mathrm{n}^{\text {os }} 9-10\right)$. On notera également de rares exemplaires de couvercles décorés (fig. $9, n^{\circ} 4$ ) et de fusaïoles (fig. 10, $\mathrm{n}^{\circ} 5$; fig. 11, $\mathrm{n}^{\mathrm{o}} 13$ ).

L'industrie lithique est globalement bien représentée dans les trous de poteau de ces bâtiments, hormis dans le bâtiment 14 qui n'a livré qu'un fragment de lamelle en silex patiné (fig. 6). Plus de $63 \%$ des trous de poteau liés à l'architecture des bâtiments 1 à 7 - soit 69 trous de poteau sur les 109 identifiés tous bâtiments confondus renfermaient de l'industrie lithique (tabl. 2). Au total, c'est 216 pièces qui en sont issues, ce qui représente entre 8 et 51 éléments par bâtiment. Cette relative abondance permet de mettre en évidence plusieurs caractéristiques lithiques à prendre en considération dans l'appréhension des bâtiments : homogénéité de la série, attribution à une phase récente du Chasséen et présence d'obsidienne. Néanmoins, l'apport de l'industrie lithique en silex bédoulien dans le cadre d'une caractérisation chronoculturelle des bâtiments s'arrête là : il n'est en effet pas possible de discuter de la chronologie relative des différents bâtiments entre eux, et ce même en s'appuyant sur les exemples de recoupements connus.

Les éléments en silex bédouliens chauffés du Vaucluse relatifs à la production, emblématique du Chasséen méridional, de lamelles débitées par pression (Binder, 1991; Léa, 2005) se retrouvent dans les trous de poteau de tous les bâtiments (tabl. 2). Les lamelles y sont représentées par plus d'une centaine d'éléments. L'analyse des modalités de débitage atteste la présence des styles quadrangulaire-plat et mixte, se référant tous deux à une phase évoluée du Chasséen, postérieure à 4100-4050 av. notre ère (Georjon et Léa, 2013). D'un point de vue technologique on peut noter l'identification de plans de pression lisses et inclinés (fig. 9, $\mathrm{n}^{\text {os }} 8$ et 11-12; fig. 11, $\mathrm{n}^{\text {os }} 1,3$ ), celle d'angles droits entre surface de débitage et flanc du nucléus (lamelles latérales à section triangulaire; par ex. dans le bât. 2b), et enfin celle de réduction de la corniche par pression, même si celle-ci n'est pas majoritaire (fig. $9, \mathrm{n}^{\circ \mathrm{s}} 6,10$; fig. $11, \mathrm{n}^{\circ} 6$; fig. 12, $\mathrm{n}^{\circ} 4$ ). Le déroulé des lamelles peut être plat avec un très bon parallélisme des nervures (fig. 9, $\mathrm{n}^{\circ} 10$ ), cependant, une certaine variabilité est attestée par des lamelles latérales couchées sur le flanc qui ont conservé un talon déjeté (fig. 8, nº 6 ; fig. 11, $\mathrm{n}^{\circ} 2$ ) ou par des lamelles centrales à enlèvements convergents et talon lisse incliné (style mixte; Léa, 2004). D'un point de vue typologique, plusieurs supports transformés sont caractéristiques d'une phase évoluée du Chasséen : burins sur lamelles en silex bédoulien chauffé (fig. 9, $\mathrm{n}^{\circ}$ 9; fig. 11, $\mathrm{n}^{\circ}$ 5), chanfreins (fig. 9, $\mathrm{n}^{\circ}$ 7) et troncatures (fig. $9, \mathrm{n}^{\circ} 5$; fig. $11, \mathrm{n}^{\circ} 7$; fig. $12, \mathrm{n}^{\circ} 5$ ). Par ailleurs, des lamelles à retouches latérales semi-abruptes (fig. 8, $\mathrm{n}^{\circ} 5$ ), des petits grattoirs en bout de lamelles (fig. 8, $n^{\circ} 4$ ), des perçoirs (fig. $10, \mathrm{n}^{\circ} 2$ ) et quelques pièces esquillées complètent l'outillage en silex ${ }^{(1)}$.

Enfin, les trous de poteau ont livré un nombre non négligeable de pièces en obsidienne (fig. 6 et tabl. 2). Il s'agit d'éclats ou de lamelles débitées par pression (fig. 8, $\mathrm{n}^{\circ} 7$; fig. 11, $\mathrm{n}^{\text {os }} 6-7$ ). Ces éléments ont fait l'objet d'analyse de provenance au sein du laboratoire l'IRAMAT-CRP2A; ils correspondent à la source sarde de type Sardaigne A : SA (fig. 13). Ce résultat est tout à fait cohérent avec une étape évoluée du Chasséen puisque l'obsidienne de type SA est prédominante à partir de 4000 av. notre ère dans la sphère du Chasséen méridional (Binder et al., 2012).

\begin{tabular}{|c|c|c|c|c|c|c|c|c|}
\hline & \multicolumn{5}{|c|}{ Nombre de trous de poteau par bâtiment } & \multicolumn{3}{|c|}{$\begin{array}{l}\text { Nombre de pièces trouvées } \\
\text { dans les trous de poteau }\end{array}$} \\
\hline & Total & $\begin{array}{l}\text { ayant livré } \\
\text { du lithique }\end{array}$ & $\begin{array}{l}\text { ayant livré du } \\
\text { silex bédoulien } \\
\text { chauffé }\end{array}$ & $\begin{array}{l}\text { ayant livré le style } \\
\text { quadrangulaire-plat ou mixte } \\
\text { sur silex bédoulien chauffé }\end{array}$ & $\begin{array}{l}\text { ayant livré } \\
\text { de l'obsi- } \\
\text { dienne }\end{array}$ & Total & $\begin{array}{l}\text { Lamelles débitées } \\
\text { par pression en silex } \\
\text { (bédoulien ou patiné) }\end{array}$ & $\begin{array}{l}\text { Pièces en } \\
\text { obsidienne }\end{array}$ \\
\hline Bât. 1a & 16 & 10 & 5 & 3 & 2 & 31 & 21 & 2 \\
\hline Bât. 1b & 12 & 7 & 2 & 1 & 0 & 14 & 3 & 0 \\
\hline Bât. 2a & 12 & 9 & 5 & 4 & 2 & 32 & 17 & 2 \\
\hline Bât. 2b & 12 & 9 & 8 & 3 & 1 & 28 & 13 & 1 \\
\hline Bât. 2c & 12 & 5 & 3 & 1 & 1 & 13 & 5 & 1 \\
\hline Bât. 4 & 12 & 7 & 3 & 3 & 1 & 51 & 28 & 4 \\
\hline Bât. 5 & 12 & 6 & 2 & 1 & 1 & 16 & 7 & 1 \\
\hline Bât. 6 & 11 à 12 & 5 & 2 & 1 & 0 & 8 & 6 & 0 \\
\hline Bât. 7 & 11 à 15 & 11 & 6 & 2 & 0 & 23 & 11 & 0 \\
\hline TOTAL & 109 à 115 & 69 & 36 & 19 & 8 & 216 & 111 & 11 \\
\hline
\end{tabular}

Tabl. 2 - Répartition des pièces lithiques au sein des bâtiments sur trous de poteau (données V. Léa).

Table 2 - Classification and distribution of the lithic fragments recovered from the buildings, defined by postholes (data V. Léa). 


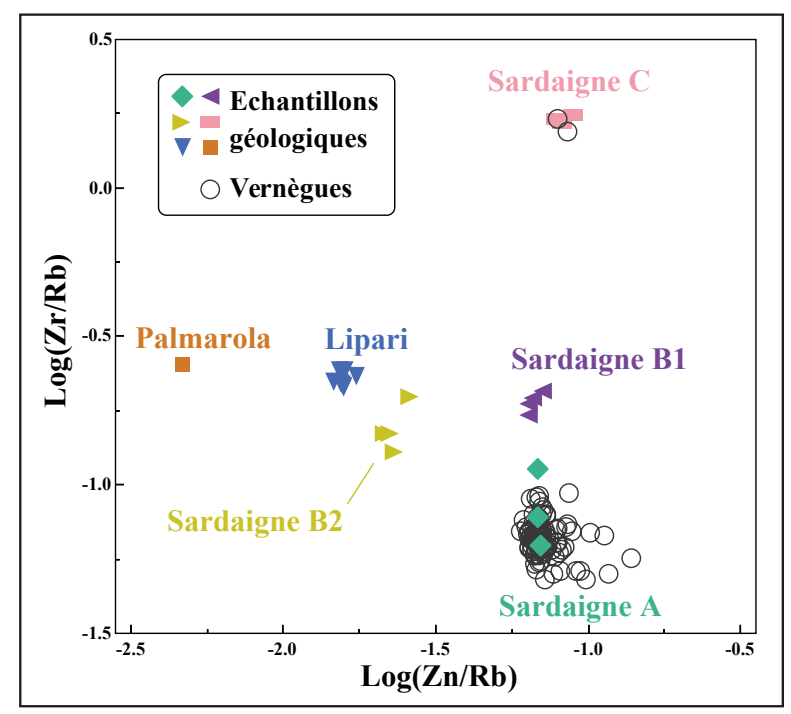

Fig. 13 - Diagramme des rapports $\log (\mathrm{Zn} / \mathrm{Rb})$ et $\log (\mathrm{Zr} / \mathrm{Rb})$ des obsidiennes du site et des sources méditerranéennes obtenus au sein de l'IRAMAT-CRP2A (Lugliè et al., 2014) par EDXRF (Energy Dispersive X-Ray Fluorescence Analysis) (DAO F.-X. Le Bourdonnec).

Fig. 13 - Chemical analysis of the obsidian artefacts from the site and comparison with the Mediterranean sources. Scatter plot graph of log ratios $(\mathrm{Zn} / \mathrm{Rb})$ vs. $\log (\mathrm{Zr} / \mathrm{Rb})$. The analysis was conducted at IRAMAT-CRP2A (Lugliè et al 2014) using EDXRF (Energy Dispersive X-Ray Fluorescence) (CAD F.-X. Le Bourdonnec).

\section{Caractérisation fonctionnelle des bâtiments}

Avec des surfaces comprises entre 80 et $180 \mathrm{~m}^{2}$, la vocation d'habitat peut être privilégiée pour ces bâtiments. Toutefois, en l'absence de niveau de sol associé, leur fonction et les activités qui y sont pratiquées ne peuvent être déduites que par les mobiliers piégés ou déposés dans les trous de poteau.

Les céramiques ne détonent pas d'une vocation domestique classique avec de nombreux récipients liés à la consommation ou au service $(53 \%$ du total) et une part minoritaire de vases morphologiquement dédiés à la préparation des aliments (10\%) ou à leur conservation $(10 \%)$. Ces derniers sont néanmoins proportionnellement plus représentés dans les bâtiments 4 et 5 que dans toutes les autres structures du site.

À côté de la céramique, certains aspects fonctionnels peuvent être déduits de l'industrie lithique taillée. Pour cela, un échantillon correspondant à l'ensemble des éléments en silex provenant des structures des bâtiments 1 et 4 (respectivement 41 et 46 pièces) a fait l'objet d'une analyse tracéologique. Cinquante-deux zones utilisées réparties sur 42 pièces ont été observées. Les usures correspondent à quatre grands groupes de matières d'œuvre : matières abrasives et tissu animal résistant, matières végétales, matières minérales et enfin matières indéterminées. Ce dernier groupe est le mieux représenté avec vingt-cinq usures répertoriées, qui n'ont pas permis de caractériser la matière d'œuvre (traces trop peu développées ou altérées), mais ont autorisé l'estimation de la dureté du matériau travaillé et de la cinématique d'utilisation. Le deuxième groupe le mieux représenté est celui des usures de matières abrasives et de tissu animal résistant $(n=22)$. Classiquement, les usures abrasives sont attribuées au travail des peaux alors que celles de tissu animal résistant sont liées aux activités de boucherie ou de découpe des tissus souples comme les tendons. Il s'agit majoritairement de stigmates d'action longitudinale. Dans sept cas, des traces de découpe d'une matière souple abrasive ont été observées (fig. 14, $\mathrm{n}^{\mathrm{os}} 1-2$ ). Les usures de travail de matières végétales ont été constatées à seulement quatre reprises. Dans trois cas il s'agit d'une usure transversale sur une matière végétale indéterminée. La quatrième pièce, qui provient du bâtiment 4 , est marquée par des stigmates typiques d'une action longitudinale sur végétaux siliceux, peut-être des céréales (fig. 14, no 3 ). Enfin, une seule pièce présente des stigmates attribuables au travail d'une matière dure minérale en action longitudinale. Il faut noter que les usures d'action longitudinale sur un matériau souple ou tendre dominent l'échantillon. Ce résultat est classique dans les ensembles chasséens où les lamelles sont majoritaires (Gassin, 1996; Gassin et al., 2010).

Comme on pouvait l'attendre d'un site d'habitat, les usures observées attestent d'activités diversifiées avec au moins sept matières d'œuvre clairement distinctes reconnues. On observe une relative souplesse d'attribution d'un type de support en silex à une activité, même s'il semble exister des attributions préférentielles; les utilisations en action longitudinale seraient par exemple réservées aux produits laminaires. De même, il ne semble pas y avoir d'associations spécifiques entre un type d'outil et une utilisation; les pièces brutes sont même mobilisées pour une gamme très variée d'utilisations. Enfin, la comparaison des résultats entre les unités domestiques 1 et 4 laisse supposer que chacune est relativement autonome, aucune spécialisation flagrante ne se dégage.

La caractérisation fonctionnelle des bâtiments peut aussi être appréhendée par des outils macrolithiques, dont la majorité (51\%) provient de ces structures (fig. 6). La mouture en va-et-vient sur des surfaces planes ou à concavité réduite est semble-t-il la plus recherchée, même si le taux de fragmentation important des outils (68\%) ne permet pas toujours de l'affirmer. La variabilité des catégories d'outils représentées ne permet pas d'aborder la problématique de la spécialisation des unités domestiques, mais on peut noter la présence de deux « meulesmortiers » (Archambault de Beaune, 2000) associées à trois pilons-broyeurs sur galet dans les bâtiments $2 \mathrm{a}$ et 4 . La répartition très inégale entre les bâtiments évoque davantage des logiques de temporalité dans l'occupation lors de l'abandon de certains édifices (voir infra).

Enfin, le bâtiment 4 a fourni deux fragments d'un même objet en terre, faiblement cuit, dont la morphologie évoque deux extrémités de croissant avec une perforation à une extrémité (fig. 11, no 8 ). Il a été façonné à partir d'une argile fine, non dégraissée sur laquelle a été appliquée une barbotine et évoque sans nul doute les poids de 


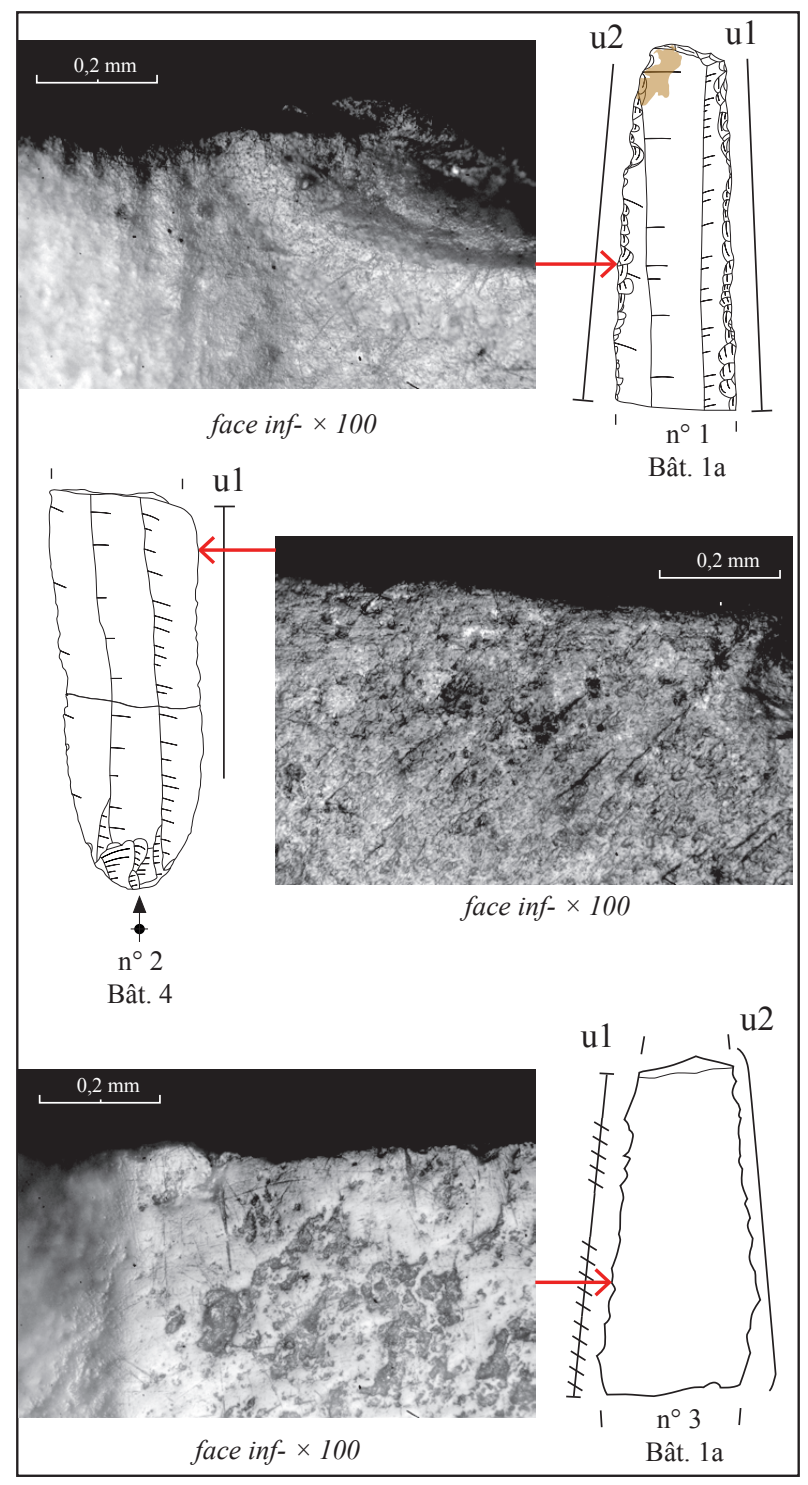

Fig. 14 - Exemples d'observations tracéologiques réalisées sur les pièces en silex des bâtiments 1 et 4 (clichés et DAO J. Linton).

Fig. 14 - Examples of use -wear analysis on worked flints from the buildings 1 and 4 (photographs and CAD J. Linton).

métier à tisser réniformes bien connus en Italie du nord et dont certains exemplaires sont identifiés dans le sud de la France (Lepère, 2009).

\section{Un bâtiment isolé}

À côté de ces dix bâtiments très standardisés, le bâtiment 12 a été identifié à partir d'un groupe isolé de quinze petits trous de poteau au sud du bâtiment 6 (fig. 2). Bien que ces structures soient relativement arasées, elles forment un ensemble cohérent qui n'a donné que peu de mobilier : quelques tessons, huit éléments en silex ou obsidienne et une meule. Parmi les éléments lithiques, il faut noter trois fragments de lamelles centrales débitées par pression en silex patiné (sans doute bédoulien), ainsi qu'une extrémité distale de lamelles de code 212 ' en silex bédoulien chauffé à retouches latérales inverses semi-abruptes (Binder, 1991). Si l'on ajoute la présence d'un fragment de bandeau multitubulé, on pourrait alors proposer une attribution au Chasséen récent. Il est possible que ce bâtiment soit contemporain des autres maisons, mais il ne s'agit pas du même type d'aménagement. Sous réserve de structures qui auraient pu disparaître, le plan actuellement visible dessine un rectangle déformé $(6,10 \times 10 \mathrm{~m})$ d'orientation ouest-sud-ouest est-nord-est. Il pourrait s'agir d'une structure légère ou d'un abri à vocation domestique ou de stabulation.

\section{Les bâtiments sur fosses d'implantation}

\section{La mise au jour de plans complexes}

Parallèlement aux bâtiments fondés sur trous de poteau, les ensembles 8,9 et 13 se démarquent au sudouest et au sud-est de l'emprise (fig. 2), car ils sont aménagés principalement sur des fosses rectangulaires que l'on peut considérer comme des fosses d'implantation de poteau. Ces structures présentent des plans allongés quadrangulaires, des profils en $U$ dans la largeur et des profils asymétriques dans la longueur avec une pente douce d'un côté et une paroi subverticale de l'autre. Leur profondeur maximum peut atteindre près de $2 \mathrm{~m}$ avec certains surcreusements au niveau le plus profond. Cette configuration permet donc d'assimiler ces structures à de très gros trous de poteau, la pente douce pouvant servir à atteindre une grande profondeur de manière plus aisée et à y insérer une pièce de bois sans doute de grande taille (fig. 15). Comme nous le verrons dans chaque ensemble,

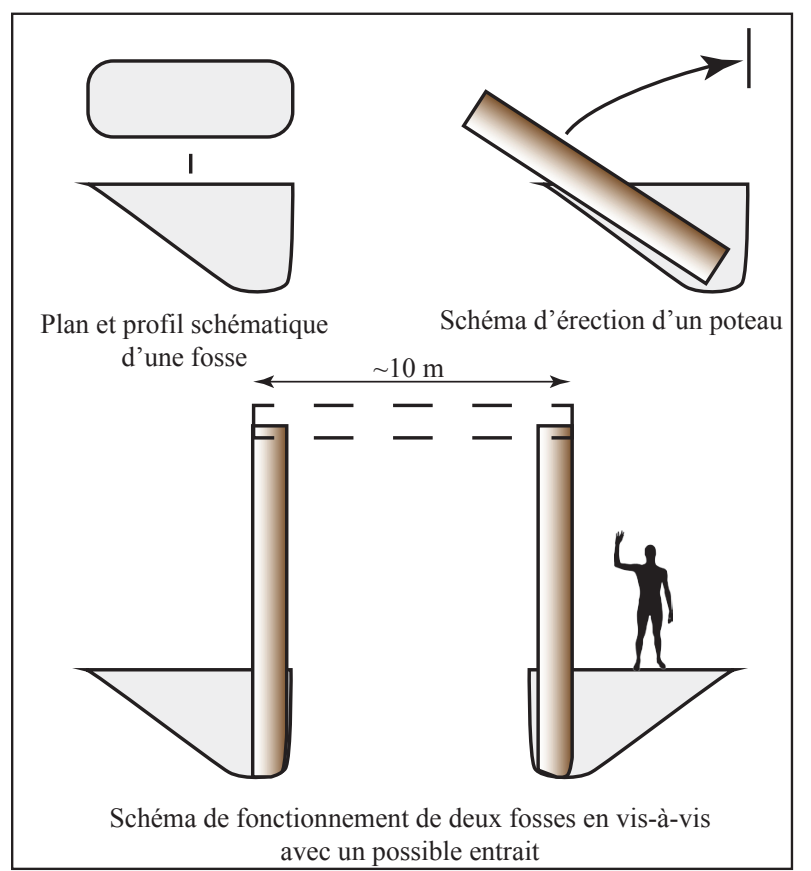

Fig. 15 - Schéma de présentation et de fonctionnement supposé d'une fosse d'implantation (DAO C. Moreau).

Fig. 15 - Schematic model for the formation and function of a foundation pit (CAD C. Moreau). 
ces fosses d'implantation participent à des alignements parallèles, avec des fosses en vis-à-vis montrant des profils en miroir. Cette configuration ne laisse que peu de doute pour l'intégration de ces fosses à des bâtiments couverts avec de probables entraits entre les alignements.

\section{L'ensemble 8}

L'ensemble 8 concerne des fosses d'implantation qui forment a priori un bâtiment comportant trois structures de chaque côté au sud-ouest de l'emprise de fouille (fig. 16A). Elles délimitent un rectangle large de 10,5 m et long de $14 \mathrm{~m}$; deux autres fosses d'implantation peuvent constituer une extension septentrionale. Au sud, une autre fosse allongée pourrait participer à cet édifice et une prolongation hypothétique peut aussi être avancée en direction d'une fosse circulaire qui présente un gros surcreusement. Hormis le fait que chaque paroi repose sur trois structures, comme les autres types de maison, ce bâtiment présente une configuration architecturale différente. Aucun poteau faitier profondément ancré n'a été repéré et, en l'absence de ligne centrale, cet édifice ne semble donc comporter qu'une seule nef. Cette absence de ligne faitière est sans doute à mettre en relation avec le mode d'implantation différent des poteaux dans les fosses rectangulaires. Les petits trous de poteau internes pourraient participer à cette configuration particulière, notamment pour aider à l'érection de pièces de bois de grande taille.

L'ensemble 8 possède également des fosses plus ou moins circulaires qui participent à des alignements parallèles au bâtiment principal, formant notamment un rectangle annexe à l'est de l'édifice (fig. 16B). Cette configuration pourrait faire penser que ces fosses sont aussi des trous de poteau profondément ancrés avec des profils différents des fosses d'implantation environnantes. Un alignement de petits trous de poteau à l'est pourrait enfin être mis en relation avec ces aménagements sans qu'il soit possible d'en assurer le fonctionnement.

\section{L'ensemble 9}

L'ensemble 9 rassemble 140 structures à $5 \mathrm{~m}$ au nordouest de l'ensemble 8 (fig. 16) : quinze fosses d'implantation allongées, 118 trous de poteau et onze fosses généralement subcirculaires. Il est probable que toutes ces structures ne soient pas strictement contemporaines, mais aucun indice chronologique ne diffère d'une attribution au Chasséen récent. De fait, elles ont toutes été regroupées en un seul et même ensemble complexe dont nous faisons ici une présentation forcément trop succincte. À ce stade, il ne s'agit bien sûr que de propositions qui devront être étayées par la suite, notamment en ce qui concerne leurs implications architectoniques.

À partir de la plupart des alignements, et en particulier ceux qui concernent les fosses d'implantation, le plan d'un grand bâtiment peut être avancé (fig. 16A). L'espace central de ce bâtiment (fosses en noir) dessine un rectangle de 10,2 m de large pour 13,1 m de long. Au centre de cet espace, un alignement central de trous de poteau peut représenter une ligne faitière. Il est à noter que cette ligne faîtière déborde de l'espace central, rappelant ainsi le plan standard des maisons sur trous de poteau.

Les autres trous de poteau ou de piquet de cet alignement et des autres aménagements internes peuvent avoir une autre fonction : ils peuvent avoir été implantés pour aider à l'érection des poteaux dans les fosses d'implantation ou supporter un plancher surélevé. Cette dernière proposition pourrait alors rejoindre les observations faites sur certains sites lacustres (Hasenfratz et GrossLee, 1995). Bien que nous ne soyons pas ici dans un tel contexte, plusieurs signes indiquent que ce secteur devait être humide au Néolithique : les fortes concrétions calcaires dans cette zone (fig. 2) attestent la présence haute de la nappe phréatique antérieurement à l'implantation des bâtiments et les sédiments observés dans les fosses montrent des traces d'hydromorphie et de pourrissement des bois des bâtiments. Un plancher surélevé pourrait donc être utile dans un tel contexte. Certains alignements de poteaux débordent clairement de l'espace central vers le sud. Ils forment des sortes d'antennes dont la fonction reste inconnue pour l'instant. Ils rappellent toutefois l'alignement de poteaux à l'est de l'ensemble 8 .

L'ensemble 9 possède des lignes de fosses d'implantation surnuméraires par rapport au plan standard (fig. 16A, structures en gris foncé). Il s'agit notamment de fosses au nord, qui renforcent le probable entrait septentrional, de fosses qui encadrent la ligne faîtière, et des alignements de fosses les plus occidentales et orientales, qui débordent de l'espace central et dégagent des bandes supplémentaires de $3 \mathrm{~m}$ de large. La présence de telles structures peut être envisagée dans des logiques de reconstruction du bâtiment, toutefois, ici, contrairement aux bâtiments 1 ou 2, on n'observe pas de décalage mais plutôt un élargissement de l'espace central qui pourrait s'expliquer par la réalisation d'un étage supplémentaire.

Enfin, l'ensemble 9 se distingue par des fosses circulaires aux remplissages plus complexes et plus riches en mobilier qui dessinent un carré de $13 \times 14 \mathrm{~m}$ au maximum, d'orientation équivalente à celle du bâtiment principal, avec un décalage vers le sud-ouest (fig. 16B). Un recoupement entre deux structures attesterait la probable antériorité de cet aménagement par rapport au bâtiment principal, mais dans un laps de temps court, comme l'indiquent les indices de datation que nous développerons plus loin. S'il est difficile d'assurer le lien chronologique entre cet aménagement et le bâtiment principal, il est aussi mal aisé de lui attribuer une fonction précise. Il est possible que ces fosses circulaires aient pu servir de trous de poteau dans une fonction primaire, mais le carré qu'elles forment se distingue des plans connus sur Cazan et une étude approfondie est nécessaire pour aider à leur compréhension. Les structures présentes sur le côté ouest ont secondairement servi de dépotoir (fig. 6).

\section{L'ensemble 13}

Enfin, au sud-est, quatre alignements de structures parallèles ont été repérés en limite d'emprise (fig. 2). Deux sont constitués de fosses d'implantation dont le premier à l'ouest rassemble douze fosses qui présentent 


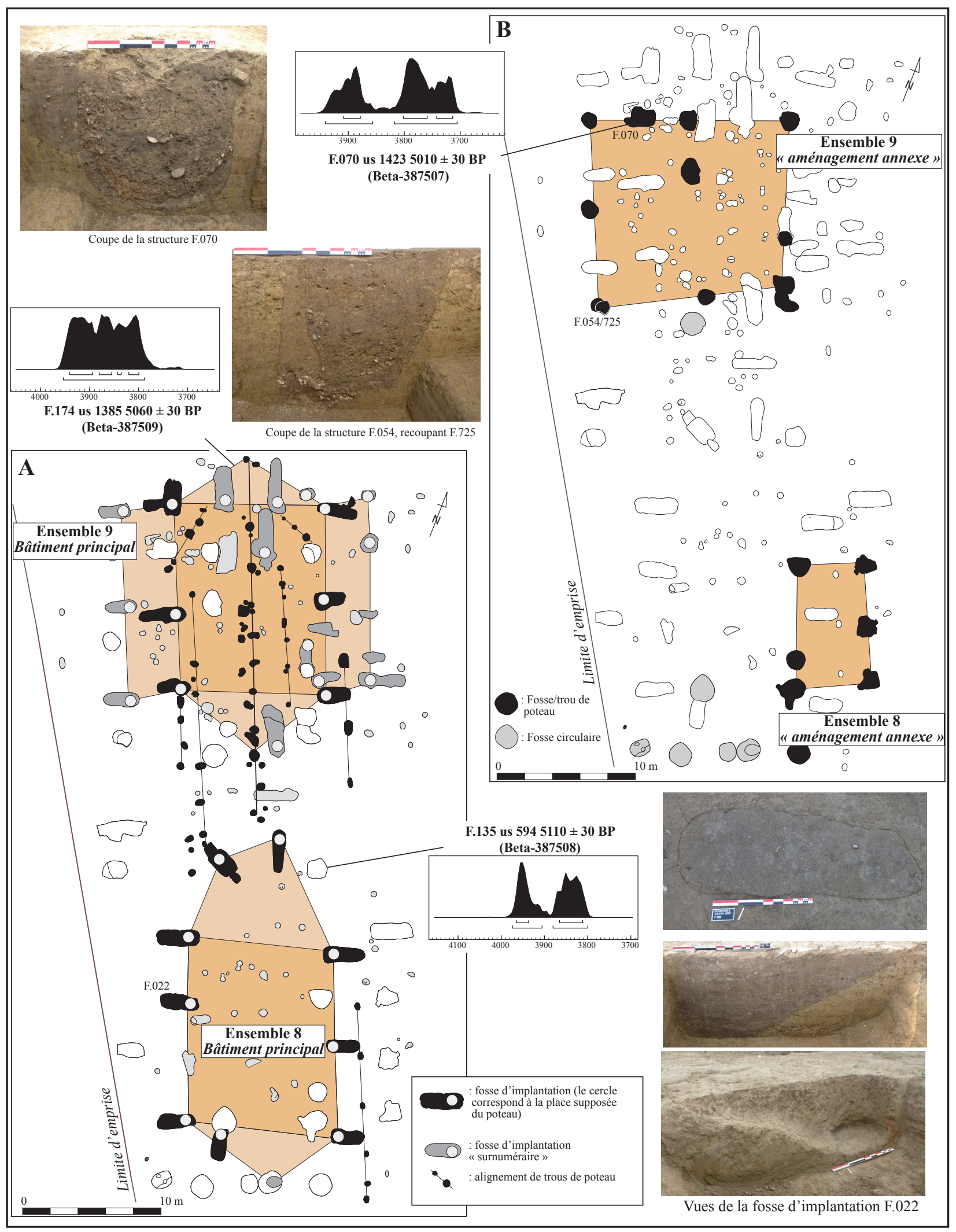

Fig. 16 - Plan des structures attribuées aux ensembles 8 et 9 avec (A) les édifices fondés sur fosses d'implantation et (B) ceux composés de fosses-trous de poteau (clichés et DAO J. Collombet, C. Moreau).

Fig. 16 - Proposed plans of the structures attributed to groups 8 and 9, as defined by (A) the foundation pits, and (B) those formed by the pit/postholes (photographs and CAD J. Collombet, C. Moreau). 
toutes un surcreusement à l'est; le second rassemble trois structures ou groupes de structures. Les deux autres lignes intermédiaires sont composées de trous de piquets. À première vue, cet ensemble pourrait s'apparenter à un aménagement palissadé avec plusieurs alignements successifs ou contemporains. Néanmoins, en comparaison avec les autres bâtiments présents sur le site, et en considérant l'éventualité d'édifices superposés, nous proposons de considérer ici l'ensemble 13 comme une succession de plusieurs bâtiments tronqués à l'est. Nous y voyons la superposition d'un minimum de trois édifices avec, pour les fosses d'implantation, un alignement de structures latérales et une ligne de structures faîtières. En fonction des caractéristiques des fosses et de leur implantation, un premier bâtiment au sud peut être proposé avec des structures latérales régulièrement espacées et une limite sud équivalente à celle des bâtiments parallèles $1 \mathrm{a}, 1 \mathrm{~b}$ et $2 \mathrm{c}$ plus à l'ouest. Deux autres bâtiments peuvent être avancés avec à chaque fois un décalage vers le nord; leurs dimensions et espacements entre les structures seraient équivalents à ceux du bâtiment 13-1.

Dans cet ensemble, il est par contre difficile d'attribuer les trous de piquets alignés à tel ou tel bâtiment. Comme pour les ensembles 8 et 9 , ces structures peuvent participer à l'érection des pièces de bois ou comme au soutien d'un plancher surélevé.

\section{Indices de fonctionnement des bâtiments sur fosses d'implantation}

Les fosses d'implantation n'ont en général fourni que très peu de mobilier archéologique, mais six d'entre elles ont fourni des assemblages anthracologiques. Comme pour les trous de poteau, les spectres sont presque toujours monospécifiques (fig. 7). Le chêne caducifolié est présent dans trois fosses, une seule fois associé à une autre espèce (le peuplier ou le saule). Les deux autres ont livré de l'arbousier d'une part et du genévrier d'autre part. Les charbons de chêne présentent les mêmes caractéristiques (thylles, signes de pourrissement antécombustion) que ceux retrouvés dans les trous de poteau des autres bâtiments.

Parallèlement, les comblements de deux fosses d'implantation ont fait l'objet d'une étude micromorphologique. L'une d'entre elle montre une concentration de bois décomposé et minéralisé pouvant traduire un fantôme de poteau, au sein d'une masse basale composée principalement de fragments remaniés d'un paléosol (s'apparentant à l'US 1721a du $\log 4$; fig. 3). Les traits micromorphologiques observés dans les deux fosses donnent l'impression de plusieurs phases d'ouverture et de comblement (revêtements d'argile poussiéreuse ou limono-argileux), peut-être pendant une durée prolongée, mais avec des phases d'accumulation de sédiment par ruissellement et des périodes de stagnation d'eau dans les fosses (présence d'argiles et de limons dans les pores, léger litage, granoclassement moyen), qui pourraient expliquer le pourrissement des bois anté-combustion. Les fréquentes inclusions de terre crue, ou de terre à bâtir, réparties aléatoirement soutiennent l'hypothèse suggérée par la morphologie des fosses de leur lien avec des phases de remplacements des poteaux. Toutes ces observations donnent l'impression de plusieurs phases d'ouverture et de comblement avec des périodes de stagnation d'eau dans les fosses. Les durées d'ouverture de ces fosses restent non définies, mais elles semblent être liées à des phases de réparations et de remplacements des poteaux en cours de décomposition.

\section{Caractérisation chronologique et fonctionnelle des bâtiments}

Grâce à la présence de quelques charbons d'espèces à croissance rapide et durée de vie relativement courte, trois datations radiocarbones ont pu être réalisées (tabl. 1 et fig. 16). Elles désignent un même intervalle entre 4000 et 3750 av. notre ère, qui corrobore les attributions révélées par le mobilier archéologique. Ce dernier a été retrouvé dans pratiquement toutes les structures, mais dans des proportions diverses.

La répartition générale de la céramique montre une faible abondance dans les fosses rectangulaires des trois ensembles, alors qu'elle est beaucoup plus présente dans les fosses circulaires, notamment celles de l'aménagement annexe de l'ensemble 9 (fig. 6). On n'observe toutefois pas de grandes variations chronoculturelles entre les différents types de structures : plusieurs exemplaires de coupes à sillon (fig. 17, $\mathrm{n}^{\circ} 1$ ), d'écuelles à carène basse (fig. 17, $\mathrm{n}^{\text {os }} 2-4$ ), de carènes perforées (fig. 17, $\mathrm{n}^{\circ}$ 9), de gobelets à ressaut et de barrette multiforées décorées (fig. $17, \mathrm{n}^{\text {os }} 6,10$ ) sont autant d'éléments caractéristiques du Chasséen récent équivalents à ceux retrouvés dans les autres structures du site. Il faut par ailleurs noter dans l'ensemble 9 la présence d'un épaulement doté de chevrons gravés et présentant des traces de peinture (fig. 17, $\mathrm{n}^{\circ} 7$ ), ainsi que celle de couvercles, dont un exemplaire décoré (fig. 17, nos 11-12); dans l'ensemble 8, une fosse a aussi donné un tesson avec une lèvre encochée (fig. 17, $\mathrm{n}^{\circ} 8$ ). Ces individus décorés trouvent de nombreux parallèles au sein des remplissages des puits que nous verrons plus loin.

Pour ce qui est du lithique, vingt-neuf fosses rectangulaires ont livré de l'industrie et totalisent près d'une centaine de pièces (tabl. 3). La moitié de ces fosses renfermait des éléments appartenant à la chaine opératoire de fabrication des lamelles en silex bédoulien chauffé. $\mathrm{Au}$ sein de chaque ensemble, au moins une des fosses rectangulaires attestait la présence d'éléments caractéristiques d'un style de débitage quadrangulaire-plat. Pour l'ensemble 8, il s'agit de lamelles centrales à talon lisse incliné dont certaines montrent une réduction de la corniche par pression ou de burins sur troncature oblique façonnée sur lamelle de code 212'. Pour l'ensemble 9, il s'agit de lamelles latérales au talon déjeté et de troncatures sur lamelle. Notons ici que la fosse F.174 a fait l'objet d'une datation qui est tout à fait cohérente avec le mobilier lithique. Deux éléments en obsidienne de type Sardaigne A sont de même identifiés dans deux fosses rectangulaires de cet ensemble. Pour l'ensemble 13, 


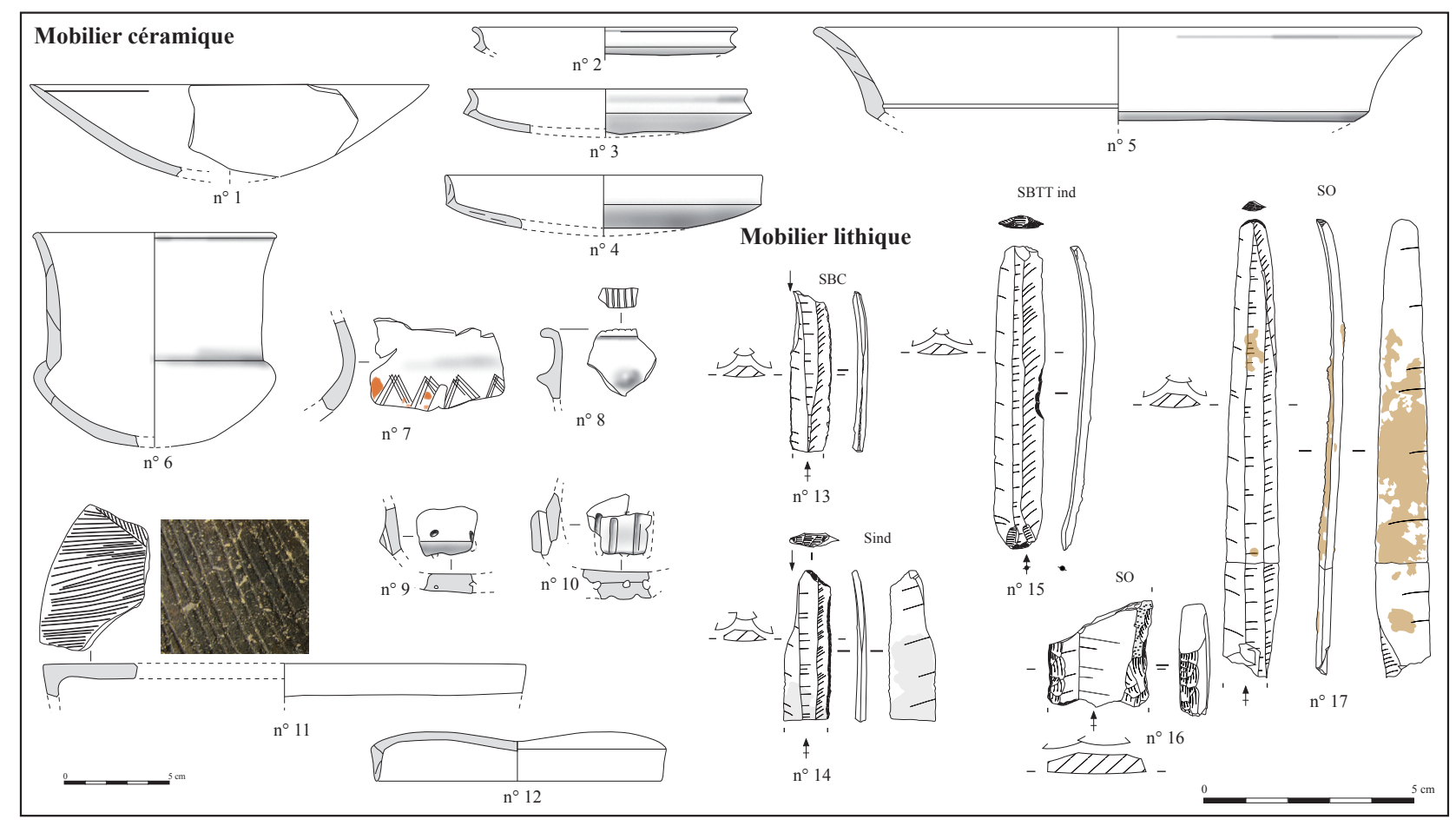

Fig. 17 - Échantillon de mobilier provenant des ensembles 8, 9 et 13 (DAO B. Bosc-Zanardo, C. Moreau, V. Léa).

Fig. 17 - Examples of finds from groups 8, 9 and 13 (CAD B. Bosc-Zanardo, C. Moreau, V. Léa).

\begin{tabular}{|l|c|c|c|c|c|c|c|c|}
\multicolumn{2}{c|}{$\begin{array}{c}\text { Nombre de fosses ayant } \\
\text { livré du lithique }\end{array}$} & $\begin{array}{c}\text { Nombre de fosses ayant } \\
\text { livré des silex bédouliens } \\
\text { chauffés }\end{array}$ & $\begin{array}{c}\text { Nombre de fosses ayant livré des éléments } \\
\text { caractéristiques d'un style quadrangulaire- } \\
\text { plat ou mixte }\end{array}$ & \multicolumn{2}{c}{ Nombre de pièces lithiques } \\
\cline { 2 - 11 } & $\begin{array}{c}\text { Fosses } \\
\text { d'implantation }\end{array}$ & $\begin{array}{c}\text { Autres } \\
\text { fosses }\end{array}$ & $\begin{array}{c}\text { Fosses } \\
\text { d'implantation }\end{array}$ & $\begin{array}{c}\text { Autres } \\
\text { fosses }\end{array}$ & $\begin{array}{c}\text { Fosses } \\
\text { d'implantation }\end{array}$ & $\begin{array}{c}\text { Autres } \\
\text { fosses }\end{array}$ & $\begin{array}{c}\text { Dans les fosses } \\
\text { d'implantation }\end{array}$ & $\begin{array}{c}\text { Dans les } \\
\text { autres fosses }\end{array}$ \\
\hline Ens. 8 & 9 & 17 & 5 & 9 & 2 & 3 & 23 & 157 \\
\hline Ens.9 9 & 13 & 37 & 6 & 25 & 2 & 0 & 55 & 119 \\
\hline Ens. 13 & 7 & 0 & 3 & 0 & 1 & $\mathbf{9}$ & 20 & 0 \\
\hline TOTAL & $\mathbf{2 9}$ & $\mathbf{5 4}$ & $\mathbf{1 4}$ & $\mathbf{3 4}$ & $\mathbf{5}$ & $\mathbf{9 8}$ & $\mathbf{2 7 6}$ \\
\hline
\end{tabular}

Tabl. 3 - Répartition des pièces lithiques au sein des ensembles 8, 9 et 13 sur fosses d'implantation (données V. Léa).

Table 3 - Classification and distribution of the lithic fragments recovered from the groups 8, 9 and 13, defined by foundation pits (data V. Léa).

il s'agit de lamelles au talon lisse incliné attestant une réduction de la corniche par pression.

L'industrie lithique des fosses autres que rectangulaires se rapportant aux ensembles 8,9 et 13, présente les mêmes caractéristiques (tabl. 3 ; fig. 17, $\mathrm{n}^{\text {os }} 13-15$ ). De l'obsidienne est de même sporadiquement présente dans les ensembles 8 et 9 (fig. 6).

Enfin, il est important de souligner que dans les ensembles 9 et 13 trois produits laminaires en silex oligocène ont été trouvés : une longue lame sans doute débitée par pression à extrémité distale retouchée en grattoir (fig. 17, $\mathrm{n}^{\circ} 17$ ); un petit fragment mésial de lame large et épaisse à retouches latérales semi-abruptes évoquant l'emploi de la pression au levier malgré sa longueur très réduite (fig. $17, \mathrm{n}^{\circ} 16$ ); un fragment de lamelle débitée par pression (ensemble 13). La présence de ce type d'éléments en contexte chasséen et notamment durant les phases récentes-finales n'est pas étonnante. Plusieurs individus sont mentionnés à la grotte de Pertus II (Méailles, Alpes-de-Haute-Provence), durant l'étape D2 de C. Lepère (Lepère, 2012; Binder et al., 2008).

Si les éléments céramiques et lithiques ne permettent pas d'établir de chronologie relative entre les aménagements, ils indiquent tout de même la réutilisation de certaines fosses au sein des ensembles 8 et 9 . Ces dernières ont pu servir dans l'érection d'aménagements dits annexes qui restent à approfondir, mais elles ont par la suite été réutilisées en dépotoirs, ce qui expliquerait leur riche mobilier. Cet aspect pourrait être comparé au phénomène de recoupement d'édifices observés pour le bâtiment 2 et ainsi attester leur antériorité relative. 


\section{Une ligne de fosses circulaires}

Par ailleurs, à quelques mètres au sud de l'ensemble 8, une ligne de cinq fosses circulaires, profondes de 70 à $150 \mathrm{~cm}$, a été mise au jour (fig. 2). La fosse la plus à l'est présente un surcreusement prononcé et un remplissage complexe qui la rapproche des structures de l'aménagement annexe de l'ensemble 8 (fig. 16). Les quatre autres fosses possèdent des profils en $U$ ou en cuvette avec deux petits surcreusements dans la fosse occidentale. Elles forment également un ensemble cohérent avec des remplissages limoneux clairs, peu organiques, qui n'ont pratiquement donné que des pièces lithiques taillées.

Ces quatre fosses sont effectivement riches en industrie lithique (trois d'entre elles sont les plus riches du site) et toutes comportent de nombreux éléments en obsidienne (fig. 6 et tabl. 4). Le style de débitage quadrangulaire-plat sur silex bédoulien est clairement révélé dans ces quatre faits, par l'observation des rythmes de débitage (lamelles de code 212 ' majoritaires; fig. $18, \mathrm{n}^{\circ} 1$ ), des préparations du plan de pression (fig. 18, $\mathrm{n}^{\circ} 7$ ), ou encore de la typologie avec une très bonne représentation des burins et des troncatures (fig. 18, $\mathrm{n}^{\text {os }} 2-6$ ).

\begin{tabular}{|l|c|c|c|c|c|} 
Industrie lithique & F.006 & F.007 & F.008 & F.089 & F.090 \\
\hline Obsidienne & 8 & 17 & 3 & 8 & 0 \\
\hline $\begin{array}{l}\text { Silex bédoulien ou } \\
\text { probablement bédou- } \\
\text { lien (patiné) }\end{array}$ & 85 & 65 & 42 & 17 & 5 \\
\hline $\begin{array}{l}\text { Silex tertiaire } \\
\text { dont oligocène }\end{array}$ & 1 & 2 & 1 & 0 & 0 \\
\hline Esquilles & 15 & 38 & 30 & 10 & 3 \\
\hline TOTAL & $\mathbf{1 0 9}$ & $\mathbf{1 2 2}$ & $\mathbf{7 6}$ & $\mathbf{3 5}$ & $\mathbf{8}$ \\
\hline
\end{tabular}

Tabl. 4 - Répartition des pièces lithiques dans la ligne de fosses circulaires au sud-ouest (données V. Léa).

Table 4 - Classification and distribution of the lithic fragments recovered from the alignment of circular pits to the south-west (data V. Léa)

Ces quatre structures peuvent être interprétées comme des fosses de rejet d'un ou plusieurs postes de taille au sud de l'ensemble 8. De nombreux témoins de débitage sur place sont en effet identifiés : éclats de mise en forme, d'entretien ou de réfection pour l'obsidienne (fig. 18, $\mathrm{n}^{\text {os }} 8-9$ ), et pour le silex bédoulien chauffé. Dans deux fosses, les éclats sont d'ailleurs majoritaires par rapport aux lamelles débitées par pression. Des esquilles de ces deux matières premières ont de même été prélevées dans les quatre structures.

\section{Une zone de concentration de foyers}

\section{Deux types de foyers principaux organisés}

Vingt structures à pierres chauffées ont également été mises en évidence, avec deux petits foyers excentrées à

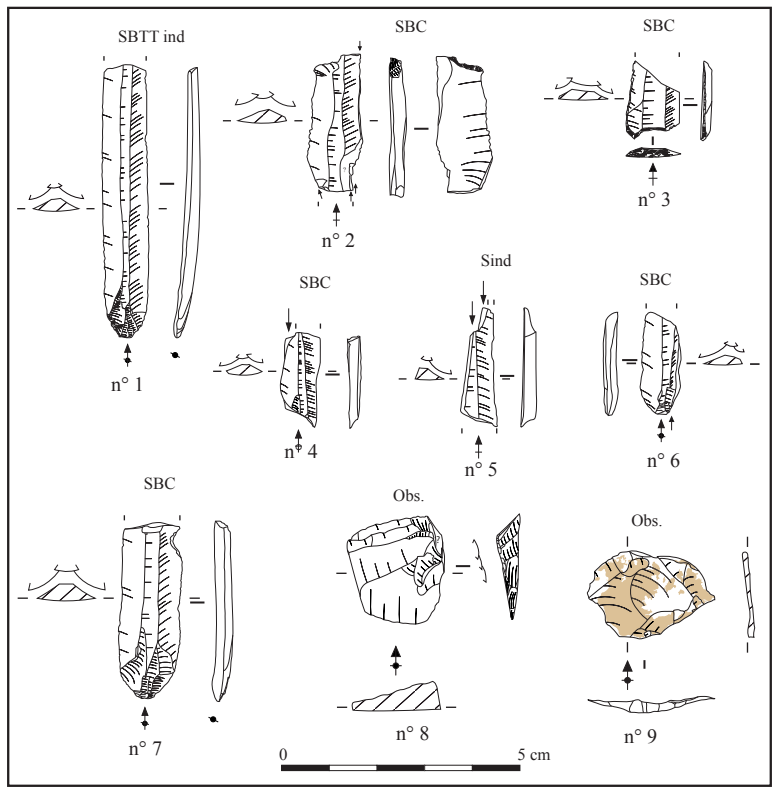

Fig. 18 - Échantillon du mobilier lithique issu de la ligne de fosses circulaires (DAO B. Bosc-Zanardo, V. Léa).

Fig. 18 - Examples of lithic artefacts from the alignment of circular pits (CAD B. Bosc-Zanardo, V. Léa).

l'ouest du site et les dix-huit autres regroupées dans une zone relativement centrale, à mi-chemin entre les bâtiments au sud et au nord de l'emprise (fig. 2). Toutes les structures possèdent un plan circulaire avec un diamètre qui varie de 86 à $165 \mathrm{~cm}$, mais leur étude a permis de révéler deux types de foyers en fonction de leur profondeur, de leur remplissage plus ou moins riche en blocs de molasse et de la taille de ces derniers.

Le premier type rassemble dix structures de petites dimensions (diamètre inférieur à $130 \mathrm{~cm}$ et profondeur inférieure à $30 \mathrm{~cm}$ ) qui présentent des traces restreintes de rubéfaction (fig. 19, F.215 et 339). Elles ont par ailleurs généralement fourni un nombre relativement réduit de pierres chauffées de petite taille et se rapprochent ainsi des foyers isolés connus dans le vallon de Cazan. Le deuxième type concerne dix foyers de plus grandes dimensions (diamètre supérieur à $120 \mathrm{~cm}$ et profondeur de $30-70 \mathrm{~cm}$ ). Ils présentent le plus souvent plus de traces de rubéfaction sur le fond et les parois, et des couches charbonneuses ont pu être observées à la base de leurs remplissages (fig. 19, F.321 et 342). Ils se distinguent aussi par un poids beaucoup plus important de pierres chauffées. Ces pierres peuvent être de petites dimensions et constituer un remplissage dense de la structure (F.321), mais il peut aussi s'agir d'un nombre réduit de très grosses pierres. Ainsi, le foyer F.342, pour lequel des questions de fonction persistent, ne contenait que sept gros blocs chauffés, posés en couronne autour d'un espace vide, surmonté par un autre gros bloc, chauffé lui aussi.

Les variations reconnues pourraient signifier des stades d'abandons différents, avec des phases de rejet à mettre en parallèle du mobilier archéologique non brûlé, retrouvé en contexte résiduel. Des fonctionnements 


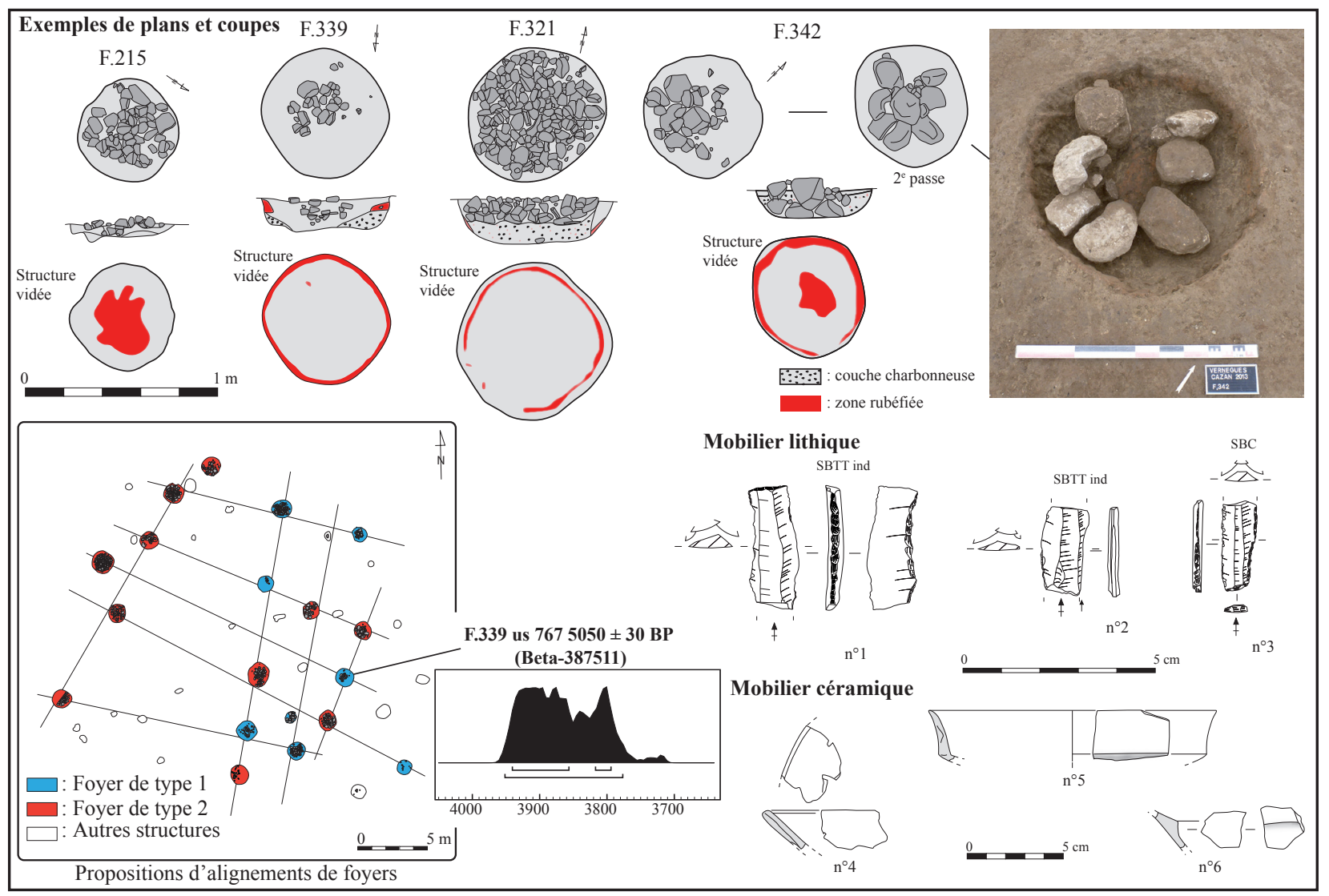

Fig. 19 - Données archéologiques et échantillon du mobilier issu des structures à pierres chauffées (cliché et DAO B. Bosc-Zanardo, A.-L. Foulché, L. Guichard-Kobal, C. Moreau, V. Léa).

Fig. 19 - Archaeological data and examples of finds from the burnt stone combustion structures (photograph and CAD B. Bosc-Zanardo, A.-L. Foulché, L. Guichard-Kobal, C. Moreau, V. Léa).

complémentaires avec récupération de pierres entre foyers sont également envisageables, mais des recollages exhaustifs entre structures n'ont pas été testés, notamment en raison du type de matériau (molasse). Une chronologie relative entre les structures est donc probable : elles ne se recoupent jamais, ce qui suggère que les traces des précédents foyers devaient être visibles lors des différentes réinstallations.

Dans la concentration centrale, l'implantation des foyers semble suivre une certaine organisation : deux alignements principaux peuvent être proposés (fig. 19). La première proposition dessine des alignements d'orientation globalement nord-ouest - sud-est qui correspondent à quatre batteries subparallèles. Chacune comporte des foyers du premier type, peu profonds, à l'est et des gros foyers du second type un peu plus éloignés à l'ouest. Cette hypothèse irait dans le sens de batteries qui rassemblent des foyers à différents stades d'utilisation ou différentes fonctions. La seconde proposition se réfère à une orientation majoritaire sud-sud-ouest - nord-nord-est. Elle dessine également quatre batteries, mais sans récurrence des combinaisons de types de foyers de l'une à l'autre. Cette hypothèse sous-entend des manières différentes d'utiliser les structures sur chaque batterie et donc peut-être aussi sur chaque phase d'utilisation.

\section{Le choix d'un combustible}

Les charbons de deux foyers du type 1 et de cinq du type 2 ont été analysés (Delhon et al., sous presse). Les structures à pierres chauffées ont permis d'identifier 190 charbons sur 294 étudiés, soit moins de $65 \%$ (fig. 20). Le spectre est très différent de celui des trous de poteau : le chêne n'est présent que dans deux assemblages sur neuf et ne représente plus que $4,2 \%$ des fragments identifiés, alors que l'arbousier, présent dans tous les assemblages sauf un, atteint $91,6 \%$ des déterminations. Le pin de type méditerranéen a été déterminé dans trois prélèvements, le nerprun alaterne ou la filaire ainsi que le peuplier ou saule apparaissent une seule fois dans l'état actuel de l'analyse. La grande quantité de feuillus indéterminés est liée à l'état de vitrification assez avancé et généralisé des fragments, ainsi qu'à l'abondance des nœuds ligneux qui, en perturbant la structure anatomique du bois, rendent l'identification très difficile. Certains traits anatomiques observés sur les charbons non-identifiés nous amènent à penser que l'arbousier, déjà très majoritaire, est sousestimé dans nos résultats (Delhon et al., sous presse).

L'arbousier est le principal combustible utilisé dans les structures à pierres chauffées, les autres essences n'apparaissant que de façon anecdotique. Pourtant, cet arbuste 
Structures à pierres chauffées

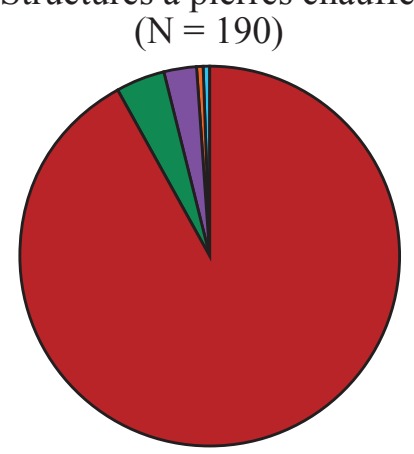

Arbousier (Arbutus unedo)

Chêne (Quercus) caducifolié

Pin (Pinus) type méd.

Filaire / Alaterne (Rhamnus alaternus/Phillyrea sp.)

Peuplier / Saule (Populus sp. / Salix sp.)

Fig. 20 - Résultats de l'analyse anthracologique des prélèvements issus des structures à pierres chauffées (DAO C. Delhon).

Fig. 20 - Results of the charcoal analysis of samples taken from the burnt stone combustion structures (CAD C. Delhon).

n'est que très rarement dominant dans les associations végétales actuelles. Si l'on signale des formations pures, denses, dans les ravins du massif des Maures, Provence cristalline (Rameau et al., 2008), mais aussi sur les pélites des environs du lac du Salagou, Hérault (Chabal et Liottier, communication personnelle), il croît le plus souvent dans des chênaies vertes claires, dans les fruticées mésoméditerranéennes ou dans les maquis, où il est associé au chêne vert, aux filaires, à la bruyère arborescente, aux cistes... Hors des terrains siliceux, l'arbousier est donc surtout un élément secondaire de formations végétales, la plupart du temps régressives (post-perturbation), sur sols généralement secs et peu développés. C'est notamment une espèce qui, rejetant de souche, réagit très bien aux incendies ou au pâturage.

L'utilisation récurrente de l'arbousier dans tous les foyers étudiés (excepté F.215 qui n'a fourni que trois fragments de pin) semble perdurer pendant toute l'occupation du site d'après les résultats obtenus sur le puits (voir infra). Il est donc difficile d'y voir un simple biais d'échantillonnage lié à un prélèvement dans des structures de combustion, dont on sait qu'elles ne fournissent souvent que les charbons du dernier feu (Chabal, 1997). Elle nous informe sur la présence de formations à arbousier (de type garrigue ou maquis) dans le territoire exploité par les occupants du site, mais aussi sur une sélection spécifique de ce taxon comme combustible, puisque le spectre des ligneux qui l'accompagnent habituellement est très loin d'être complet.

Cette sélection peut répondre à des choix culturels impossibles à cerner, mais aussi à un certain nombre de contraintes pyrotechniques ou de gestion de la ressource végétale. Il s'agit d'un bois réputé excellent combustible (Lieutaghi, 2004) et qui a été exploité par les charbonniers médiévaux et modernes (Fabre et Gervet, 1992; Acovitsióti-Hameau, 2001). Il est possible que la cinétique de combustion de l'arbousier soit particulièrement adaptée au fonctionnement des structures à pierres chauffées, mais aussi que l'exploitation ciblée de cette essence prenne place dans une stratégie globale de gestion du territoire. L'approvisionnement en combustible pourrait se faire dans les zones pâturées où se développent les végétations de garrigue-maquis. L'arbousier, par sa capacité à rejeter de souche et sa croissance juvénile relativement importante, s'y renouvelle rapidement. Son exploitation permet de contenir l'embroussaillement et de préserver d'autres ligneux (e.g. le chêne caducifolié) pour d'autres usages (e.g. le bois d'œuvre). Toutefois, cette explication en termes de zone d'approvisionnement ne se suffit pas à elle seule, car d'autres taxons de garrigue également favorisés par le pâturage et potentiellement envahissants devraient être présents ou mieux représentés (nerprunfilaire, cistes, bruyère...). Un choix spécifique de l'arbousier nous semble nécessaire à la constitution des spectres que nous avons observés.

\section{Éléments de chronologie}

Une datation ${ }^{14} \mathrm{C}$ a été effectuée sur un charbon du F.339; elle donne un résultat entre 3950 et 3780 av. notre ère (tabl. 1). Elle atteste la contemporanéité avec les autres structures du site, mais ne révèle, à elle seule, ni la durée, ni la fréquence d'utilisation des différents foyers. Le mobilier archéologique retrouvé dans les remplissages de ces structures se raccorde aussi au Chasséen récent, mais il ne permet pas non plus d'établir de variation chronologique.

Le matériel céramique ne rassemble qu'une centaine de tessons et les seuls éléments typologiques ne renvoient qu'à la fonction de service ou de consommation (coupes évasées, à carène basse ou à rebord large; fig. 19, nos 4-6). Le mobilier lithique présent dans quatorze structures à pierres chauffées s'élève à une quarantaine de pièces. Le silex bédoulien chauffé, identifié au sein de dix faits, atteste quelques rares éléments qui font référence à une étape évoluée du Chasséen : un burin sur cassure (fig. 19, $\mathrm{n}^{\circ} 2$ ) et deux troncatures sur lamelle de code 212' (fig. 19, $\mathrm{n}^{\text {os }} 1$ et 3). Peu de mobilier porte toutefois la trace du feu. Sa position pourrait donc être secondaire et postérieure à l'utilisation réelle des foyers, ce qui n'est pas le cas de quelques éléments macrolithiques, qui ne constituent qu'une proportion très réduite de la grande quantité de pierres issues des foyers ( $2 \mathrm{~kg}$ d'outils sur galet au total pour $181 \mathrm{~kg}$ de pierres par foyer en moyenne). Il s'agit de deux fragments de molette, deux broyons et un fragment d'outil probablement passif. Aucune meule volumineuse n'a été retrouvée, même au sein des foyers du deuxième type; les outils déposés dans ces structures le sont vraisemblablement dans un rôle utilitaire de pierre de chauffe, comme le fait supposer leur état fragmentaire ou leur petite dimension ainsi que les traces de chauffe. 


\section{Des puits réutilisés en dépotoirs et révélateurs d'une spatialisation des activités}

\section{Caractérisation des puits et de leur environnement immédiat}

Plusieurs structures présentent des profondeurs importantes avec des remplissages complexes laissant supposer qu'il peut s'agir de puits réutilisés par la suite en dépotoirs (fig. 2). Deux d'entre eux sont particulièrement profonds à proximité des bâtiments $1 \mathrm{a}$ et $1 \mathrm{~b}: \mathrm{F} .431$ et F.433; deux autres sont localisés dans la pointe nordest de l'emprise: F.714 et F.720; un quatrième se situe plus à l'ouest (F.532) et il est recoupé par une structure postérieure (F.785).

Ces puits possèdent tous des plans circulaires et présentent deux types principaux de profils en coupe (fig. 21). Le premier correspond aux deux structures septentrionales à section quasi cylindrique profonde (profondeur de 150-170 cm) avec un fond en cuvette. Le second se rapporte aux deux puits méridionaux à profil quasi cylindrique très profond (entre 240 et $260 \mathrm{~cm}$ ) avec un évasement inférieur; l'un des puits (F.431) possède par ailleurs un léger évasement en surface avec des traces de rubéfaction qui pourraient faire penser aux vestiges d'un système de fermeture. Le cinquième puits à l'ouest possède un profil qui se rapproche de ce deuxième type, mais avec un diamètre beaucoup plus important.

Ces deux types de creusement peuvent dépendre de la durée de fonctionnement, l'évasement inférieur pouvant correspondre à un temps de battement de la nappe phréatique. Ils semblent toutefois aussi et surtout concorder avec la localisation des puits sur l'emprise de fouille et leurs profondeurs respectives : le type 1 correspond aux structures plus septentrionales et donc plus proches du fond du vallon et de la nappe phréatique; les autres puits s'ouvrent plus hauts et il est probable que leur creusement ait atteint des couches plus profondes et plus instables.

La fouille de ces puits a permis de révéler des stratigraphies plus ou moins complexes en leur sein, avec des couches riches en mobilier archéologique et des rejets charbonneux ou cendreux (fig. 21). À partir de ces concentrations de matériel, trois principales dynamiques de comblement peuvent être observées. Le premier type correspond à un remplissage avec du mobilier en abondance sur la totalité du puits; il concerne les structures F.431 et F.720. Le deuxième type (F.433 et F.714), montre une alternance de trois couches de rejets riches en charbons et en mobilier avec des couches limoneuses stériles qui peuvent être interprétées comme des effondrements de parois. Enfin, le couple de structures F.532/785 est original avec un remplissage rapide et stérile du puits, puis une phase de recreusement avec une logique finale de dépotoir. Ces dynamiques de creusement et de comblement mettent ainsi en valeur le caractère particulier de ce dernier puits, qui occupe une localisation isolée sur l'emprise.

L'environnement immédiat des puits peut être appréhendé grâce à la malacofaune. Si tous n'ont pas été ana- lysés de manière détaillée de ce point de vue - les puits F.431 et 720 ont été entièrement étudiés alors que les puits 433 et 714 ont fait l'objet d'une analyse préliminaire - il est tout de même possible de mettre en évidence l'homogénéité des assemblages d'un bout à l'autre de chacune des stratigraphies. Les puits F.431, 433 et 720 ont des profils relativement similaires et attestent une végétation herbacée clairsemée et fortement artificialisée (fig. 4 et 5). Les espèces aquatiques sont absentes et les espèces hygrophiles et palustres, présentes en très petit nombre, sont probablement remaniées du substrat. L'espèce xérothermophile et anthropophile Cernuella virgata est dominante (environ $40 \%$ des coquilles dans F.720; 30 à $60 \%$ dans F.431). Elle est accompagnée par d'autres espèces caractéristiques des pelouses sèches, en particulier Candidula rugosiuscula, Candidula gigaxii et Oxychilus hydatinus. En revanche, la malacofaune du puits F.714, quoique également homogène le long de la stratigraphie, donne une image totalement différente de l'environnement. Pomatias elegans (milieux forestiers ouverts, fruticées) domine partout. Il est accompagné par des espèces typiques des garrigues et des pelouses sèches : C. rugosiuscula, C. gigaxii, Trochoidea pyramidata, Vitrea narbonensis. Cette singularité du puits 714 reste pour l'heure difficile à interpréter.

\section{Des puits ayant fonctionné avec les bâtiments et les structures à pierres chauffées?}

Le puits F.433 a bénéficié de deux datations au radiocarbone (tabl. 1; fig. 21). La première, réalisée sur un charbon de pin issu de la couche la plus profonde, donne un résultat à 4230-3970 av. notre ère; la seconde, réalisée sur une graine carbonisée issue d'une couche supérieure, donne une date à 3970-3800 av. notre ère. Les deux dates concordent avec celles réalisées dans les autres structures. Toutefois, en l'absence de données chronologiques absolues plus nombreuses, le mobilier céramique et lithique issu des puits a fait l'objet d'une attention particulière afin de tester son homogénéité d'un bout à l'autre des stratigraphies et voir dans quelle mesure les puits pouvaient être perçus comme contemporains, d'une part entre eux, et d'autre part avec les bâtiments et les foyers.

Le mobilier céramique issu des puits totalise presque $30 \mathrm{~kg}$ de restes, soit $44 \%$ du corpus total du site (fig. 22). Certaines portions de vases sont relativement bien conservées, mais, dans l'ensemble, le degré de fragmentation des restes est le même que sur l'ensemble du site. À l'heure actuelle, les essais de sériation typologique au sein de ces puits se sont avérés vains et de grandes similitudes se retrouvent dans chacun des puits, des couches les plus anciennes aux horizons les plus récents. Par rapport aux céramiques issues des structures d'habitat, les écuelles à carène haute (fig. 22, nos 5-6) se retrouvent surtout à la base des F.431 et F.720; on peut par contre noter une présence beaucoup plus forte de vases décorés au sein des puits. En effet, la très grande majorité des coupes à sillons sont issues de ces structures (fig. 22, $\mathrm{n}^{\circ} 1$ ), des décors gravés sur les bords des vases sont présents sur toute la stratigraphie 


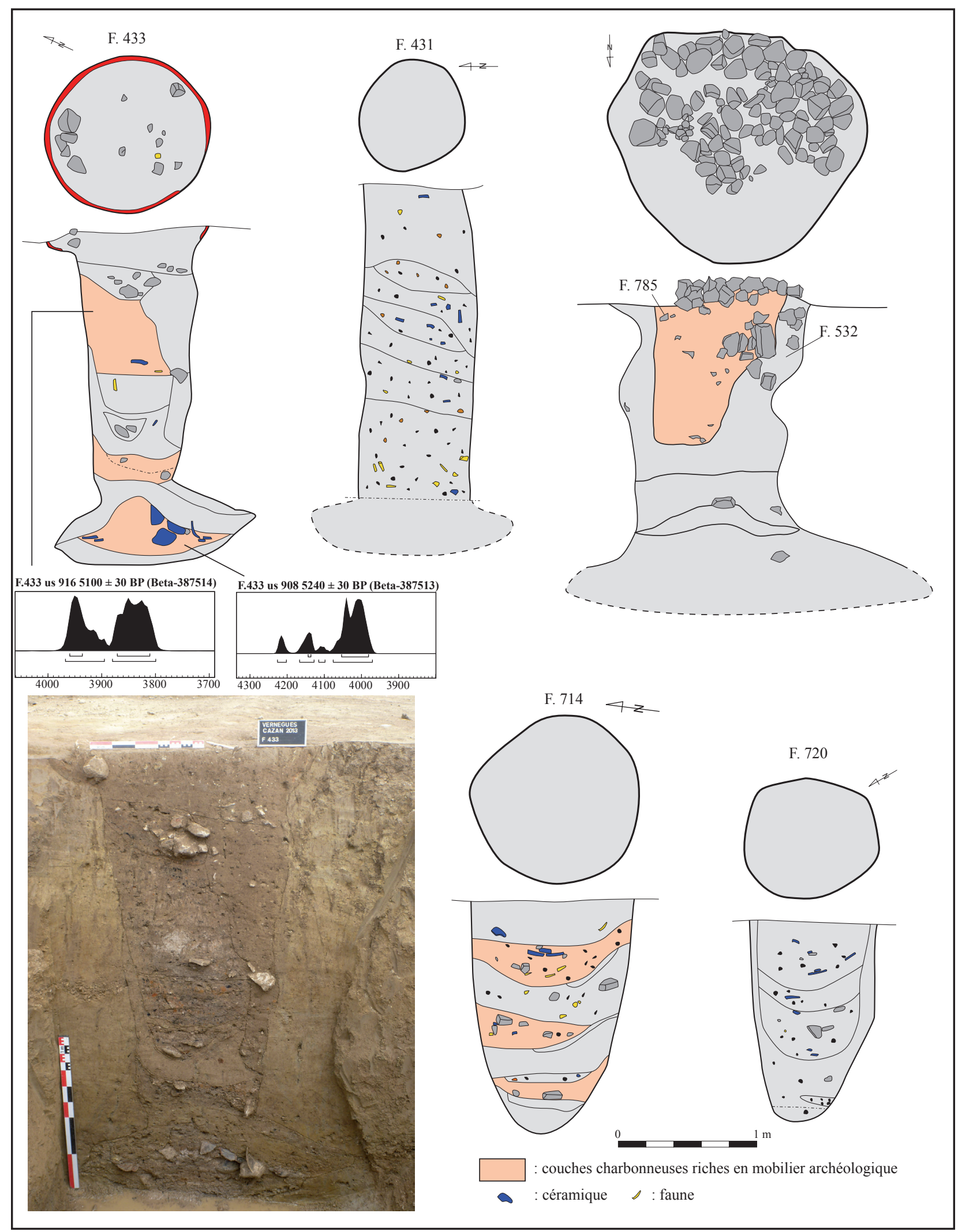

Fig. 21 - Plans et coupes des puits réutilisés en dépotoirs (cliché et DAO Y. Elodie-Guerrero, L. Guichard-Kobal, C. Moreau).

Fig. 21 - Plans and sections of the wells re-used as middens (photograph and CAD Y. Elodie-Guerrero, L. Guichard-Kobal, C. Moreau). 


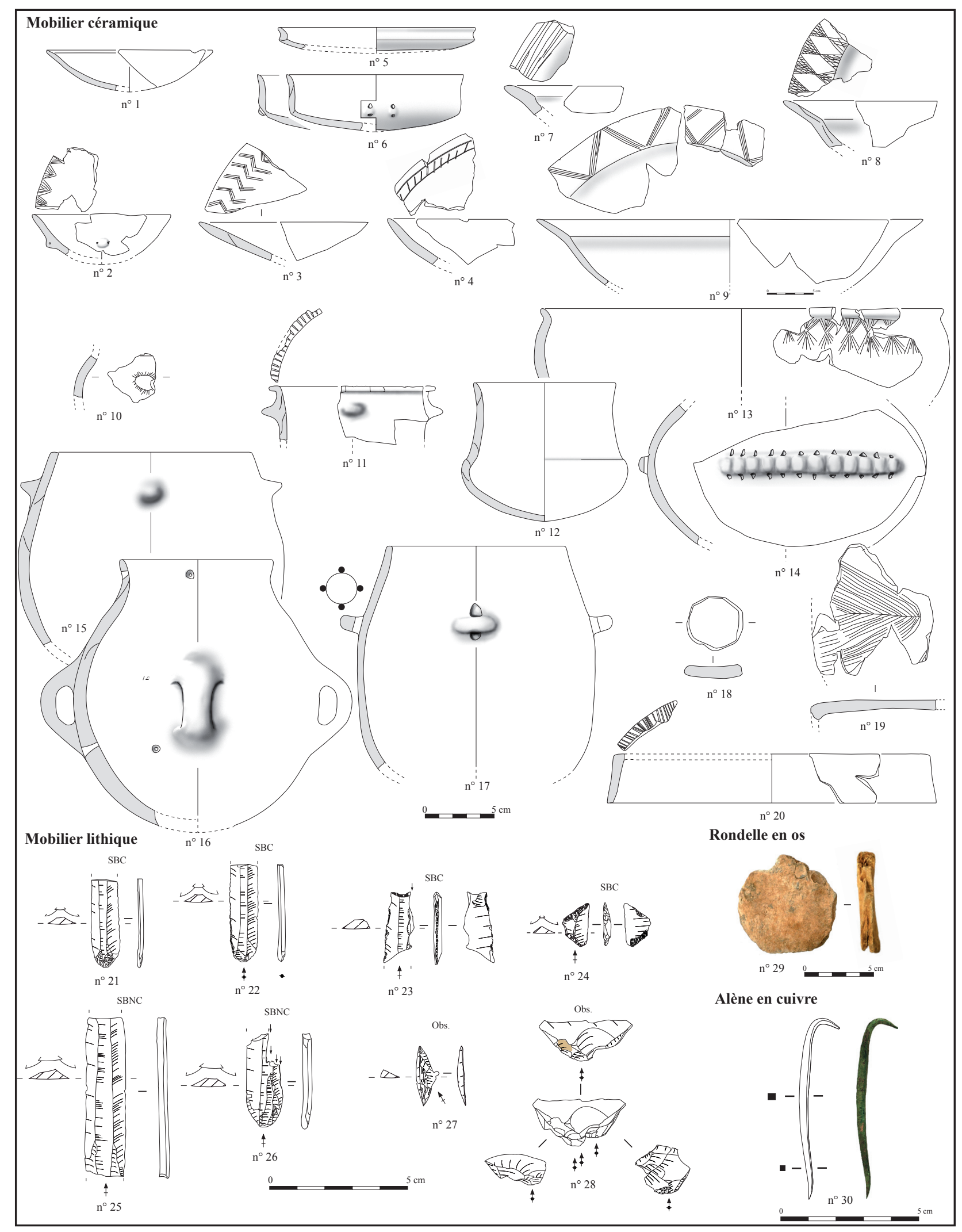

Fig. 22 - Échantillon du mobilier issu des puits F.431, 433, 714 et 720 (DAO B. Bosc-Zanardo, F. Cattin, C. Moreau, I. Sénépart, V. Léa).

Fig. 22 - Examples of finds from the wells F.431, 433, 714 and 720 (CAD B. Bosc-Zanardo, F. Cattin, C. Moreau, I. Sénépart, V. Léa). 
du F.433 et des analogies directes sur des coupes à rebord court peuvent être faites entre F.433, F.431 et F.720 (fig. 22, nos 2-4, 7-9). Des décors sont aussi présents au sein de toutes les US de F.431 avec notamment des lèvres ornées de lignes subparallèles (fig. 22, nº 7). F.431 et 433 possèdent également des vases à bandeaux multiforés sur toutes leurs stratigraphies (fig. 22, no 14). Enfin, le F.720 se distingue par une plus forte présence de pots possédant des languettes ou des anses (fig. 22, $\mathrm{n}^{\text {os }} 15-17$ ).

Le mobilier lithique issu de ces structures totalise un peu plus de $12 \%$ de l'assemblage total. L'observation des éléments en silex bédoulien permet de mettre en évidence une possible contemporanéité entre les puits et avec les bâtiments. Il s'agit avant tout de lamelles (tabl. 5), alors que les éclats en silex bédoulien sont beaucoup mieux représentés dans la ligne de fosses circulaires (voir infra). Dans tous les puits, le traitement thermique est présent dès l'US la plus ancienne, attestant un fonctionnement autour de ou postérieur à 4100-4000 av. notre ère (Georjon et Léa, 2013). Dans le F.433, la datation la plus ancienne est cohérente avec le mobilier lithique (tabl. 1). Au sein des quatre puits, de nombreux témoins d'un style de débitage évolué sont présents d'un bout à l'autre des us ayant livré du lithique, que ce soit au niveau du type de la mise en forme du plan de pression (fig. 22, $\mathrm{n}^{\text {os }} 21-22$ ) ou du point de vue de l'outillage identifié (fig. 22, nos 23-24). Néanmoins, dans les F.431 et 714, l'importation de lames en silex bédoulien non chauffé est attestée dans la couche la plus ancienne aux côtés de la production de lamelles en silex traité thermiquement (fig. 22, $\mathrm{n}^{\text {os }} 25-26$ ). Ces lames disparaissent de toutes les US supérieures, marquant donc une étape antérieure dans les US les plus basses.

La relation entre les puits et les structures en pierres chauffées est plus difficile à cerner sur la seule base du mobilier céramique ou lithique, même si certains arguments vont dans le sens d'une possible contemporanéité (voir infra). Elle est en revanche mieux argumentée lorsque l'on considère les données anthracologiques du puits F.433. L'analyse montre une grande homogénéité du spectre anthracologique pendant toute la durée du remplissage (fig. 23). L'arbousier, combustible très majoritaire dans les structures à pierres chauffées, domine (46\%). Le chêne caducifolié, identifié majoritairement dans les trous de poteau, représente un quart des charbons identifiés dans le puits. La présence en assez grande quantité $(20 \%)$ de pin de type méditerranéen, identifié seulement de façon très ponctuelle dans les autres structures, montre que cette essence était également utilisée sur le site, mais pour un usage qui semble différent du bois d'œuvre et du combustible des foyers collectif. Quelques espèces de garrigue ou héliophiles sont présentes pour un total de moins de $8 \%$. Les charbons étant en position secondaire et la durée de leur accumulation relativement longue, les biais de représentativité pouvant affecter les autres structures pèsent beaucoup moins ici. Ainsi, la faible diversification du spectre anthracologique tout au long du remplissage plaide en faveur d'un choix persistant de certaines essences pour des usages particuliers : le chêne pour la fabrication des poteaux des bâtiments et l'arbousier pour l'alimentation des foyers à pierres chauffées. Ces résultats trahissent un lien entre les puits et les autres structures - bâtiments et foyers à pierres chauffées - les structures profondes ayant pu servir de zone de rejet.

\section{Quel statut pour le mobilier issu des puits?}

Les puits sont les structures les plus riches en mobilier archéologique. Ils ont livré de nombreux éléments concernant la céramique, le lithique, l'industrie osseuse et un objet en cuivre qui nous amènent à nous interroger sur leur statut.

Comme nous l'avons souligné plus haut, les puits se distinguent des autres structures par une très grande proportion d'individus céramiques décorés, dont les couvercles ornés de sillons qui sont encore parfois emplis d'un colorant rouge (fig. 22, nos 19-20). Ces types de couvercles décorés sont encore relativement rares dans le sud de la France et rappellent les traits caractéristiques de la série de la Lagozza di Besnate (Borrello et Van Willigen, 2012). Parmi les types d'objets particuliers retrouvés dans les puits, on peut aussi citer quelques fusaïoles et jetons circulaires (fig. 22, $\mathrm{n}^{\circ} 18$ ).

Du point de vue lithique, le puits F.714 se distingue par un nombre d'éléments en obsidienne (tabl. 5) correspondant à près de la moitié de l'obsidienne trouvée

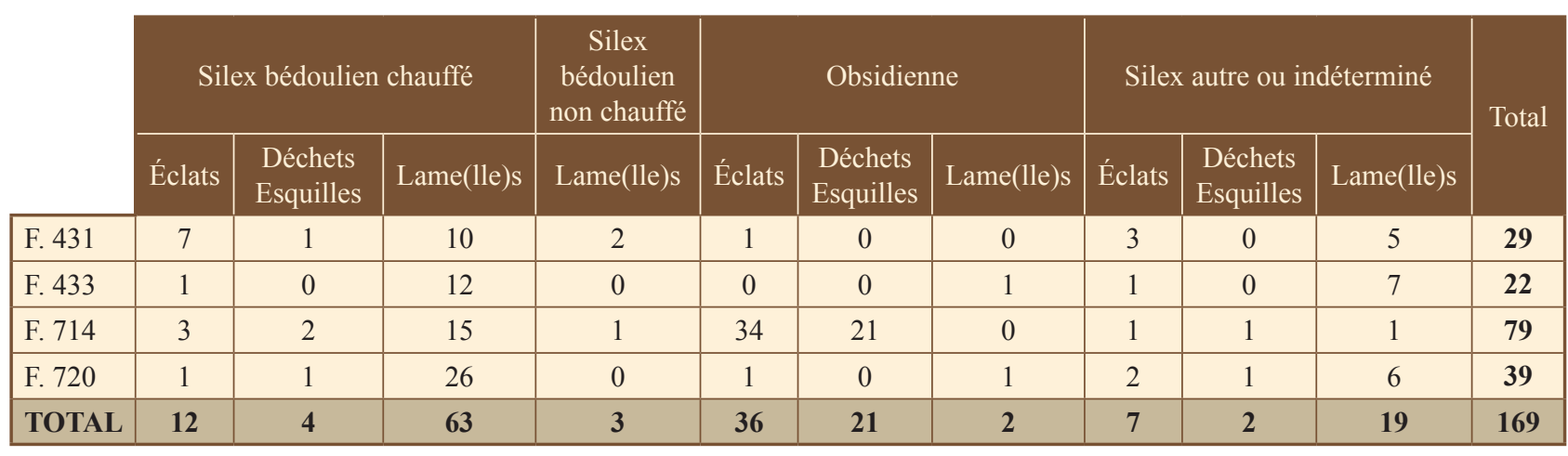

Tabl. 5 - Répartition des pièces lithiques au sein des puits F.431, 433, 714 et 720 (données V. Léa).

Table 5 - Classification and distribution of the lithic fragments recovered from the wells F.431, 433, 714, and 720 (data V. Léa). 


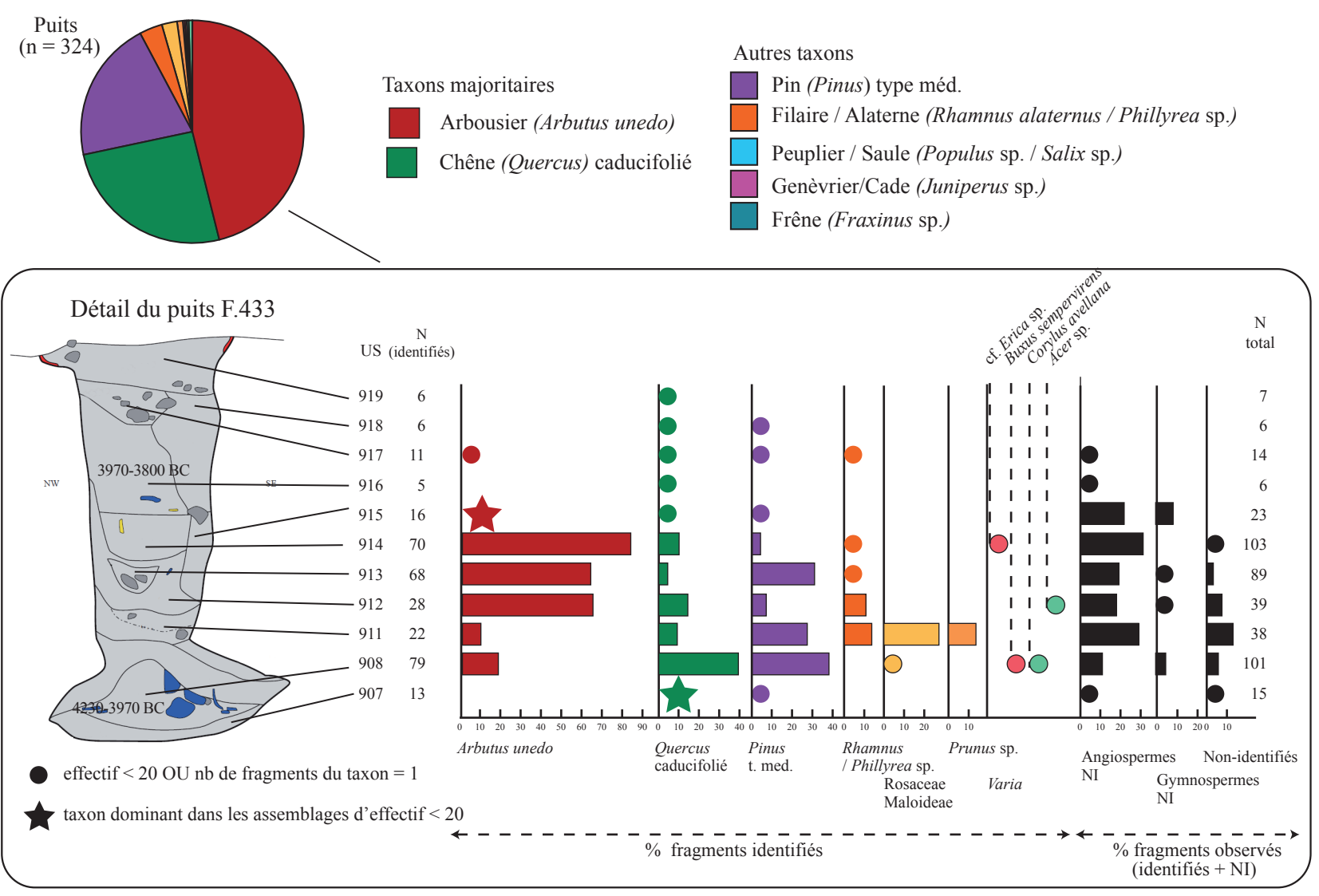

Fig. 23 - Résultats de l'analyse anthracologique du puits F.433 (DAO C. Delhon).

Fig. 23 - Results of the charcoal analysis from well F.433 (CAD C. Delhon).

globalement sur le site et attestant le rejet d'un atelier de taille. Ces effectifs sont singuliers en contexte chasséen, mis à part le site des Terres-Longues à Trets, Bouchesdu-Rhône (Léa, 2012). Les analyses de provenance révèlent une origine sarde sans exception et de type SA de manière quasi exclusive; seuls deux éclats en SC ont été identifiés (fig. 13). À l'instar du silex bédoulien chauffé, l'obsidienne a été utilisée dans le cadre d'une production de lamelles débitées par pression, correspondant à ce que l'on connait par ailleurs sur les sites chasséens (Binder et al., 2012). Dans le cas du F.714, les éléments en obsidienne présents évoquent une phase de mise en forme du nucléus à lamelles : les éclats et les esquilles sont nombreux, plusieurs éclats montrent une surface naturelle ou une face inférieure d'éclat trahissant le recours à des éclats-nucléus (fig. 22, $\mathrm{n}^{\circ} 27$ ), et certains remontages illustrent des mises en forme de flanc de nucléus (fig. 22, $\mathrm{n}^{\circ} 28$ ). Enfin, les lamelles en obsidienne sont totalement absentes du puits, alors qu'elles sont par ailleurs présentes sur le site ( $n=34$ produits lamellaires) et que celles en silex bédoulien chauffé sont bien représentées au sein de ce même puits (tabl. 5). Ajoutons à cela qu'aucun éclat de reprise ou d'entretien du nucléus à lamelles n'est identifié. C'est donc bien la phase de mise en forme (et non celle d'entretien) qui est attestée ici de manière tout à fait inédite, mais attendue (Léa, 2012), le débitage de lamelles sur place étant illustré par ailleurs sur le site.
Les puits sont les seules structures à avoir livré de la faune en abondance (voir infra) et de l'industrie osseuse. Pour cette dernière, il s'agit toutefois d'un corpus assez faible, composé de deux extrémités distales de pointes indéterminées, d'une rondelle (fig. 22, n²9) et d'un fragment de coxal de grand ruminant. L'ensemble est bien conservé et les deux pointes ont subi l'action du feu. La rondelle est issue d'une scapula de Bos taurus et constitue un « fossile directeur » de l'industrie osseuse chasséenne. On en rencontre sur plusieurs autres sites de plein air comme à Auriac, Aude (Gaillard, 1998), ou à Montélimar, Drôme (Sénépart, 2006). Les dimensions de celle du Clos $\mathrm{du}$ Moulin sont toutefois exceptionnelles. Le fragment de coxal est quant à lui encore plus énigmatique, car il présente une perforation et des découpes qui ne résultent pas d'un travail de boucherie, mais plutôt de l'élaboration d'un objet qui pourrait avoir l'allure d'une tête de bovidé.

Enfin, une alêne en cuivre a été découverte au cœur du puits F.720. Il s'agit d'une tige de section quadrangulaire, épointée aux deux extrémités (fig. 22, no 30). L'une des pointes est très légèrement recourbée, alors que l'autre présente un angle beaucoup plus fermé. Cette alêne fait partie des premiers objets métalliques du Néolithique retrouvés dans le Sud de la France avec les deux exemplaires de Daurelle à Montélimar (Thiercelin-Ferber, 2013) et il renvoie aux débuts de la métallurgie en Italie du Nord (Dolfini, 2013). 


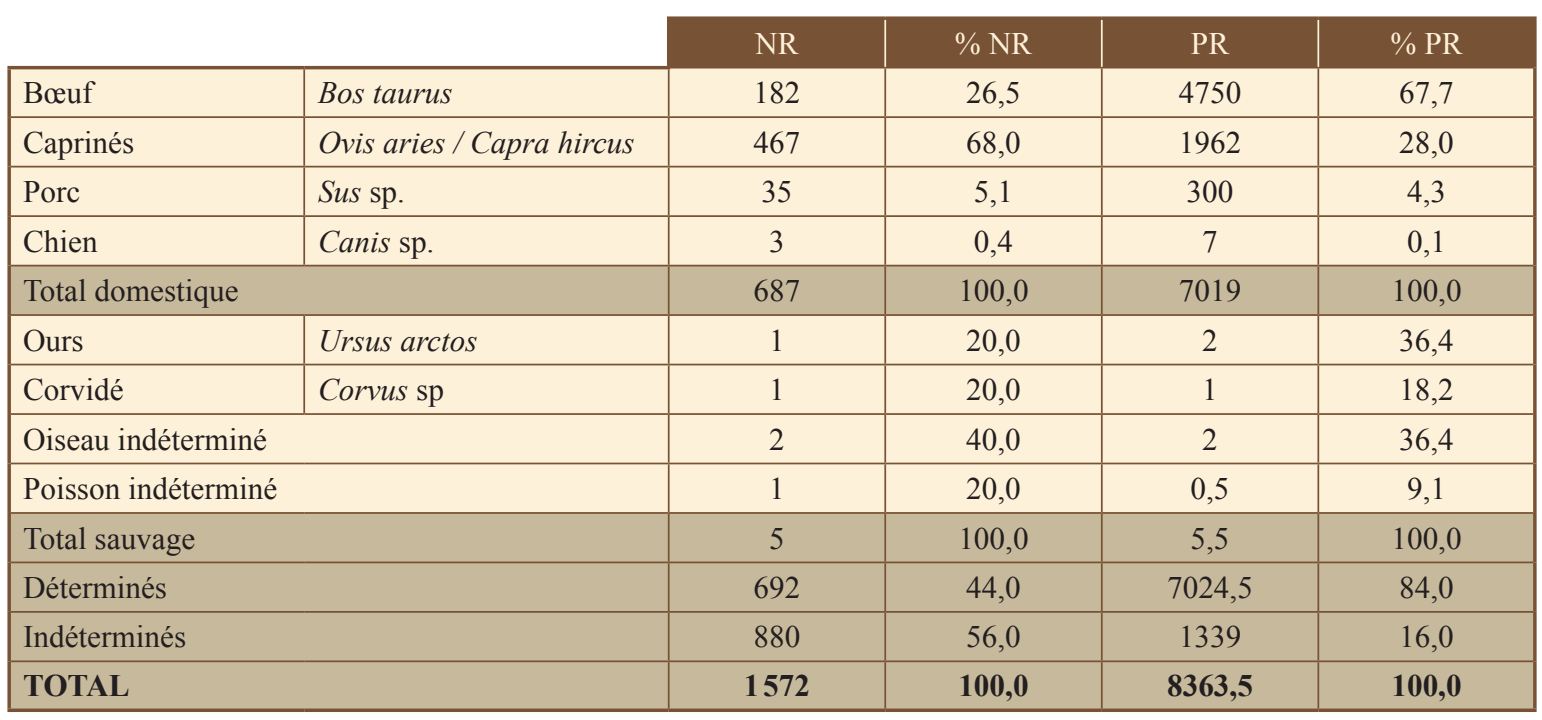

Faune calcinée : NR $=418(26,6 \%)$

Tabl. 6 - Répartition des espèces fauniques observées dans les puits F.431, 433, 714 et 720 (données S. Foucras).

Table 6 - Species distribution of the animal remains observed in wells F.431, 433, 714, and 720 (data S. Foucras).

Hypothèse sur le fonctionnement des puits et sur la sectorisation des activités du site

Si des différences chronologiques ne sont pas flagrantes au sein de ces puits, certains indices nous incitent à proposer des hypothèses relatives à leur fonctionnement ainsi qu'à une certaine spatialisation des activités sur le site.

Tout d'abord, les puits semblent fonctionner deux par deux : F.431/433 d'une part et F.714/720 d'autre part. Hormis la proximité des puits de chacune des paires, l'étude des comblements montre une symétrie dans la disparité des remplissages : à chaque fois, un puits à colmatage continu avoisine un puits avec un remplissage à trois phases distinctes. L'hypothèse d'une complémentarité en termes de fonctionnement peut donc être posée pour ces quatre puits.

Les restes fauniques du Clos du Moulin proviennent presque exclusivement des puits. S'ils mettent en évidence un fonds commun pour les quatre puits orientaux (F.431, 433, 714 et 720), le caractère original de la fosse F.785, qui recoupe le puits F.532, s'exprime par trois aspects.

Tout d'abord, du point de vue de la représentation des différentes espèces, les puits orientaux ont fourni un spectre des espèces largement conforme aux faciès des sites chasséens du midi provençal ou de la moyenne vallée du Rhône (Blaise et al., 2010; Beeching et al., 2000) : une moyenne de $68 \%$ de caprinés, $26 \%$ de bœuf et une part minime de porcs (tabl. 6). Au contraire, dans le puits F.532/785, c'est le bœuf qui domine, devant les caprinés et le porc (tabl. 7).

Ensuite, si l'estimation des âges n'est guère aisée, elle montre toutefois que les quatre puits orientaux se caractérisent par une certaine diversité des cheptels avec une présence des jeunes animaux qui n'a rien d'anecdotique, alors que, pour le puits F.532/785, on peut considérer que les matures étaient les plus nombreux, l'intégralité des restes de bovins étant épiphysés. Pour les caprinés, seules les dents isolées nous renseignent sur la présence d'individus relativement jeunes sans qu'il s'agisse pour autant de juvéniles.

Enfin, si les restes calcinés sont totalement absents de la fosse F.785, ils représentent 21 à $24 \%$ du corpus des quatre autres puits. Autant d'indices trahissant une pratique de mise au feu courante sur l'habitat de Vernègues et qui montre une certaine constance. Plus qu'un témoignage des activités alimentaires, nous y voyons plutôt une pratique d'élimination des déchets par le feu. Le degré d'ustion, manifestement élevé, parait plaider en ce sens, comme la concentration des restes animaux dans les structures profondes qui semblent avoir pour fonction secondaire de recueillir l'essentiel de ces déchets.

Toutes ces différences sont significatives et ont peutêtre trait à la fonction de la structure ou à sa localisation.

\begin{tabular}{|l|c|c|}
\multicolumn{1}{l|}{} & NR & $\%$ \\
\hline Bœuf & 47 & 61,0 \\
\hline Caprinés & 23 & 29,9 \\
\hline Porc & 6 & 7,8 \\
\hline Ours & 1 & 1,3 \\
\hline Déterminés & 77 & 30,3 \\
\hline Indéterminés & 177 & 69,7 \\
\hline TOTAL & $\mathbf{2 5 4}$ & $\mathbf{1 0 0 , 0}$ \\
\hline
\end{tabular}

Tabl. 7 - Répartition des espèces fauniques observées dans la structure F.785, recoupant le puits F.532 (données S. Foucras).

Table 7-Species distribution of the animal remains observed in the structure F.785 which cuts through well F.532 (data S. Foucras). 
Une sectorisation des activités accomplies dans cette zone nord-ouest peut ainsi être proposée à titre d'hypothèse, à l'instar de ce que le puits F.714 pouvait évoquer, pour la zone nord-est, à partir de la mise en évidence du rejet d'un poste de taille d'obsidienne.

\section{SYNTHESE ET MISE EN PERSPECTIVE}

\section{Caractérisation d'un habitat structuré du Chasséen}

Le caractère exceptionnel du site de Cazan « le Clos du Moulin » à Vernègues réside dans la mise en évidence d'un habitat structuré, alors que les maisons avérées étaient encore rares dans le Sud de la France. Cet habitat repose notamment sur dix plans de bâtiments qui répètent un modèle architectural standard. Les seules variations notables entre ces maisons se limitent aux dimensions absolues, les implantations des poteaux suivant un schéma défini et réfléchi (Moreau et al., à paraître).

Ces plans ne trouvent que peu de comparaisons au sein du Chasséen méridional et des cultures contemporaines. La plupart des exemplaires connus présentent en effet des plans quadrangulaires bien souvent implantés sur tranchées de fondation et sablières basses. C'est le cas Italie du Nord, pour le Neolitico recente à Travo, Alba, Isera, ou encore Piacenza (Beeching et al., 2009). Dans le Massif central, plusieurs autres plans de bâtiments quadrangulaires ont été mis en évidence à Beaumont et Champ-Chalatras (Saintot et Le Barrier, 2009; Saintot, 2012). L'exemple le plus similaire aux structures du Clos du Moulin a été mentionné à Montmeyran (Drôme) où une construction isolée à deux nefs possède des murs gouttereaux composés de trois poteaux régulièrement espacés (Saintot, 2002). Sa ligne faîtière se conclut au sud par deux à trois petites implantations qui dépassent du cadre des parois latérales, ce qui rapproche pleinement ce plan de ceux de Vernègues, avec une datation au ${ }^{14} \mathrm{C}$ concordante (A.A. 21721 Tucson-Arizona : 5095 $\pm 70 \mathrm{BP})$.

Sur le site, trois ensembles de construction reposent aussi sur des fosses d'implantation nettement plus imposantes. Leur érection semble relever de la même logique que celle qui a prévalu à l'édification des maisons standards (murs gouttereaux en rythme ternaire notamment), mais avec des pratiques différentes et un investissement beaucoup plus important. La fonction de tels édifices est donc particulière et une visée collective vient immédiatement à l'esprit. Toutefois, les parallèles archéologiques sont ici encore moins nombreux que ce soit dans le Sud de la France ou même, à notre connaissance, à travers l'Europe.

Les bâtiments, pris dans leur ensemble, montrent une certaine organisation (fig. 24) : tous suivent une même orientation et leurs entrées sont tournées vers le sud, à l'abri du mistral. Bien que cette configuration semble logique pour la préservation de l'habitat, elle suppose aussi une volonté collective qui se manifeste également par des emplacements prédéfinis pour l'implantation des maisons (Moreau et al., à paraître). L'organisation spatiale des installations du Clos du Moulin paraît se transmettre sur l'ensemble de la période d'occupation du Chasséen récent. Même si certains bâtiments sont reconstruits, ils le sont pratiquement au même endroit (cf. bâtiments 1 et 2). À l'inverse, les bâtiments au nord sont alignés et régulièrement espacés. Ces bâtiments peuvent être contemporains ou quasi contemporains, mais, s'ils se succèdent chronologiquement (ce que suggèrent certains remplissages pierreux), une même gestion de l'espace semble perdurer.

Il s'agit donc d'un site organisé collectivement avec des habitations alignées comme on en retrouve à Travo (Beeching et al., 2009), mais également sur les berges des lacs suisses (Hasenfratz et Gross-Klee, 1995). Le site des Piécettes, Marin-Épagnier (Neuchâtel, Suisse) est plus récent (environ 3450 av. notre ère), mais il présente plusieurs phases de reconstructions au même endroit, notamment pour un édifice central beaucoup plus imposant (Honegger, 2005). À ce titre il permet un parallèle avec les ensembles sur fosses d'implantations qui constituent sans doute des aménagements socialement valorisés.

\section{Fonctions du site et spatialisation des activités}

En l'absence de niveau de sol conservé, les activités menées sur le site ne peuvent être déduites que du mobilier présent dans les structures en creux, ce qui limite les observations possibles notamment pour les aménagements architecturaux. Au mieux, peut-on avancer que l'identification de meules dans les trous de poteau atteste l'activité de mouture dans ou au moins à proximité des édifices. Dans le bâtiment 4 , leur présence est à mettre en parallèle d'une lame qui comporte un lustré dû au travail des céréales et d'une plus forte proportion de céramiques dédiées au stockage.

Néanmoins, l'approche des autres types de structures permet d'appréhender la nature et la spécialisation des activités. Les foyers ne sont pas sans rappeler les exemplaires de la ZAC Saint-Antoine II à Saint-Aunès, Hérault (Furestier et al., 2012), mais également la zone foyère de Beaumont (Saintot, 2012). La faible diversité des assemblages anthracologiques suggère une sélection de l'arbousier et, sans présager d'une fonction particulière de ce combustible, ce phénomène induit une connaissance et une maitrise du territoire autour du site. Cette sélection semble avoir perduré comme l'attestent les rejets successifs dans les puits, qui ont été réutilisés en dépotoir. Les dynamiques de comblement semblent traduire des fonctionnements complémentaires pour deux paires de puits. Ces structures sont parmi les seules à avoir donné des restes fauniques (notamment calcinés), mais également une grande quantité de céramique; l'une d'elle indique un rejet ponctuel d'éclats de mise en forme de nucléus d'obsidienne au nord du site. Enfin, des fosses circulaires au sud de l'emprise ont également été réutilisées en dépotoir à proximité d'atelier de taille de silex. 


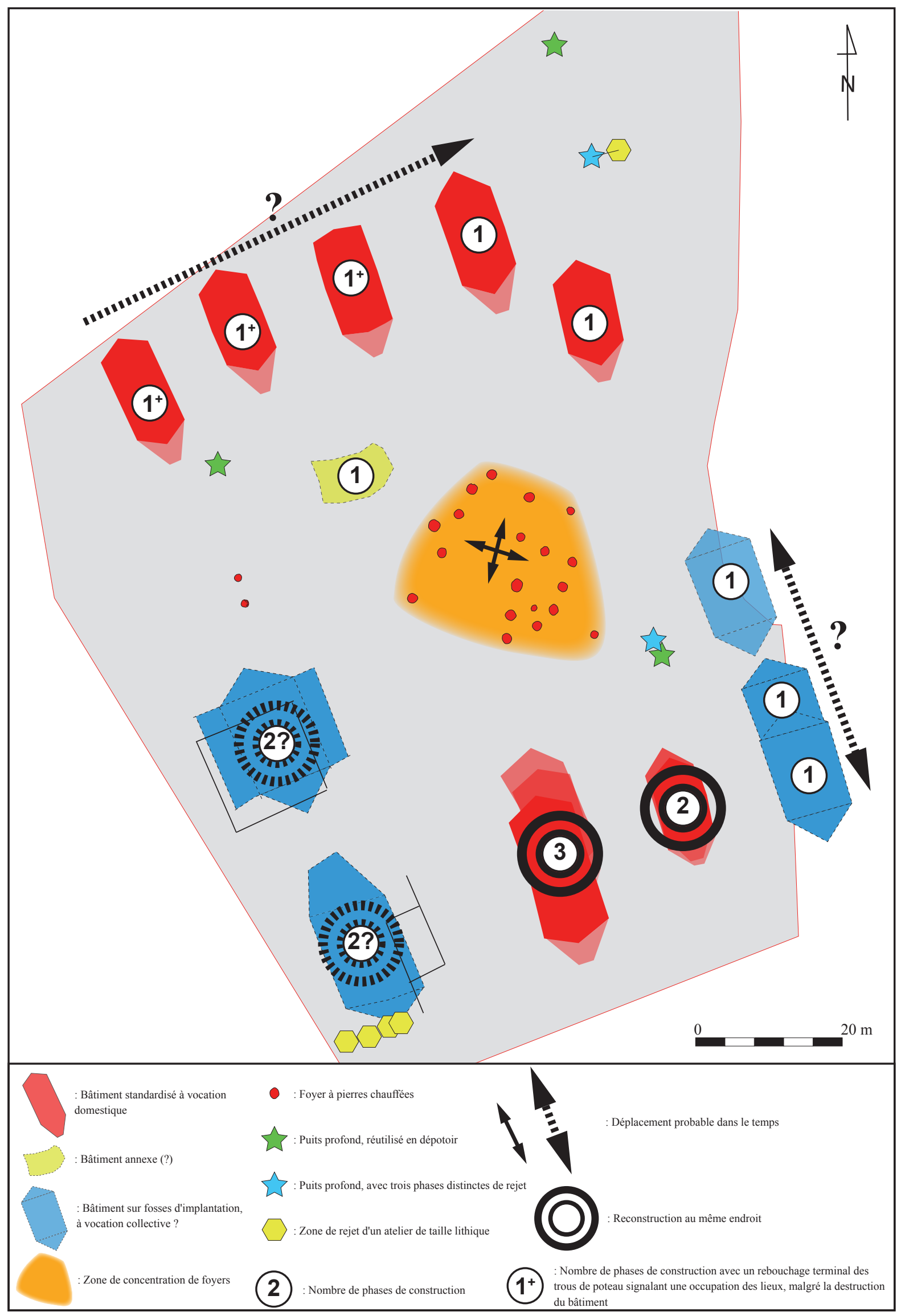

Fig. 24 - Schéma synthétique de l'occupation du Clos du Moulin (DAO C. Moreau).

Fig. 24 - Schematic model of the occupation of Clos du Moulin (CAD C. Moreau). 


\section{Un habitat organisé dans le temps}

Le site de Vernègues présente donc les caractéristiques d'un habitat avec les vestiges d'une occupation domestique et des zones d'activités définies spatialement (fig. 24). Le mobilier archéologique, ainsi que les datations ${ }^{14} \mathrm{C}$, désignent une durée maximum d'occupation de 300 ans et les diverses reconstructions d'édifices au même endroit (après pourrissement et carbonisation des bois) suggèrent de multiples phases d'occupation successives. Tous ces éléments nous interrogent ainsi sur le statut de ce site en fonction du rythme et de la durée de ses occupations.

De telles questions sont récurrentes en contexte chasséen. Elles ont notamment été développées à partir de la découverte des grands sites de terrasse de la moyenne vallée du Rhône sur lesquels les indices de structures d'habitat restent extrêmement ténus malgré toute l'attention portée à cette problématique (Beeching et al., 2000; Beeching et Léa, 2015).

À Vernègues, les implantations récurrentes et l'organisation même de l'habitat traduisent un attachement des populations à ce lieu, tandis que les résultats malacologiques et anthracologiques suggèrent l'exploitation de l'environnement du site, du terroir qui pouvait englober les espaces avoisinants du vallon. Tous ces éléments amènent à la notion de village, à savoir un regroupement d'habitations en milieu rural pour lesquelles l'activité agricole s'exerce sur un terroir associé (Gallay, 1995; Hasenfratz et Gross-Klee, 1995 ; Lévy et Lussault, 2003). En outre, les bâtiments sur fosses d'implantation peuvent évoquer la présence d'édifices socialement valorisés ou à vocation éventuellement collective.

Cette organisation en village au Clos du Moulin n'exclut pas toutefois un mode de vie en partie itinérant, compatible notamment avec la prédilection affirmée pour les caprinés et l'élevage pastoral. Les habitants ont très bien pu conserver une certaine mobilité avec des installations récurrentes au même emplacement. Ce phénomène pourrait alors rejoindre certaines observations archéologiques réalisées autour des lacs suisses (Gallay, 1995) et des parallèles ethnographiques faits par exemple sur des populations pastorales du delta du Niger (Gallais, 1960). Pour ces dernières, les déplacements saisonniers ne semblent pas incompatibles avec l'existence d'un véritable sens villageois dans son double contenu : esprit communautaire et attachement précis à un certain espace organisé.

Enfin, la notion de village renvoie bien souvent à un rôle économique local, qui ne fait pas de doute en ce qui concerne Vernègues. Néanmoins, ce gisement montre aussi une connexion à des réseaux de diffusion beaucoup plus larges : les traits principaux de la céramique et de l'industrie lithique plaident en faveur d'une pleine intégration au sein du monde chasséen et même au-delà si l'on considère l'obsidienne sarde par exemple; certains aspects céramiques renvoient également à l'Italie du Nord, tout comme certains objets originaux, tels le poids réniforme et surtout l'alène en cuivre.

Remerciements : Que soient ici remerciés les archéologues qui ont œuvré sur le terrain pour la révélation de ce site : M.-J. Ancel, N. Caballero, J. Collombet, Y. Elodie-Guerrero, A.-L. Foulché, J. Fuentes, L. Guichard-Kobal, T. Repellin, G. Turgis, L. Varlet-Zago. Merci également à F. Trial et $\mathrm{X}$. Margarit pour leur suivi scientifique, à B. Bosc-Zanardo pour les dessins de pièces lithiques, à P. Perez pour son aide à l'interprétation architecturale et à $\mathrm{F}$. Granier pour ses relectures. Enfin, les analyses EDXRF n'auraient pas été possibles sans le soutien financier du conseil régional d'Aquitaine et du LabEx Sciences archéologiques de Bordeaux, programme financé par l'ANR (n ${ }^{\circ}$ ANR-10-LABX-52)

\section{NOTES}

(1) Deux éléments en silex évoquent une phase plus ancienne, par ailleurs présente sur le site (voir l'introduction). Il s'agit dans les deux cas de grands trapèzes sur éclat. Le premier (bât. 6), patiné, semble réutilisé dans un second temps en pièce esquillée - au moment de l'occupation du bâtiment 6 ? - (différence de patine). Le deuxième pourrait provenir d'un linéaire antérieur recoupé par le trou de poteau faitier du bâtiment 7 duquel il est issu.

(2) Codes de matière première utilisés pour le lithique taillé : Sind : silex indéterminable; SB : silex bédoulien; SBC : Silex bédoulien chauffé; SBTT : Silex bédoulien avec traitement thermique; SO : silex oligocène; Obs : Obsidienne. Zone grisée : plage mate; zone beige : concrétions.

\section{RÉFÉRENCES BIBLIOGRAPHIQUES}

Acovitsióti-Hameau A. (2001) - Aller au charbon... Les sites de charbonnage et leur impact sur les paysages forestiers de la colline varoise, Forêt méditerranéenne, 23, 4, p. 329344.

Archambault de Beaune S. (2000) - Pour une archéologie du geste. Broyer, moudre, piler, des premiers chasseurs aux premiers agriculteurs, Paris, CNRS, $231 \mathrm{p}$.

Beeching A., Berger J.-F., Brochier J.-L., Ferber F., HelMER D., Sidi MaAmar H. (2000) - Chasséens : agriculteurs ou éleveurs, sédentaires ou nomades? Quels types de milieu, d'économies et de sociétés?, in M. Leduc,
N. Valdeyron et J. Vaquer (dir.), Sociétés et espaces, actes des $3^{\mathrm{e}}$ Rencontres méridionales de Préhistoire récente (Toulouse, 6-7 novembre 1998), Toulouse, Archives d'écologie préhistorique, p. 59-79.

Beeching A., Bernabó Brea M., Castagna D. (2009) - Le village de Travo près de Piacenza (Émilie-Romagne, Italie) et les structures d'habitat du Néolithique d'Italie septentrionale, in A. Beeching et I. Sénépart, De la maison au village dans le Néolithique du Sud de la France et de l'Ouest méditerranéen, actes de la table ronde (Marseille, 23-24 mai 2003), Paris, Société préhistorique française (Mémoire, 48), p. 123-141. 
BEECHING A., LÉA V. (2015) - Interroger les mobilités des sociétés du Néolithique : l'exemple du Chasséen méridional, in $\mathrm{N}$. Naudinot et al. (dir.), Les systèmes de mobilité de la Préhistoire au Moyen Âge, actes des XXXV Rencontres internationales d'archéologie et d'histoire d'Antibes (Antibes, 14-16 octobre 2014), Antibes, APDCA, p. 273-289.

BINDER D. (1991) - Facteurs de variabilité des outillages lithiques chasséens dans le Sud-Est de la France, in A. Beeching et al. (dir.), Identité du Chasséen, actes du colloque international (Nemours, 1989), Nemours, APRAIF (Mémoires du musée de Préhistoire d'Île de France, 4), p. 261-272.

Binder D., Lepère C., MagGi R. (2008) - Épipaléolithique et Néolithique dans l'arc liguro-provençal : bilan et perspectives de recherche, in D. Binder, X. Delestre et P. Pergola (dir.), Archéologies transfrontalières, actes du colloque (Nice, 13-15 décembre 2007), Monaco, musée d'Anthropologie préhistorique (Bulletin du musée d'Anthropologie préhistorique de Monaco, supplément 1), p. 49-52.

Binder D., Gratuze B., Vaquer J. (2012) - La circulation de l'obsidienne dans le Sud de la France au Néolithique, in J. Guilaine et al. (éd.), Exchange of Raw Materials, Products and Ideas in the Western Mediterranean, VII-III Millennium $B C$, actes du colloque international de Gavà, Rubricatum (Barcelone), 5, p. 189-199.

Blaise É., Bréhard S., Carrère I., Favrie T., Gourichon L., Helmer D., Riviere J., Tresset A., Vigne J.-D. (2010) - L'élevage du Néolithique moyen 2 au Néolithique final dans le midi méditerranéen de la France : état des données archéozoologiques, in O. Lemercier, R. Furestier et É. Blaise (dir.), Quatrième millénaire, La transition du Néolithique moyen au Néolithique final dans le sud-est de la France et les régions voisines, Lattes, ARALO (Monographies d'archéologie méditerranéenne, 27), p. 261-284.

Borrello M. A., VAn Willigen S. (2012) - Lagozza e Chassey. Inquadramento cronologico e culturale delle ceramiche della Lombardia occidentale e del Sud-est della Francia, Sibrium (Collana di studi e documentazioni, Centro di studi preistorici a archeologici di Varese), 26, p. 69-111.

Centre technique du bois et de l'ameublement (1985) Guide pour le choix des essences des bois en menuiserie, Paris, CTBA, $162 \mathrm{p}$

Chabal L. (1997) - Forêts et sociétés en Languedoc (Néolithique final, Antiquité tardive). L'anthracologie, méthode et paléoécologie, Paris, Maison des sciences de l'homme, $192 \mathrm{p}$.

Chapon P., Hasler A., Renault S., Villemeur I. (2002) Le site chasséen de l'Héritière II à Vernègues, in Archéologie du TGV Méditerranée. Fiches de synthèse, 1. Préhistoire, Lattes, ARALO (Monographies d'archéologie méditerranéenne, 8), p. 203-212.

Delhon C., Moreau C., Magnin F., Howarth L. (soumis) - Rotten Posts and Selected Fuel: Charcoal Analysis of the First Middle Neolithic Village Identified in Provence (Cazan-Le Clos du Moulin, Vernègues, Bouches-du-Rhône, South of France), Quaternary International.

Dolfini A. (2013) - The Emergence of Metallurgy in the Central Mediterranean Region: a New Model, European Journal of Archaeology, 16, 1, p. 21-62.
FAbre L., Gervet X. (1992) - Première approche du charbonnage et de l'histoire de la forêt méditerranéenne : l'exemple du canton d'Aniane (Hérault), Bulletin de la société botanique française, 2-3-4, p. 617-625.

Furestier R., Sendra B., Gourlin B., Cocklin G. et al. (2012) - Évolution du Chasséen montpelliérain : premiers résultats des fouilles préventives du site de la ZAC SaintAntoine à Saint-Aunès (Hérault), in T. Perrin et al. (dir.), Dynamismes et rythmes évolutifs des sociétés de la Préhistoire récente, actes des $9^{e}$ Rencontres méridionales de Préhistoire récente (Saint-Georges-de-Didonne, octobre 2010), Toulouse, Archives d'écologie préhistorique, p. 197-214.

Gaday R., SARgiano J.-P. (2008) - Cazan " l'Héritière 》 à Vernègues (Bouches-du-Rhône), rapport final d'opération de diagnostic, INRAP Méditerranée, service régional de l'Archéologie de Provence-Alpes-Côte-d'Azur, Aix-enProvence, $29 \mathrm{p}$.

GaIllard A. (1998) - L'outillage osseux du site chasséen méridional classique d'Auriac, Carcassonne (Aude), mémoire de diplôme de l'EHESS, Centre d'anthropologie de Toulouse, 2 vol.

Gallais J. (1960) - La signification du village en Afrique soudanienne de l'Ouest, Cahiers de sociologie économique, 2, p. $128-162$.

Gallay A. (1995) - Pour un modèle de la société néolithique, in W. Stöckli, U. Niffeler et E. Gross-Klee (dir.), La Suisse du Paléolithique à l'aube du Moyen-âge, 2. Le Néolithique, Bâle, Société suisse de Préhistoire et d'archéologie, p. 275288.

Gassin B. (1996) - Évolution socio-économique dans le Chasséen de la grotte de l'Église supérieur (Var). Apport de l'analyse fonctionnelle des industries lithiques, Paris, CNRS (Monographie du CRA, 17), 326 p.

Gassin B., LÉa V., Astruc L., Linton J. (2010) - Lithic Management in the Chassey Culture Neolithic, Human Evolution, 25, 1-2, p. 125-142.

Georjon C., LÉA V. (2013) - Les styles céramiques du Néolithique moyen en Languedoc oriental : caractérisation et confrontation avec la périodisation des industries lithiques taillées, Gallia Préhistoire, 55, p. 31-71.

Hamon C. (2006) - Broyage et abrasion au Néolithique ancien. Caractérisation technique et fonctionnelle des outillages en grès du Bassin parisien, Oxford, Archaeopress (BAR, International Series 1551), $342 \mathrm{p}$.

Hamon C. (2008) - Meules rubanées, meules blicquiennes : nouvelles réflexions sur les dépôts du Hainaut (Belgique), in L. Burnez-Lanotte, M. Ilett et P. Allard (dir.), Fin des traditions danubiennes dans le Néolithique du Bassin parisien et de la Belgique (5100-4700 av. J.-C.). Autour des recherches de Claude Constantin, Paris, Société préhistorique française (Mémoire, 44), p. 197-208.

Hasenfratz A., Gross-Klee E. (1995) - Habitat et modes de construction, in W. Stöckli, U. Niffeler et E. Gross-Klee (dir.), La Suisse du Paléolithique à l'aube du Moyen Âge, 2. Le Néolithique, Bâle, Société suisse de Préhistoire et d'archéologie, p. 195-230.

Honegger M. (2005) - Les villages littoraux du Néolithique : égalité et autarcie ou complémentarité et mise en réseau, 
in P. Della Casa et M. Trachsel (éd.), Wetland Economies and Societies, actes de la conférence internationale (Zurich, mars 2004), Zürich, Chronos (Collectio Archaeologica, 3), p. $185-194$

LÉA V. (2004) - Les industries lithiques du Chasséen en Languedoc oriental : caractérisation par l'analyse technologique, Oxford, Archaeopress (BAR, International Series 1232), $215 \mathrm{p}$.

LÉA V. (2005) - Raw, Pre-heated or Ready to Use: Discovering Specialist Supply Systems for Flint Industries in MidNeolithic (Chasséen) Communities in Southern France, Antiquity, 79, p. 51-65.

LÉA V. (2012) - The Diffusion of Obsidian in the North-West Mediterranean: Toward a New Model of the Chassey Culture?, Journal of Mediterranean Archaeology, 25, 2, p. 147173.

LEPÈRE C. (2009) - Identités et transferts culturels dans le domaine circumalpin : l'exemple des productions céramiques du Chasséen provençal, thèse de doctorat, université d'Aix-Marseille, Aix-en-Provence, 524 p.

LEPÈrE C. (2012) - Chronologie des productions céramiques et dynamiques culturelles du Chasséen de Provence, Bulletin de la société préhistorique française, 109, 3, p. 513-545.

Lévy J., Lussault M., dir. (2003) - Dictionnaire de la géographie et de l'espace des sociétés, Belin, Paris, 1127 p.

Lieutaghi P. (2004) - Le Livre des arbres, arbustes et arbrisseaux, Arles, Actes Sud, $1322 \mathrm{p}$

Lugliè C., Le Bourdonnec F.-X., Poupeau G. (2014) Caratterizzazione elementare e provenienza delle ossidiane mediante analisi non distruttiva PIXE e EDXRF, in $\mathrm{M}$. Venturino Gambari (éd.), La memoria del passato. Castello di Annone tra archeologia e storia, Alessandria, LineLab (Archeologia Piemonte, 2), p. 333-336.

Macphail R.-I., Courty M.-A., Gebhardt A. (1990) - Soil Micromorphological Evidence of Early Agriculture in North-West Europe, World Archaeology, 22, p. 53-69.

Magnin F., Martin S. (2012) - Escargots synanthropiques et domestication de la nature : mécanismes, processus et représentations, Techniques et Culture, 59, p. 260-283.

Magnin F., Tatoni T. (1995) - Secondary Successions on Abandoned Cultivation Terraces in Calcareous Provence (France), II. The gastropod communities, Acta Oecologica, 16, p. 89-103.

Martin S., Magnin F., Chevillot P. (2005) - Mise en évidence des discontinuités spatiales et temporelles dans l'anthropisation de la plaine de la Vistrenque à Nîmes (Gard) durant l'Holocène. Apport de l'analyse malacologique, Quaternaire, 16, p. 339-352.

Moreau C., avec la coll. de Ancel M.-J., Astruc L., BoscZanardo B., Cattin F., Delhon C., Gilles A., Léa V., Linton J. (2014) - Vernègues, Cazan (Bouches-du-Rhône) : découverte d'un habitat structuré du Chasséen récent, Bulletin de la société préhistorique française, 111, 2, p. 341-344.

Moreau C., dir., Ancel M.-J, Astruc L., Bosc-Zanardo B., Brochier J.-E., Cattin F., Collombet J., Delhon C., Foucras S., Foulché A.-L., Gerez J., Gilles A.,
Guichard-Kobal L., Howarth L., Magnin F., Léa V., Linton J., Nicosia C., Pacotte L., Sénépart I., Thirault É., (2015). - Vernègues, Cazan «le Clos du Moulin » (parcelle B2-523). Un habitat structuré du Néolithique moyen entre 4100 et 3800 avant notre ère, rapport final d'opération d'archéologie préventive, Archeodunum, service régional de l'Archéologie de Provence-Alpes-Côte-d'Azur, Aix-enProvence, $1145 \mathrm{p}$.

Moreau C., Perez P., Lesueur F., Léa V. (à paraître) - Vernègues, Cazan « le Clos du Moulin » (Bouches-du-Rhône) : architecture et organisation d'un site d'habitat du Chasséen récent, in Habitations et habitat du Néolithique à l'âge du Bronze en France et ses marges, actes des $2^{\text {es }}$ Rencontres Nord-Sud de Préhistoire récente (Dijon, novembre 2015).

Rameau J.-C., Mansion D., Dume G., Gauberville C. (2008) - Flore forestière française, guide écologique illustré, 3. Région méditerranéenne, Paris, Institut pour le développement forestier, $2426 \mathrm{p}$.

SAintot S. (2002) - La maison chasséenne du site de Blagnat à Montmeyran (Drôme), in Archéologie du TGV Méditerranée. Fiches de synthèse, 1. Préhistoire, Lattes, ARALO (Monographies d'archéologie méditerranéenne, 8), p. 19-22.

Saintot S., Le Barrier C. (2009) - L'habitat chasséen de Champ Madame et Artière-Ronzière à Beaumont (Puyde-Dôme). Structuration, architecture du bâtiment 3, in A. Beeching et I. Sénépart (dir.), De la maison au village dans le Néolithique du Sud de la France et de l'Ouest méditerranéen, actes de la table ronde (Marseille, 23 et 24 mai 2003), Paris, Société préhistorique française (Mémoire, 48), p. $99-121$

Saintot S. (2012) - Continuité et ruptures des ensembles architecturaux et des productions matérielles au cours du Néolithique moyen II à Champ Madame (Beaumont, Puy-de-Dôme), in T. Perrin et al. (dir.), Dynamismes et rythmes évolutifs des sociétés de la Préhistoire récente, actes des $9^{\mathrm{e}}$ Rencontres méridionales de Préhistoire récente (Saint-Georges-de-Didonne, 8-9 octobre 2010), Toulouse, Archives d'écologie préhistorique, p. 33-49.

Schмiт S. (2000) - Vernègues. Fouille de l'Héritière II, 2000, document final de synthèse, service régional de l'Archéologie de Provence-Alpes-Côte-d'Azur, Aix-en-Provence, 3 p.

SÉNÉPART I. (2006) - Cent ans de recherches sur les industries osseuses du Midi de la France, in J. Évin (dir.), Un siècle de construction du discours scientifique en Préhistoire, 2. Des idées d'hier..., actes du $26^{\mathrm{e}}$ Congrès préhistorique de France, congrès du centenaire de la Société préhistorique française (Avignon, 21-25 septembre 2004), Paris, Société préhistorique française, p. 11-18.

Thiercelin-Ferber F., avec la coll. de LéA V. (2013) - Découverte de deux alênes en cuivre dans le site chasséen de Daurelle (Montélimar, Drôme), Bulletin de la Société préhistorique française, 110,1 , p. 134-137.

Thirault É., Léa V., Lepère C., Vannieuwenhuyse D. (2016) - Un nouveau « très grand site » du IV e millénaire dans le Sud de la France : l'apport du chantier « Cazan l'Héritière 2008 » à Vernègues (Bouches-du-Rhône), Bulletin de la Société préhistorique française, 113, 3, p. 523-570. 


\section{Clément Moreau}

Archeodunum, 500 , rue J. Récamier, F-69970 Chaponnay c.moreau@archeodunum.fr

Vanessa LÉA UMR 5608 TRACES, Maison de la Recherche, 5, allées A. Machado, F-31058 Toulouse cedex 9 Vanessa.LEA@univ-tlse2.fr

Claire Delhon UMR 7264 CEPAM université Côte d'Azur Pôle universitaire Saint-Jean-d'Angély, Av. des diables bleus, F-06357 Nice cedex 4 claire.delhon@cepam.cnrs.fr

Frédéric MAGNin IMBE Europôle méditerranéen de l'Arbois, BP 80, F-13545 Aix-en-Provence cedex 4 frederic.magnin@univ-amu.fr

Luke HowarTH Chercheur associé à l'UMR 5140, Archéologie des Sociétés Méditerranéennes, 390, av. de Pérols, F-34970 Lattes lukehwth@gmail.com

Jimmy LinToN Traceolab, université de Liège, Place du 20 Août, B-4000 Liège (Belgique) jimmy.linton@me.com
Lucas Pacotte

11, Montée Saint-Sébastien, F-69001 Lyon lucas.pacotte@gmail.com

Sylvain Foucras

Archeodunum, 500 , rue J. Récamier, F-69970 Chaponnay s.foucras@archeodunum.fr

Cristiano Nicosia

Université libre de Bruxelles Centre de recherches en archéologie et patrimoine, CP175, 50 avenue F. D. Roosevelt,

B-1050 Bruxelles (Belgique) cristianonicosia@yahoo.it

\section{François-Xavier LE BourdonneC} UMR5060 IRAMAT-CRP2A, univiversité Bordeaux Montaigne, Maison de 1'Archéologie, F-33607 Pessac

Francois-Xavier.Le-Bourdonnec@u-bordeauxmontaigne.fr

Julie Gerez Archeodunum, 500, rue J. Récamier, F-69970 Chaponnay

Ingrid SÉNÉPART UMR 7264 CEPAM DAPA - Ville de Marseille, 146, av. Salengro, F-13003 Marseille senepart@neuf.fr 